Portland State University

PDXScholar

\title{
Individual and Community Supports that Impact Community Inclusion and Recovery for Individuals with Serious Mental Illnesses
}

Rachel Elizabeth Terry

Portland State University

Follow this and additional works at: https://pdxscholar.library.pdx.edu/open_access_etds

Part of the Mental and Social Health Commons, and the Psychology Commons Let us know how access to this document benefits you.

\section{Recommended Citation}

Terry, Rachel Elizabeth, "Individual and Community Supports that Impact Community Inclusion and Recovery for Individuals with Serious Mental Illnesses" (2020). Dissertations and Theses. Paper 5466. https://doi.org/10.15760/etd.7338

This Dissertation is brought to you for free and open access. It has been accepted for inclusion in Dissertations and Theses by an authorized administrator of PDXScholar. Please contact us if we can make this document more accessible: pdxscholar@pdx.edu. 
Individual and Community Supports that Impact Community Inclusion and Recovery for Individuals with Serious Mental Illnesses

by

Rachel Elizabeth Terry

A dissertation submitted in partial fulfillment of the

Requirements for the degree of

\author{
Doctor of Philosophy \\ in \\ Applied Psychology
}
Dissertation Committee:
Greg Townley, Chair
Eric Mankowski
Mark Salzer
Melissa Thompson

Portland State University

2020 


\begin{abstract}
The current dissertation presents two published manuscripts and discusses a third study that explored the role of social support in promoting community participation for individuals with serious mental illnesses. The first manuscript investigated sense of community as a potential mediating factor between community participation, psychological distress, and mental health functioning utilizing quantitative methods. The results indicated that sense of community acted as a partial mediator between community participation and psychological distress, as well as mental health functioning. The second manuscript is a literature review that explored the influence of social support on community integration for individuals with serious mental illnesses. A total of 32 articles in three categories (i.e., defining community integration, supportive relationships, and mental health services) revealed that social support, which may be provided by a variety of individuals (e.g., friends, families) and services (e.g., Housing First), plays an important role in promoting community integration for individuals with serious mental illnesses. Finally, the third study identified and explored the association between social support and community participation for adults with serious mental illnesses living independently in community settings. Family, friends, and neighbors were most commonly reported as sources of support, but spouses, religious leaders, and pets provided higher levels of emotional support. Average total support was significantly related to the amount of community participation reported. Qualitative analysis revealed six themes pertaining to social support and participation, such as families spending time together and the desire to do activities with others. Overall, the three manuscripts aim to enhance our understanding of individual and community level supports that promote
\end{abstract}


mental health, community participation, and ultimately, community inclusion and recovery for individuals with serious mental illnesses. 


\section{Acknowledgements}

I would like to thank my advisor, Dr. Greg Townley, for his patience and mentorship throughout the past five years. I would also like to acknowledge the important advice and support from the rest of my committee, Drs. Eric Mankowski, Mark Salzer, and Melissa Thompson. Finally, thank you to my cohort, friends, partner, and family for their endless support and encouragement. 
Table of Contents

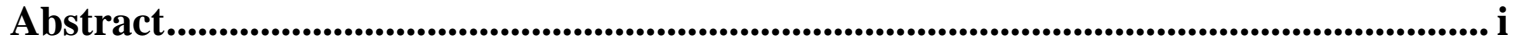

Acknowledgements ....................................................................................................... iii

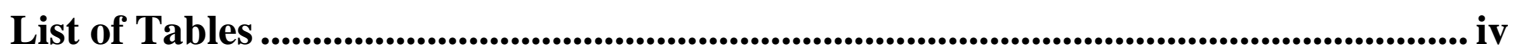

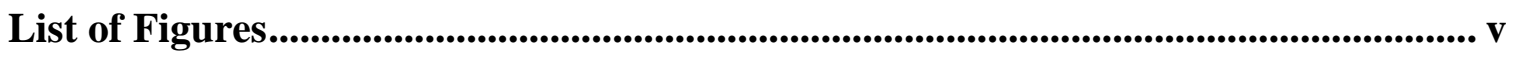

Chapter 1: Introduction ........................................................................................... 1

Community Inclusion and Integration .....................................................................................2

Community Participation ..........................................................................................................................5

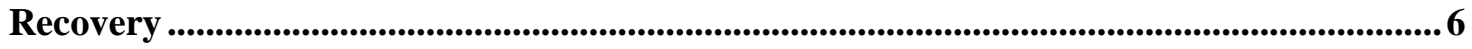

The Impact of Social Support and Sense of Community on Community Inclusion and

Recovery ............................................................................................................................................... 9

Present Investigation .......................................................................................................................... 14

Chapter 2: Study 1 ...................................................................................................................... 42

The influence of sense of community on the relationship between community participation and mental health for individuals with serious mental illnesses* ................................................ 42

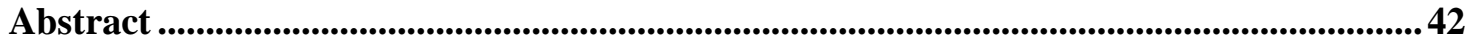

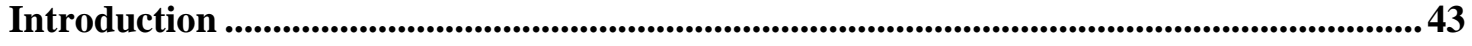

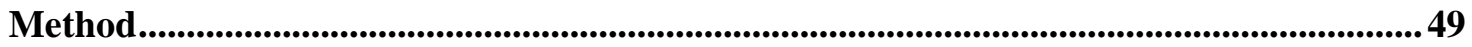

Results...............................................................................................................................................5 52

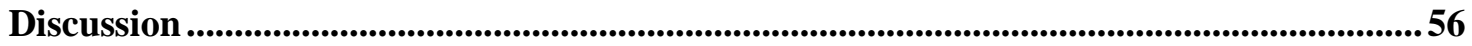

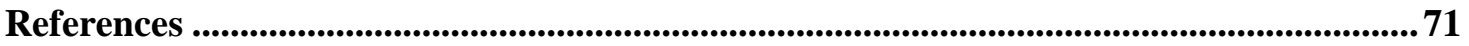

Chapter 3: Study 2 .................................................................................................................. 78

Exploring the role of social support in promoting community integration: An integrated

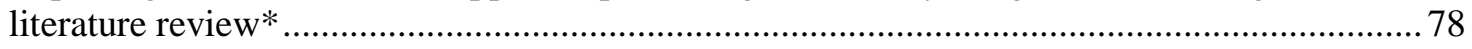

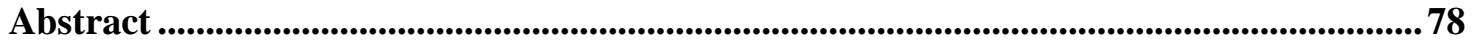

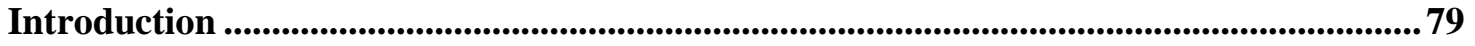

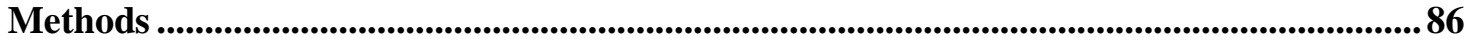

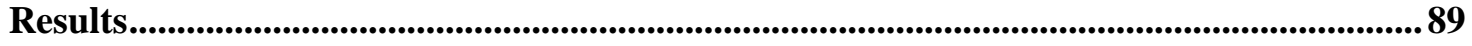

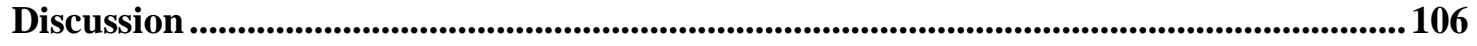

Conclusion ................................................................................................................................. 120

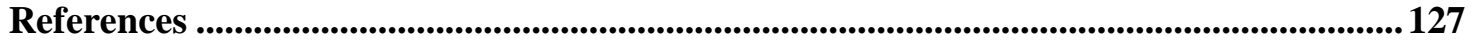




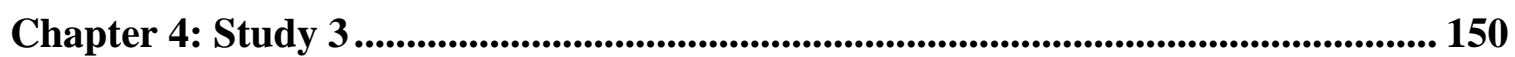

Exploring the influence of social support on community participation for adults with serious

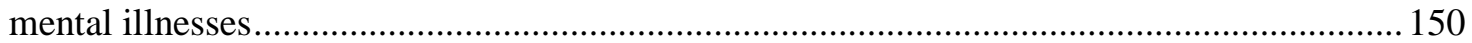

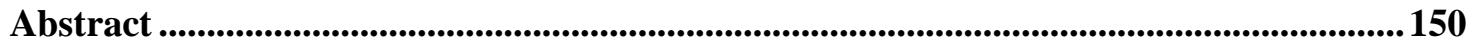

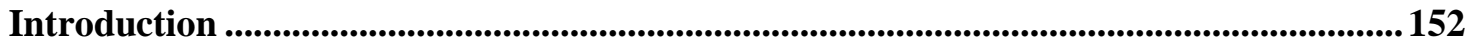

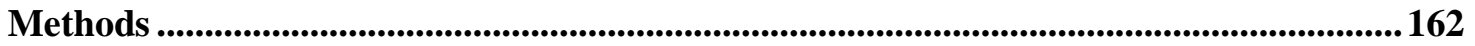

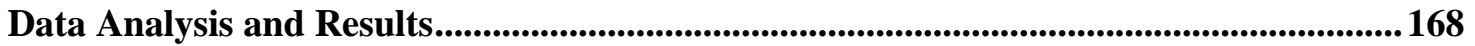

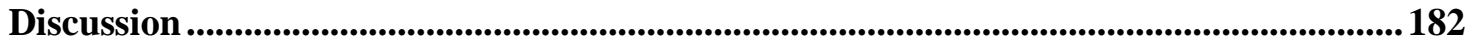

References ...................................................................................................................................................... 211

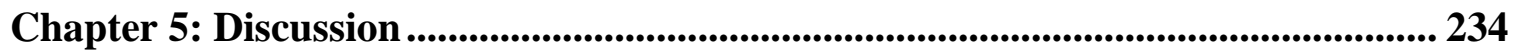

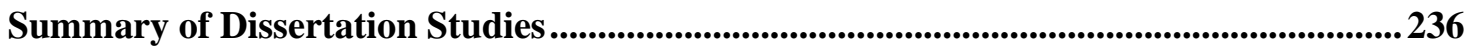

Contributions, Implications, and Future Directions ......................................................... 238

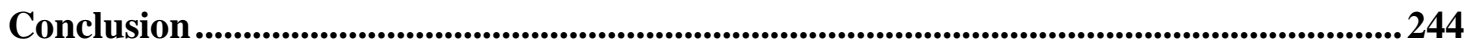

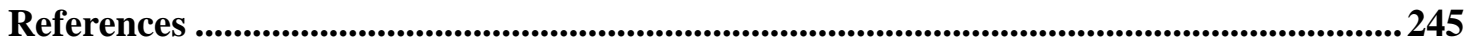

Appendix A. Study 3 Measures ......................................................................................... 268

Appendix B. Study 3 Recruitment Flyer and Consent Form ................................. 274 


\section{List of Tables}

\begin{tabular}{lll}
\hline Table & Title & Page \\
\hline 2.1 & Descriptive Statistics & 65
\end{tabular}

2.2 Correlation Matrix of Study Variables 66

2.3 Independent Samples T-Test: Outcome Variables by Gender 67

2.4 Independent Samples T-Test: Outcome Variables by Diagnosis 68

2.5 Summary of Mediation Model 1, with Psychiatric Distress as the 69 Outcome

2.6 Summary of Mediation Model 2, with Mental Health Functioning as 70 the Outcome

3.1 Journals Included in the Integrative Literature Review 121

$\begin{array}{lll}3.2 & \text { Article Characteristics } & 122\end{array}$

4.1 Descriptive Statistics with All Supports 200

4.2 Descriptive Statistics with Natural Supports 201

4.3 Descriptive Statistics for Community Participation 202

4.4 Correlation Matrix of Social Support and Community Participation 203 Variables

4.5 Average Emotional Support by Source 204

4.6 Tangible Support by Source 205

4.7 Average Total Support by Source 206

4.8 Correlation Matrix for Natural Supports 207

4.9 Participation Areas with Natural Supports 208 


\section{List of Figures}

\begin{tabular}{lll}
\hline Figure & Title & Page \\
\hline 2.1 & $\begin{array}{l}\text { Location of partnering community mental health organizations with } \\
\text { participant recruitment totals }\end{array}$ & 62 \\
2.2 & $\begin{array}{l}\text { Statistical model of the mediation analysis with psychological } \\
\text { distress as an outcome }\end{array}$ & 63 \\
$2.3 \quad \begin{array}{l}\text { Statistical model of the mediation analysis with mental health } \\
\text { functioning as an outcome }\end{array}$ & 64 \\
$4.1 \quad$ & $\begin{array}{l}\text { Frequencies of sources of support reported by participants } \\
4.2\end{array} \quad \begin{array}{l}\text { Number of participants who reported at least one individual in a } \\
\text { given support category }\end{array}$ & 209 \\
\hline
\end{tabular}




\section{Chapter 1: Introduction}

A common perspective in community psychology, and also in the community mental health systems from which this field emerged, is that there will never be enough professionals to meet the demand of all of the people that require mental health services (Albee, 1959). The supply and demand issue is especially relevant in the context of the deinstitutionalization movement, which moved individuals with serious mental illnesses from psychiatric hospitals to community settings beginning in the 1960 s without the proper resources to function in the community (Carling, 1995). Although the mental health field was initially in favor of deinstitutionalization, people now often recognize it as a failure of policy to translate into effective action, commonly known as the implementation problem (Mechanic \& Rochefort, 1990). In response to the deinstitutionalization movement, mental health policies and practices had to identify alternative ways to address mental health issues in the community, such as harnessing support networks in a community and promoting community inclusion (Carling, 1990; Davidson, Stayner, et al., 2001; Salzer \& Baron, 2016; Sarason, 1976). Unfortunately, research and consumer narratives continue to demonstrate that individuals with serious mental illnesses often lack opportunities for employment, have fewer meaningful personal relationships, struggle to obtain stable, decent housing, and experience discrimination from community members (Carling, 1995; Townley, Brown, \& Sylvestre, 2018; Ware et al., 2007).

The World Health Organization states that mental illnesses are one of the leading causes of disability worldwide, with estimates that one in four people will experience a diagnosable mental illness at some point in their lives (WHO, 2001). Furthermore, the 
National Institute of Mental Health estimated that there were 10.4 million adults with a diagnosis of serious mental illness in the United States in 2016 (NIH, 2016). Although numerous definitions exist, most researchers, advocates, and practitioners agree that the term "serious mental illness" describes individuals who have been diagnosed with at least one persistent psychiatric condition that significantly influences their life, such as schizophrenia-spectrum disorder, bipolar disorder, or severe and persistent depression (Kloos, 2010).

The following dissertation is composed of three studies that examine individual and community level supports that impact community inclusion and recovery for individuals with serious mental illnesses. The first paper examines sense of community as a mediating factor between community participation, psychological distress, and mental health functioning for clients utilizing mental health services. Next, the second paper presents a comprehensive literature review to identify and analyze social support that positively or negatively influences community integration for adults with serious mental illnesses. Finally, the third paper discusses a study that investigates social support and community participation for adults with serious mental illnesses. Collectively, the three manuscripts aim to enhance our understanding of individual and community level supports that promote mental health, community participation, and ultimately, community inclusion and recovery.

\section{Community Inclusion and Integration}

Most recently, mental health practice and policy has emphasized the importance of community inclusion, which is conceptualized as an equal opportunity for everyone to participate in the community (Davidson, 2005; Nelson, Lord, \& Ochocka, 2001; Salzer \& 
Baron, 2016). A similar term frequently used in the mental health literature is community integration, which is typically defined as the belief that people with psychiatric disabilities should have the same opportunities as individuals without disabilities to live, form relationships, and experience a sense of belonging in their communities (Carling, 1995; Townley \& Kloos, 2011; Wong \& Solomon, 2002). However, according to the disability literature, community inclusion goes beyond individuals being simply physically integrated in the community and endorses removing systematic barriers to create a truly inclusive environment (Salzer \& Baron, 2016). Consequently, the construct will be referred to as community inclusion in Chapters 1,4 , and 5 . Community integration is used in Chapters 2 and 3 because those papers are published manuscripts in journals where community integration is the more commonly used terminology.

The importance of community inclusion is emphasized by policymakers, researchers, and advocates (Bond, Salyers, Rollins, Rapp, \& Zipple, 2004; Townley, Kloos, \& Wright, 2009; Yanos, Felton, Tsemberis, \& Frye, 2007). For example, the President's New Commission on Mental Health (2003) highlights the importance of community inclusion for people with serious mental illnesses by stating that recovery refers to "the process in which people are able to work, learn, and participate fully in their communities" (pg. 5). Furthermore, the United Nations has recognized community inclusion as a fundamental human right (Salzer \& Baron, 2016; United Nations, 2006).

Research suggests numerous positive outcomes of community inclusion, including a reduction of symptoms, a decrease in symptom severity, and less overall psychiatric symptom distress for individuals with serious mental illnesses (Abdallah, Cohen, Sanchez-Almira, Reyes, \& Ramirez, 2009; Badger, McNiece, Bonham, Jacobson, 
\& Gelenberg, 2003; Kloos \& Townley, 2011; Prince \& Gerber, 2005). Additionally, community inclusion is associated with higher levels of life satisfaction and quality of life for this population (Aubry \& Myner, 1996; Prince \& Gerber, 2005).

Past research suggests that individuals with serious mental illnesses identify community inclusion as important to their recovery and well-being (Davidson, Stayner, et al., 2001; Townley, 2015; Ware, Hopper, Tugenberg, Dickey, \& Fisher, 2007). However, the majority of studies have found that individuals with serious mental illnesses continue to report fewer meaningful relationships with others, social isolation, low levels of participation, and barriers to community inclusion (Bradshaw, Armour, \& Roseborough, 2007; Davidson, Stayner, et al., 2001; Dewees, Pulice, \& McCormick, 1996; Pinfold, 2000). For example, Pinfold (2000) observed that while community inclusion has become central to mental health policy, people with mental health problems continue to experience social isolation. Social isolation is known to lead to increased mortality, physiological aging, cognitive decline, and an increase in negative feelings such as depression, anxiety, and stress in the general population (Hawkley \& Cacioppo, 2010). After completing qualitative interviews and observations with mental health staff and service users, Pinfold (2000) argued that participation in a variety of activities is an important component of community inclusion.

Barriers to community inclusion exist at both individual and societal levels and include psychological distress, poor physical health, low socioeconomic status, lack of employment opportunities, inadequate access to healthcare, transportation barriers, and mental health stigma (Bradshaw, Armour, \& Roseborough, 2007; Dewees, Pulice, \& McCormick, 1996). The results of these studies suggest that although mental health 
policies strive towards community inclusion, implementation of these policies has not been entirely successful, and additional research examining factors that promote full community inclusion is needed.

\section{Community Participation}

Community participation is conceptualized as an outcome of community inclusion, such that people who live in inclusive environments are more likely to have opportunities to participate in community activities (Salzer, Kottsieper, \& Brusilovskiy, 2015). According to the World Health Organization's International Classification of Functioning, Disability, and Health framework (ICF: World Health Organization, 2001), community participation is defined as independent engagement in community-based contexts across any of the following social life domains: domestic life (e.g., cleaning, shopping), interpersonal life (e.g., formal relationships, intimate relationships, family relationships), major life activities (e.g., education and employment), and community, civic, and social life (e.g., politics, religion, culture). The ICF framework is a biopsychosocial model that places health and disability on a spectrum, recognizing that health is more than an absence of disease or dysfunction (Kostanjsek, 2011). Additionally, the model posits that contextual factors (e.g., social, environmental) interact with personal factors to influence functioning and disability (Kostanjsek, 2011).

Past research suggests that community participation has numerous benefits for people with serious mental illnesses, including promoting a better quality of life and recovery (Badger et al., 2003; Burns-Lynch, Brusilovskiy, \& Salzer, 2016; Kaplan, Salzer, \& Brusilovskiy, 2012). For example, Burns-Lynch, Brusilovskiy, and Salzer (2016) found that social participation (e.g., spending time with others in the community, 
visiting family or friends) had the strongest correlations with quality of life and recovery. Additionally, people with larger activity spaces (i.e., those who participate in more activities across larger distances in their communities) reported higher life satisfaction compared to people with smaller activity spaces (Townley, Kloos, \& Wright, 2009). In conclusion, community participation provides individuals with serious mental illnesses opportunities to interact and develop relationships with others, foster a sense of belonging in the community, and experience greater community inclusion.

\section{Recovery}

As mentioned previously, the mental health field has shifted to focusing on community inclusion both because of its social benefits and also because research suggests that it promotes recovery for people with serious mental illnesses (Abdallah et al., 2009; Kloos \& Townley, 2011; Prince \& Gerber, 2005; Whitley \& Drake, 2010). For example, a review of literature about social factors that influence recovery suggests that empowerment, developing positive social identities, fostering supportive personal relationships, and social inclusion may promote recovery (Tew et al., 2012).

Additionally, larger social network and subjective ratings of its supportiveness have been noted as predictors of recovery (Corrigan \& Phelan, 2004; Hendryx, Green, \& Perrin, 2009; Mattsson, Topor, Cullberg, \& Forsell, 2008).

The formerly accepted understanding within the mental health field was that adults with serious mental illnesses could not recover, and therefore mental health services should focus on symptom maintenance rather than increasing quality of life and general health (Anthony, 2000). However, the emergence of consumer narratives about recovery and the resulting increase in empirical research related to recovery altered this 
understanding. People with serious mental illnesses began sharing detailed accounts of personal growth and development that focused on moving beyond the damaging effects of mental illness and learning to live a meaningful life in the community (Anthony, 1993).

At the same time, a review of several longitudinal studies found that most people with serious mental illnesses did not suffer a deteriorating disease course after initial diagnosis (Harding \& Zahniser, 1994). Rather, many people were recovering from serious mental illnesses over time, a finding that has been supported in recent populationlevel research examining mental illness recovery-remission rates (Salzer, Brusilovskiy, \& Townley, 2018). Additionally, Harding, Zubin, and Strauss (1987) suggested that there are environmental and social factors that influence the continuing effects of mental illnesses beyond individual functioning, including reduced economic opportunities, negative effects of institutionalization, and lower social status resulting from pervasive mental health stigma.

The National Institute of Mental Health (NIMH) developed the community support system (CSS) model informed by the emerging consumer narratives and empirical research related to recovery (Anthony, 1993). The CSS model outlines ways that mental health services can provide assistance for adults with serious mental illnesses and focuses on their full inclusion in all aspects of the community. Additionally, psychiatric rehabilitation studies recognized that the impact of severe mental illnesses on individuals includes disability, disadvantage, and dysfunction, as well as impairment (i.e., symptoms). The combination of the CSS model and the rehabilitation model led to a focus on recovery in the 1990 s and into the $21^{\text {st }}$ century. Anthony (1993) used these two 
models to discuss how mental health services can become recovery-oriented. He and his colleagues suggested that recovery outcomes include symptom reduction, increased sense of well-being, increased physical and spiritual health, and becoming an active member of the community (Farkas, Gagne, Anthony, \& Chamberlin, 2005)

Individuals with serious mental illnesses who are working towards recovery are not only seeking to reduce distressing symptoms, but also to gain improved health and well-being (Badger et al., 2003). This is especially relevant because people with serious mental illnesses tend to experience worse physical and mental health than the general population (Jones et al., 2004; Robson \& Gray, 2007). In more recent theoretical work related to recovery, Whitley \& Drake (2010) proposed five dimensions of recovery for people with serious mental illnesses: clinical, existential, functional, physical and social. Clinical recovery is the reduction and control of symptoms, such that symptoms do not disable the individual. Existential recovery aims to enhance personal feelings of control, hope, and empowerment. Functional recovery is defined as the ability to participate in aspects of daily life that facilitate community inclusion (e.g., employment, housing, education). Physical recovery refers to improvements in physical health and well-being. Finally, social recovery focuses on improving relationships with others and integrating into the community. Whitley \& Drake (2010) suggest that the five dimensions of recovery presented in their theoretical framework overlap in the lives of people with serious mental illnesses and argue that an increase in any of the dimensions is likely to positively affect other dimensions, as well as recovery as a whole. 


\section{The Impact of Social Support and Sense of Community on Community Inclusion} and Recovery

Following this discussion of community inclusion and recovery, it is important to unpack the role that social support and sense of community may play in helping individuals with serious mental illnesses achieve these goals. These constructs will be the primary focus of this dissertation research.

Social support. Historically, social support has been a widely studied phenomenon in community psychology, sociology, health psychology, and many other fields (Felton \& Shinn, 1992). However, social support has not been as prominent of a focus in the recent literature despite its importance and relevance in bolstering a variety of beneficial outcomes, particularly among members of marginalized groups (e.g., Felton \& Shinn, 1992; Israel, Farquhar, Schulz, James, \& Parker, 2002; Maton et al., 1996). The majority of social support definitions are aimed at the individual-level and focus on the support received by a person, including feeling loved or valued, or on an exchange of resources between two individuals that aim to benefit the receiver (Felton \& Shinn, 1992; Shinn, Lehmann, \& Wong, 1984; Shumaker \& Brownell, 1984). Social support measurement at the extra-individual level includes examining group membership, behavior settings, and local or relational communities (Felton \& Shinn, 1992).

Most scholars acknowledge the presence of three types of support exchanged between individuals: emotional support (e.g., love or empathy), tangible support (e.g., purchasing coffee), and informational (e.g., providing advice) support (House, 1981; Langford, Bowsher, Maloney, \& Lillis, 1997). Past research suggests that social support contributes to community integration for individuals with serious mental illnesses 
(Carling, 1990; Davidson et al., 2001; Wong \& Solomon, 2002). For example, Townley, Miller and Kloos (2013) found that traditional supports accounted for $11.9 \%$ of the variance in community integration, with distal supports accounting for an additional $3.1 \%$ of the variance after controlling for traditional support for adults with serious mental illnesses.

Social networks are a common method of conceptualizing and measuring social support and its association with health for individuals with serious mental illnesses (Beels, 1981; Cohen \& Sokolovsky, 1978; Hammer, 1981). Social networks are characterized by the size of one's network as well as the connections among network members (i.e., density; Morin \& Seidman, 1986). Previous research examining the impact of both size and density on a variety of positive recovery outcomes for individuals with serious mental illnesses (e.g., reduced rehospitalization, symptom reduction) is mixed. Further, while some researchers consider social networks as an acceptable proxy for social support, Leavy (1983) contends that examining network frequency or density does not adequately capture the type or quality of support that is provided. Researchers suggest that the flexibility and stability of social networks must also be considered (Morin \& Seidman, 1986). Flexible and stable networks include members who share roles, provide more than one type of social support, and remain stable over time despite changes in the network. Such networks have been associated with increased satisfaction, reduced hospitalization, and less dependency on any one member (Hirsch, 1980; Morin \& Seidman, 1986).

Previous research on social support has overlooked the importance of social roles and participation in the community and instead focused on romantic partners and family 
members. However, many individuals with serious mental illnesses do not report romantic relationships and have conflicted relationships with family members (Bradshaw et al., 2007; Wright, Wright, Perry, \& Foote, 2007). Therefore, it is important to consider alternative ways that individuals with serious mental illnesses can engage in social support, such as developing relationships with community members (e.g., landlords) or participating in local events (e.g., going to a farmers market).

Individuals with serious mental illnesses may engage in social support from formal or informal supports (Walsh \& Connelly, 1996). Informal supports are relationships with others that provide support in our daily lives, such as friends, family members, co-workers, and neighbors. Formal supports may include therapists, case managers, or peer workers. Informal supports are commonly referred to as natural supports. Natural supports are not paid to provide support to an individual, compared to formal supports such as therapists or doctors. For example, a hairdresser may be a natural support because the person is paid to cut hair, not to provide support. Natural supports can be found in a variety of settings (e.g., home, community) and provide support that formal supports are often not able to. For instance, a therapist is not allowed to provide money or a ride to an appointment, but a neighbor can. Additionally, natural supports likely have more opportunities to invite individuals to community activities (Kloos, Zimmerman, Scrimenti, \& Crusto, 2002). The following chapters will use the term natural supports to refer to these types of relationships.

Seeman (1996) conducted a review of epidemiological research to examine the relationship between social integration, defined as connections to others, and several health factors. The majority of results were inconclusive or conflicting regarding the 
influence of social integration on mental health. However, results suggested that social integration may play a protective role for mental health by reducing feelings of social isolation (Seeman, 1996). In an attempt to explain these findings, Berkman, Glass, Brissette, and Seeman (2000) developed a conceptual framework examining social integration as a mediating factor between individuals' social networks and health. The authors argue that social integration is a psychosocial pathway that utilizes a person's social network to influence their health. In other words, individuals rely on social support to develop a sense of belonging and attachment to the community, and it is this resulting sense of community that affects health outcomes (Berkman, Glass, Brissette, \& Seeman, 2000).

Sense of community. Sarason (1974) defines sense of community as the feeling that one belongs to, and participates in, a larger collective of individuals. McMillan and Chavis (1986) later proposed a theoretical framework for sense of community that included the following four components: membership, influence, integration and fulfillment of needs, and shared emotional connection. An absence of a sense of community may lead to social isolation and psychological distress, expressed as increased psychiatric symptom severity (McMillan \& Chavis, 1986; Sarason, 1974; Townley \& Kloos, 2009). Felton and Shinn (1992) have posited that sense of community is comparable to emotional support at the community level. Indeed, there are several similarities in the definitions of emotional support and sense of community, such as feeling valued, cared for, and that one belongs (Cobb, 1976; McMillan \& Chavis, 1986; Sarason, 1974). 
Additionally, sense of community is an important component to promoting community inclusion and recovery that coincides with participation in community activities (Cummins \& Lau, 2003; Talò, Mannarini, \& Rochira, 2014). When people spend more time actively participating in their communities, they are likely to develop a sense of belonging, or connectedness, to the community (Salzer \& Baron, 2016). Furthermore, people that are more connected to the community may be more likely to participate in community activities (Chavis \& Wandersman, 1990; Prince \& Gerber, 2005). Past studies have demonstrated that individuals with serious mental illnesses consider sense of community important towards achieving community inclusion and recovery (Prince \& Gerber, 2005; Townley, 2015; Ware et al., 2007; Wong, Stanton, \& Sands, 2014). For example, Ware and colleagues (2007) found that individuals with serious mental illnesses identified sense of community, defined as connectedness, as essential to social integration and recovery. As such, research and practice should emphasize both opportunities to develop social relationships and participate in the community (Cummins \& Lau, 2003).

\section{The Relationship between Community Participation, Social Support and Sense of Community}

Community participation, social support, and sense of community are recognized as constructs that are associated with community inclusion for individuals with serious mental illnesses. For example, a friend, neighbor, or family member (i.e., social support) may invite an individual with a serious mental illness to a community activity, such as grabbing coffee or volunteering at an event. If the individual continues to participate in community activities, they may develop a sense of belongingness and emotional 
connection in their community (i.e., sense of community). Alternatively, if individuals with serious mental illnesses feel more safe and welcome in their community (i.e., sense of community), they may feel more comfortable engaging in other community events (i.e., community participation). As individuals spend more time in the community, they may meet and form relationships with other community members (i.e., social support). Therefore, community participation, social support, and sense of community work together to enhance community inclusion for individuals with serious mental illnesses.

\section{Present Investigation}

Although there is consensus in the mental health field that community inclusion and recovery are positive outcomes for individuals with serious mental illnesses, research and interventions are still attempting to find more effective ways to accomplish these goals. Additionally, mental health services struggle to assist individuals with serious mental illnesses in achieving community inclusion and recovery (Davidson, O’Connell, Tondora, Styron, \& Kangas, 2006). Social support and sense of community have been widely accepted as beneficial to community inclusion and recovery for individuals with serious mental illnesses (Davidson, Haglund, et al., 2001; Dewees et al., 1996; Leavy, 1983; Townley, 2015). However, the connections between social support, sense of community, and community participation have not been adequately explored. Finding ways to increase individual and community supports that influence community inclusion and recovery is a crucial task for researchers, practitioners, and advocates working with individuals with serious mental illnesses.

The following section will briefly review two published manuscripts that examine community participation, sense of community, and social support as factors that influence 
community integration and mental health. A third paper that investigates the impact of social support on community participation for adults with serious mental illnesses is then discussed. Findings will produce recommendations aimed at benefiting individuals with serious mental illnesses; their support networks of friends, family, and community members; and mental health service providers and organizations. Additionally, future research directions will be provided for community psychologists and the community mental health field.

\section{Chapter II Overview: The influence of sense of community on the relationship between community participation and mental health for individuals with serious mental illnesses}

Study 1 is a published manuscript in the Journal of Community Psychology that investigated whether sense of community acted as a mediator between community participation, psychological distress, and mental health functioning for adults with serious mental illnesses. Survey methodology was used to collect data from adults with serious mental illnesses utilizing community mental health services across the United States. It was hypothesized that participants who reported higher levels of community participation would report less psychological distress, better mental health functioning, and a stronger sense of community than participants with lower levels of participation. Further, it was hypothesized that participants who reported a stronger sense of community would also report less psychological distress and better mental health functioning than participants who reported lower levels of sense of community. Finally, it was hypothesized that sense of community would mediate the relationship between community participation and the proposed outcomes. 
Mediation analyses revealed that sense of community acted as a partial mediator between community participation and psychological distress, as well as mental health functioning. Consistent with past research, these findings suggest that while community participation is important, the feelings of belonging and acceptance from community members are also needed to positively influence psychological distress and mental health (Prince \& Gerber, 2005; Greg Townley \& Kloos, 2011; Yin-Ling I Wong \& Solomon, 2002). Overall, this study highlighted the importance of community supports in affecting mental health outcomes for individuals with serious mental illnesses.

\section{Chapter III Overview: Exploring the role of social Support in promoting community integration: An integrated literature review}

Study 2 was accepted for publication in the American Journal of Community Psychology as an integrative literature review that applies a community psychology lens to examine the influence of social support on community integration for adults with serious mental illnesses. Social support was operationalized as a range of resources that may provide support to a person, including other individuals (e.g., neighbors) and also services (e.g., supported employment; Leavy, 1983). A total of 32 articles from 19 journals were organized into three major categories (defining community integration, supportive relationships, and mental health services) and analyzed according to the types of support being provided.

As expected, findings suggest that social support provided by a variety of sources plays an important role in promoting community integration for individuals with serious mental illnesses. Additionally, although individuals with serious mental illnesses typically report smaller social networks (Beels, 1981; Dewees et al., 1996), the natural 
supports that exist can positively or negatively impact community integration. The results also revealed characteristics of relationships that positively influenced community integration, such as recognizing independence, engaging in reciprocity, and providing the person with space to enter or exit an interaction at any time (Beal, 1999; Beal et al., 2005; Chen, 2010; Davidson, Haglund, et al., 2001).

\section{Chapter IV Overview: Exploring the influence of social support on community participation for adults with serious mental illnesses}

Natural supports emerged as important relationships that influence community integration for adults with serious mental illnesses in Study 2. In response, Study 3 involved a deeper examination of the role of social support, with a particular focus on natural supports. The study aimed to identify and explore the association between social support and community participation for adults with serious mental illnesses living independently in community settings. Specifically, the study examined the influence of different types of support (i.e., emotional, tangible) that are provided by various individuals, with a focus on the role of natural supports in promoting community participation. Additionally, several characteristics of natural support relationships, including frequency of contact, method of interaction, peer status, and length of relationship, were investigated in relation to community participation. Participants completed a survey followed by semi-structured qualitative questions to gain a richer understanding of the relationship between social support and community participation. Descriptive statistics and qualitative thematic analysis were employed to answer the exploratory research questions. 
Participations identified family, friends, and neighbors as the most common sources of support. However, spouses, religious leaders, and pets were reported to provide higher levels of emotional support. Additionally, average total support was positively associated with the amount of community participation reported. Finally, qualitative analysis revealed six themes pertaining to social support and participation: 1) families spend time together; 2) neighbors provide social interaction and tangible support, but may not lead to community participation; 3) friends support community participation; 4) pets provide emotional support and encourage physical activity, but may not lead to community participation; 5) mental health challenges can be barriers to participation; and 6) desire to do activities with others.

Findings from this research contribute to our knowledge of social support for individuals with serious mental illnesses while also illuminating the relationship between natural support and community participation for members of this population.

Recommendations include suggestions for increasing relationships with natural supports in the community or providing resources to enhance opportunities for community participation with existing natural supports. Overall, individuals with serious mental illnesses who receive support from friends, families, and members of the community will likely have more opportunities to participate in the community and ultimately achieve greater levels of community inclusion.

\section{Summary}

The current dissertation presents two published papers and a third study that investigates individual and community level supports that impact community inclusion and recovery for individuals with serious mental illnesses. Both quantitative and 
qualitative methods are utilized in the manuscripts. The first manuscript examined sense of community as a mediator between community participation and mental health outcomes. The second manuscript produced a literature review exploring the role of social support in promoting community integration. This literature review informed the development of the third study, which focuses on natural supports and community participation for adults with serious mental illnesses.

The results from Study 1 suggest that community participation and sense of community are positively associated with mental health outcomes for adults with serious mental illnesses. Study 2 and 3 focus on social support and its influence on community participation and integration. The findings from Study 2 suggest that natural supports are important sources of social support that have the potential to promote community integration. The third study furthered our understanding of natural supports and reveal ways in which individuals and services can increase community participation. The findings from Study 3 suggest that the support provided by natural supports is positively associated with community participation. 


\section{References}

Abdallah, C., Cohen, C. I., Sanchez-Almira, M., Reyes, P., \& Ramirez, P. (2009).

Community integration and associated factors among older adults with schizophrenia. Psychiatric Services, 60(12), 16-64. Retrieved from https://ps.psychiatryonline.org/doi/pdf/10.1176/ps.2009.60.12.1642

Anthony, W. A., \& Blanch, A. (1987). Supported employment for persons who are psychiatrically disabled: An historical and conceptual perspective. Psychosocial Rehabilitation Journal, 11(2), 5-23. Retrieved from https://search-proquestcom.proxy.lib.pdx.edu/docview/1504152173/fulltextPDF/B9256567386A43DFPQ/1 ?accountid $=13265$

Anthony, W, Rogers, E., \& Farkas, M. (2003). Research on evidence-based practices: Future directions in an era of recovery. Community Mental Health Journal. Retrieved from http://link.springer.com/article/10.1023/A:1022601619482

Anthony, WA. (1993). Recovery from mental illness: The guiding vision of the mental health service system in the 1990s. Psychosocial Rehabilitation Journal, 16(4), 521538. Retrieved from http://psycnet.apa.org/journals/prj/16/4/11/

Anthony, WA. (2000). A recovery-oriented service system: Setting some system level standards. Psychiatric Rehabilitation Journal, 24(2), 159-168. Retrieved from http://psycnet.apa.org/journals/prj/24/2/159/

Aubry, T., \& Myner, J. (1996). Community integration and quality of life: A comparison of persons with psychiatric disabilities in housing programs and community residents who are neighbours. Canadian Journal of Community Mental Health, 15(1), 5-20. https://doi.org/10.7870/cjcmh-1996-0001 
Badger, T. A., McNiece, C., Bonham, E., Jacobson, J., \& Gelenberg, A. J. (2003). Health outcomes for people with serious mental illness: A case study. Perspectives in Psychiatric Care, 39(1), 23-32. https://doi.org/10.1111/j.1744-6163.2003.tb00670.x

Balcazar, F. E., Taylor, R. R., Keilhorner, G. W., Tamley, K., Benziger, T., Carlin, N., \& Johnson, S. (2004). Participatory action research: General principles and a study with a chronic health condition. In In L.A. Jason, C.B. Keys, Y.S. Suarez-Balcazar, R.R. Taylor, \& M.I. Davis (Eds). Participatory Community Research: Theories and Methods in Action. (pp. 17-35). Washington D.C.: American Psychological Association.

Banks, B., Charleston, T. G., \& Mank, D. (2001). Workplace supports, job performance, and intergration outcomes for people with psychiatric disabilities. Psychiatric Rehabilitation Journal, 24(4), 389-396. Retrieved from https://search-proquestcom.proxy.lib.pdx.edu/docview/1347253418/fulltextPDF/6D9724A99D184D76PQ/ 1 ?accountid=13265

Basset, T., Faulkner, A., Repper, J., \& Stamou, E. (2010). Lived Experience Leading The Way Peer Support in Mental Health. Nottingham.

Beal, G. (1999). The constitution of community: How individuals diagnosed with schizophrenia and their friends achieved community. Psychiatry, 62(2), 173-186. https://doi.org/10.1080/00332747.1999.11024863

Beal, G., Veldhorst, G., McGrath, J.-L., Guruge, S., Grewal, P., DiNunzio, R., \& Trimnell, J. (2005). Constituting community: Creating a place for oneself. Psychiatry, 68(3), 199-211. https://doi.org/10.1521/psyc.2005.68.3.199 Beels, C. C. (1981). Social support and schizophrenia. Schizophrenia Bulletin, 7(1), 58- 
72. https://doi.org/10.1093/schbul/7.1.58

Berkman, L., Glass, T., Brissette, I., \& Seeman, T. (2000). From social integration to health: Durkheim in the new millennium. Social Science \& Medicine, 51(6), 843857. Retrieved from https://scholar.google.com/citations?view_op=view_citation\&continue=/scholar\%3 Fhl\%3Den\%26as_sdt\%3D0,38\%26authuser\%3D1\%26scilib\%3D1\&citilm=1\&citati on_for_view=Xac0OKUAAAAJ:hC7cP41nSMkC\&hl=en\&authuser=1\&oi=p

Blazer, D. G. (1982). Social support in an elderly community population. American Journal of Epidemiology, 115(5), 684-694. https://doi.org/10.1093/oxfordjournals.aje.a113351

Bond, G. R., Salyers, M. P., Rollins, A. L., Rapp, C. A., \& Zipple, A. M. (2004). How evidence-based practices contribute to community integration. Community Mental Health Journal, 40(6), 569-588. https://doi.org/10.1007/s10597-004-6130-8

Bradshaw, W., Armour, M. P., \& Roseborough, D. (2007). Finding a place in the world: The experience of recovery from severe mental illness. Qualitative Social Work, 6(1), 27-47. https://doi.org/10.1177/1473325007074164

Braun, V., \& Clarke, V. (2006). Using thematic analysis in psychology. Qualitative Research in Psychology, 3(2), 77-101. Retrieved from http://eprints.uwe.ac.uk/11735/2/thematic_analysis_revised_-_final.pdf

Brusilovskiy, E., Townley, G., Snethen, G., \& Salzer, M. S. (2016). Social media use, community participation and psychological well-being among individuals with serious mental illnesses. Computers in Human Behavior, 65, 232-240. https://doi.org/10.1016/j.chb.2016.08.036 
Burns-Lynch, W., Brusilovskiy, E., \& Salzer, M. S. (2016). An empirical study of the relationship between community participation, recovery, and quality of life of individuals with serious mental illnesses. Israel Journal of Psychiatry, 53(1), 46-55. Retrieved from https://cdn.doctorsonly.co.il/2016/08/09_Burns-Lynch_AnEmpirical-Study.pdf

Carling, P.J. (1995). Return to Community: Building Support Systems for People with Psychiatric Disabilities. Guilford Press.

Carling, Paul J. (1990). Major mental illness, housing, and supports: The promise of community integration. American Psychologist, 45(8), 969-975. https://doi.org/10.1037/0003-066X.45.8.969

Chavis, D. M., \& Wandersman, A. (1990). Sense of community in the urban environment: A catalyst for participation and community development. American Journal of Community Psychology, 18(1), 55-81. https://doi.org/10.1007/BF00922689

Chen, F.-P. (2010). Assisting adults with severe mental illness in transitioning from parental homes to independent living. Community Mental Health Journal, 46, 372380. https://doi.org/10.1007/s10597-009-9263-y

Cobb, S. (1976). Social support as a moderator of life stress. Psychosomatic Medicine, 38(5), 300-314. Retrieved from https://pdfs.semanticscholar.org/10ec/c3df00f4472cbdfc5509c77d43ecc85193da.pdf

Cohen, C. I., \& Sokolovsky, J. (1978). Schizophrenia and social networks: Ex-patients in the inner city. Schizophrenia Bulletin, 4(4), 546-560.

Cohen, S., \& Wills, T. A. (1985). Stress, social support, and the buffering hypothesis. 
Psychological Bulletin, 98(2), 310-357.

Cook, J. A., Lehman, A. F., Drake, R., McFarlane, W. R., Gold, P. B., Leff, H. S., ... Grey, D. D. (2005). Integration of psychiatric and vocational services: A multisite randomized, controlled trial of supported employment. American Journal of Psychiatry, 162(10), 1948-1956. https://doi.org/10.1176/appi.ajp.162.10.1948

Corin, E., \& Lauzon, G. (1992). Positive withdrawal and the quest for meaning: The reconstruction of experience among schizophrenics. Psychiatry, 55(3), 266-278. https://doi.org/10.1080/00332747.1992.11024600

Corrigan, P. W., \& Phelan, S. M. (2004). Social support and recovery in people with serious mental illnesses. Community Mental Health Journal, 40(6), 513-523. https://doi.org/10.1007/s10597-004-6125-5

Corrigan, P. W., \& Watson, Amy, C. (2002). Understanding the impact of stigma on people with mental illness. World Psychiatry. Retrieved from https://www.ncbi.nlm.nih.gov/pmc/articles/PMC1489832/pdf/wpa010016.pdf

Cummings, S. M., \& Kropf, N. P. (2009). Formal and informal support for older adults with severe mental illness. Aging \& Mental Health, 13(4), 619-627. https://doi.org/10.1080/13607860902774451

Cummins, R., \& Lau, A. (2003). Community integration or community exposure? A review and discussion in relation to people with an intellectual disability. Journal of Applied Research in .... Retrieved from http://onlinelibrary.wiley.com/doi/10.1046/j.1468-3148.2003.00157.x/full

Davidson, L. (2005). More fundamentally human than otherwise. Psychiatry, 68(3), 243249. Retrieved from 
http://web.a.ebscohost.com.proxy.lib.pdx.edu/ehost/pdfviewer/pdfviewer?vid=1\&si d=7fbff5cb-6651-40cb-9347-1a279950de49\%40sessionmgr4010

Davidson, L., Bellamy, C., Guy, K., \& Miller, R. (2012). Peer support among persons with severe mental illnesses: A review of evidence and experience. World Psychiatry, 11(2), 123-128. https://doi.org/10.1016/j.wpsyc.2012.05.009

Davidson, L., Chinman, M., Kloos, B., Weingarten, R., Stayner, D., \& Tebes, J. K. (1999). Peer support among individuals with severe mental illness: A review of the evidence. Clinical Psychology: Science and Practice, 6(2), 165-187. Retrieved from https://s3.amazonaws.com/academia.edu.documents/44465989/Peer_Support_Amon g_Individuals_With_Seve20160406-203791e7a6po.pdf?AWSAccessKeyId=AKIAIWOWYYGZ2Y53UL3A\&Expires=152286 8305\&Signature=StSN5GLL8oFZUnqY1pI\%2B VZzqNQg\%3D\&response-contentdisposition=inli

Davidson, L., Haglund, K. E., Stayner, D. A., Rakfeldt, J., Chinman, M. J., \& Kraemer Tebes, J. (2001). “It was just realizing...that life isn’t one big horror”: A qualitative study of supported socialization. Psychiatric Rehabilitation Journal, 24(3), 275292. https://doi.org/10.1037/h0095084

Davidson, L., \& McGlashan, T. H. (1997). The varied outcomes of schizophrenia. The Canadian Journal of Psychiatry, 42(1), 34-43. https://doi.org/10.1177/070674379704200105

Davidson, L., O’Connell, M., Tondora, J., Styron, T., \& Kangas, K. (2006). The top ten concerns about recovery encountered in mental health system transformation. Psychiatric Services, 57(5), 640-645. https://doi.org/10.1176/ps.2006.57.5.640 
Davidson, L., Stayner, D. A., Nickou, C., Styron, T. H., Rowe, M., \& Chinman, M. L. (2001). "Simply to be let in": Inclusion as a basis for recovery. Psychiatric Rehabilitation Journal, 24(4), 375-388. Retrieved from https://search-proquestcom.proxy.lib.pdx.edu/docview/1347253334/fulltextPDF/7D1D6248E6BA4C57PQ/ 1 ?accountid $=13265$

Dewees, M., Pulice, R., \& McCormick, L. (1996). Community integration of former state hospital patients: Outcomes of a policy shift in Vermont. Psychiatric Services. Retrieved from http://psycnet.apa.org/psycinfo/1996-06687-006

Drake, R. E., McHugo, G. J., Bebout, R. R., Becker, D. R., Harris, M., Bond, G. R., \& Quimby, E. (1999). A randomized clinical trial of supported employment for innercity patients with severe mental disorders. Archives of General Psychiatry, 56(7), 627. https://doi.org/10.1001/archpsyc.56.7.627

Drake, R. E., McHugo, G. J., Becker, D. R., \& Clark, R. E. (1996). The New Hampshire study of supported employment for people with severe mental illness. Journal of Consulting and Clinical Psychology, 64(2), 391-399. Retrieved from https://search.proquest.com/docview/614315911/fulltextPDF/E30068843D5247E6P $\mathrm{Q} / 1$ ?accountid=13265

Farkas, M., Gagne, C., Anthony, W., \& Chamberlin, J. (2005). Implementing recovery oriented evidence based programs: Identifying the critical dimensions. Community Mental Health Journal, 41(2), 141-158. Retrieved from http://link.springer.com/article/10.1007/s10597-005-2649-6

Felton, B., \& Shinn, M. (1992). Social integration and social support: Moving "Social Support" beyond the individual level. Journal of Community Psychology, 20(2), 
103-115. Retrieved from

http://web.a.ebscohost.com.proxy.lib.pdx.edu/ehost/pdfviewer/pdfviewer?vid=1\&si d=3dd58681-b925-473c-b885-7853d92e1ee8\%40sessionmgr4010

Gold, P. B., Meisler, N., Santos, A. B., Carnemolla, M. A., Williams, O. H., \& Keleher, J. (2006). Randomized trial of supported employment integrated with assertive community treatment for rural adults with severe mental illness. Schizophrenia Bulletin, 32(2), 378-395. https://doi.org/10.1093/schbul/sbi056

Granerud, A., \& Severinsson, E. (2006). The struggle for social integration in the community - the experiences of people with mental health problems. Journal of Psychiatric and Mental Health Nursing, 13(3), 288-293. https://doi.org/10.1111/j.1365-2850.2006.00950.x

Greene, J. C., \& Caracelli, V. J. (1997). Defining and describing the paradigm issue in mixed-method evaluation. New Directions for Evaluation, 1997(74), 5-17. https://doi.org/10.1002/EV.1068

Greene, J. C., Caracelli, V. J., \& Graham, W. F. (1989). Toward a conceptual framework for mixed-method evaluation designs. Educational Evaluation and Policy Analysis Fall, 11(3), 255-274. Retrieved from https://journals.sagepub.com/doi/pdf/10.3102/01623737011003255?casa_token=g6 Q7jY9QNqAAAAAA:xGL3SSFuvWRGnE3zgkhd8EQZGKcH5gNqnnb3LHJY4Z_O3JfyULT57YmYaoIncpAnInATVhVNO2e

Hammer, M. (1981). Social supports, social networks, and schizophrenia. Schizophrenia Bulletin, 7(1), 45-57.

Harding, C. M., Zubin, J., \& Strauss, J. S. (1987). Chronicity in schizophrenia: Fact, 
partial fact, or artifact? Psychiatric Services, 38(5), 477-486.

https://doi.org/10.1176/ps.38.5.477

Harding, C., \& Zahniser, J. (1994). Empirical correction of seven myths about schizophrenia with implications for treatment. Acta Psychiatrica Scandinavica, 90, 140-146. Retrieved from http://www.psychodyssey.net/wpcontent/uploads/2012/05/Empirical-correction.pdf

Hawkley, L. C., \& Cacioppo, J. T. (2010). Loneliness matters: A theoretical and empirical review of consequences and mechanisms. Annals of Behavioral Medicine : A Publication of the Society of Behavioral Medicine, 40(2), 218-227. https://doi.org/10.1007/s12160-010-9210-8

Headey, B. (2003). Pet ownership: Good for health? Medical Journal of Australia, 179(9), 460-461. Retrieved from www.mja.com.au

Heaney, Catherine, A., \& Israel, Barbara, A. (2008). Social networks and social support. In K. Glanz, B. K. Rimer, \& K. Viswanath (Eds.), Health behavior and health education: Theory, research, and practice (4th ed., pp. 189-210). San Francisco: Jossey-Bass. Retrieved from http://iums.ac.ir/files/hshesoh/files/beeduhe_0787996149(1).pdf\#page=227

Hendryx, M., Green, C. A., \& Perrin, N. A. (2009). Social support, activities, and recovery from serious mental illness: STARS study findings. The Journal of Behavioral Health Services \& Research, 36(3), 320-329. Retrieved from https://link.springer.com/content/pdf/10.1007\%2Fs11414-008-9151-1.pdf

Hennings, B. A. (1999). Are consumers going to the dogs (and cats and birds)? New Directions for Mental Health Services, 1999(83), 45-49. 
https://doi.org/10.1002/yd.23319998307

Hesse-Biber, S., \& Leavy, P. (2010). The Practice of Qualitative Research. Sage.

Retrieved from

https://scholar.google.com/scholar?hl=en\&as_sdt=0\%2C $38 \& q=$ the+practice + of + qu alitative+research+hesse+biber\&btnG=

Horwitz, A. V, Reinhard, S. C., \& Howell, S. (1996). Caregiving as reciprocal exchange in families with seriously mentally ill members. Journal of Health and Social Behavior, 37(37), 149-162. Retrieved from http://www.jstor.org/stable/2137270

House, J. S. (1981). Work stress and social support. Reading, Mass.: Addison-Wesley.

Israel, B. A., Farquhar, S. A., Schulz, A. J., James, S. A., \& Parker, E. A. (2002). The relationship between social support, stress, and health among women on Detroit's east side. Health Education \& Behavior, 29(3), 342-360.

https://doi.org/10.1177/109019810202900306

Jones, D. R., Macias, C., Barreira, P. J., Fisher, W. H., Hargreaves, W. A., \& Harding, C. M. (2004). Prevalence, severity, and co-occurrence of chronic physical health problems of persons with serious mental illness. Psychiatric Services, 55(11), 12501257. Retrieved from http://ps.psychiatryonline.org/doi/abs/10.1176/appi.ps.55.11.1250

Kaplan, K., Salzer, M. S., \& Brusilovskiy, E. (2012). Community participation as a predictor of recovery-oriented outcomes among emerging and mature adults with mental illnesses. Psychiatric Rehabilitation Journal, 35(3), 219-229. https://doi.org/10.2975/35.3.2012.219.229

Kaplan, K., Salzer, M. S., Solomon, P., Brusilovskiy, E., \& Cousounis, P. (2011). 
Internet peer support for individuals with psychiatric disabilities: A randomized controlled trial. Social Science \& Medicine, 72(1), 54-62.

https://doi.org/10.1016/J.SOCSCIMED.2010.09.037

Kawachi, I., \& Berkman, L. F. (2001). Social ties and mental health. Journal of Urban Health: Bulletin of the New York Academy of Medicine, 78(3). Retrieved from https://link.springer.com/content/pdf/10.1093/jurban/78.3.458.pdf

Kennedy, C. (1989). Community integration and well-being: Toward the goals of community care. Journal of Social Issues, 45(3), 65-77. https://doi.org/10.1111/j.1540-4560.1989.tb01555.x

Kline, R. B. (2015). The mediation myth. Basic and Applied Social Psychology, 37(4), 202-213. https://doi.org/10.1080/01973533.2015.1049349

Kloos, B, \& Townley, G. (2011). Investigating the relationship between neighborhood experiences and psychiatric distress for individuals with serious mental illness. Administration and Policy in Mental Health and Mental Health Services Research, 38(2), 105-116. Retrieved from http://link.springer.com/article/10.1007/s10488010-0307-y

Kloos, Bret, Zimmerman, S. O., Scrimenti, K., \& Crusto, C. (2002). Landlords as partners for promoting success in supported housing: "It takes more than a lease and a key.” Psychiatric Rehabilitation Journal, 25(3), 235-244. Retrieved from https://search-proquestcom.proxy.lib.pdx.edu/docview/1347253476/fulltextPDF/C3191BE677FD44FEPQ/ 1 ?accountid $=13265$

Kostanjsek, N. (2011). Use of The International Classification of Functioning, Disability, 
and Health (ICF) as a conceptual framework and common language for disability statistics and health information systems. BMC Public Health, 11(4).

https://doi.org/10.1186/1471-2458-11-S4-S3

Kraut, R., Kiesler, S., Boneva, B., Cummings, J., Helgeson, V., \& Crawford, A. (2002). Internet paradox revisited. Journal of Social Issues, 58(1), 49-74. https://doi.org/10.1111/1540-4560.00248

Kraut, R., Patterson, M., Lundmark, V., Kiesler, S., Mukophadhyay, T., \& Scherlis, W. (1998). Internet paradox: A social technology that reduces social involvement and psychological well-being? American Psychologist , 53(9). Retrieved from https://scholar.google.com/citations?user=HKGYvu4AAAAJ\&hl=en\&oi=sra\#d=gs_ md_cita$\mathrm{d} \& \mathrm{u}=\% 2$ Fcitations $\% 3$ Fview_op\%3Dview_citation\%26hl\%3Den\%26user\%3DHKG Yvu4AAAAJ\%26citation_for_view\%3DHKGYvu4AAAAJ\%3Au5HHmVD_uO8C $\% 26$ tzom\%3D420

Kruzich, J. M. (1985). Community integration of the mentally iII in residential facilities. American Journal of Community Psychology, 13(5), 553-564. Retrieved from https://s3.amazonaws.com/academia.edu.documents/46229950/bf009232672016060 4-11909-

ii3rjn.pdf?AWSAccessKeyId=AKIAIWOWYYGZ2Y53UL3A\&Expires=15196981 04\&Signature=yW076Wtoz8UW\%2FfN7spiCyZHFDig\%3D\&response-contentdisposition=inline $\% 3 \mathrm{~B}$ filename\%3DCommunity_in

Langford, C. P. H., Bowsher, J., Maloney, J. P., \& Lillis, P. P. (1997). Social support: A conceptual analysis. Journal of Advanced Nursing, 25(1), 95-100. 
https://doi.org/10.1046/j.1365-2648.1997.1997025095.x

Leavy, R. L. (1983). Social support and psychological disorder: A review. Journal of Community Psychology, 11(1), 3-21. https://doi.org/10.1002/15206629(198301)11:1<3::AID-JCOP2290110102>3.0.CO;2-E

Lester, H., \& Gask, L. (2006). Delivering medical care for patients with serious mental illness or promoting a collaborative model of recovery? British Journal of Psychiatry, 188(5), 401-402. Retrieved from http://www.improvingchroniccare.

Machin, K., \& Repper, J. (2013). Recovery: a carer's perspective. Retrieved from http://citeseerx.ist.psu.edu/viewdoc/download?doi=10.1.1.688.2639\&rep=rep1\&typ $\mathrm{e}=\mathrm{pdf}$

Maton, K. I., Teti, D. M., Corns, K. M., Vieira-Baker, C. C., Seattle, J. R. L., Karen, W., ... Keating, D. P. (1996). Cultural specificity of support sources, correlates and contexts: Three studies of African-American and Caucasian youth. American Journal of Community Psychology, 24(4), 551-587. Retrieved from https://s3.amazonaws.com/academia.edu.documents/46431330/bf025067962016061 2-12045-

18yxc6f.pdf?AWSAccessKeyId=AKIAIWOWYYGZ2Y53UL3A\&Expires=155772 2849\&Signature=fpj\%2FV\%2B6wFScZFKIRrXYUFWSv52I\%3D\&responsecontent-disposition=inline\%3B filename\%3DCultural_

Mattsson, M., Topor, A., Cullberg, J., \& Forsell, Y. (2008). Association between financial strain, social network and five-year recovery from first episode psychosis. Social Psychiatry and Psychiatric Epidemiology, 43(12), 947-952. https://doi.org/10.1007/s00127-008-0392-3 
McColl, M. A., Davies, D., Carlson, P., Johnston, J., \& Minnes, P. (2001). The community integration measure: Development and preliminary validation. Archives of Physical Medicine and Rehabilitation, 82(4), 429-434. https://doi.org/10.1053/apmr.2001.22195

Mccorkle, B. H., Dunn, E. C., Mui Wan, Y., \& Gagne, C. (2009). People with Serious Mental Illness Compeer Friends: a Qualitative Study of a Volunteer Friendship Programme for. International Journal of Social Psychiatry, 55(291), 291-305. https://doi.org/10.1177/0020764008097090

Mccorkle, B. H., Sally, A. E., Ae, R., Dunn, E. C., Lyass, A., Yu, A., \& Wan, M. (2008). Increasing social support for individuals with serious mental illness: Evaluating the compeer model of intentional friendship. Community Mental Health Journal, 44(5), 359. https://doi.org/10.1007/s10597-008-9137-8

McFarlane, W. R., Dushay, R. A., Deakins, S. M., Stastny, P., Lukens, E. P., Toran, J. W., \& Link, B. (2000). Employment outcomes in family-aided assertive community treatment. American Journal of Orthopsychiatry, 70(2), 203-214. Retrieved from https://search.proquest.com/docview/1038624044/fulltextPDF/A54A0F5C7E1742A $\mathrm{EPQ} / 1$ ?accountid=13265

McMillan, D., \& Chavis, D. (1986). Sense of community: A definition and theory. Journal of Community Psychology, 14(1), 6-23. Retrieved from http://mc7290.bgsu.wikispaces.net/file/view/McMillan_1986.pdf

Mechanic, D., \& Rochefort, D. A. (1990). Deinstitutionalization: An appraisal of reform. Annual Review of Sociology, 16, 301-328. Retrieved from https://about.jstor.org/terms 
Morgan, D. L. (1998). Practical strategies for combining qualitative and quantitative methods: Applications for health research. Qualitative Health Research, 3, 362-376. Retrieved from https://journals-sagepubcom.proxy.lib.pdx.edu/doi/pdf/10.1177/104973239800800307

Naslund, J. A., Grande, S. W., Aschbrenner, K. A., \& Elwyn, G. (2014). Naturally occurring peer support through social media: The experiences of individuals with severe mental illness using YouTube. PLoS ONE, 9(10), 1-9. https://doi.org/10.1371/journal.pone.0110171

Nations, U. (2006). United Nations convention on the rights of persons with disabilities. Retrieved from http://www.un.org/esa/socdev/enable/rights/convtexte.htm

Nelson, G, Lord, J., \& Ochocka, J. (2001). Empowerment and mental health in community: Narratives of psychiatric consumer/survivors. Journal of Community \& Applied Social Psychology. Retrieved from http://onlinelibrary.wiley.com/doi/10.1002/casp.619/full

Nelson, Geoffrey, Ochocka, J., Janzen, R., Trainor, J., Goering, P., \& Lomotey, J. (2007). A longitudinal study of mental health consumer/survivor initiatives: Part Voutcomes at 3-year follow-up. Journal of Community Psychology, 35(5), 655-665. https://doi.org/10.1002/jcop.20171

Norbeck, J. S., Lindsey, A. M., \& Carrieri, V. L. (1981). The development of an instrument to measure social support. Nursing Research, 30(5), 264-269. https://doi.org/10.1097/00006199-198109000-00003

Norbeck, J. S., Lindsey, A. M., \& Carrieri, V. L. (1983). Further development of the norbeck social support questionnaire. Nursing Research, 32(1), 4-9. 
https://doi.org/10.1097/00006199-198301000-00002

Organization, W. H. (2001). International classification of functioning, disability and health: ICF.

Orth-Gomér, K., \& Johnson, J. V. (1987). Social network interaction and mortality. Journal of Chronic Diseases, 40(10), 949-957. https://doi.org/10.1016/00219681(87)90145-7

Perkins, D. D., Florin, P., Rich, R. C., Wandersman, A., \& Chavis, D. M. (1990). Participation and the social and physical environment of residential blocks: Crime and community context. American Journal of Community Psychology, 18(1), 83115. https://doi.org/10.1007/BF00922690

Pinfold, V. (2000). "Building up safe havens all around the world": Users' experiences of living in the community with mental health problems. Health \& Place, 6, 201-212. Retrieved from http://www.sciencedirect.com/science/article/pii/S135382920000023X

Prince, P. N., \& Gerber, G. J. (2005). Subjective well-being and community integration among clients of assertive community treatment. Quality of Life Research, 14(1), 161-169. https://doi.org/10.1007/s11136-004-2407-1

Robson, D., \& Gray, R. (2007). Serious mental illness and physical health problems: A discussion paper. International Journal of Nursing Studies, 44(3), 457-466.

Retrieved from https://www.sciencedirect.com/science/article/pii/S0020748906002306

Royce-Davis, J. C. (2001). “It's the Day-to-Day Living That Matters": The meaning and process of community in the lives of a couple with significant psychiatric 
disabilities. American Journal of Community Psychology, 29(6), 807-832. Retrieved from https://link.springer.com/content/pdf/10.1023/A:1012957014209.pdf

Ryan, G. W., Health, R., \& Russell Bernard, H. (2003). Techniques to identify themes. Field Methods, 15(1), 85-109. https://doi.org/10.1177/1525822X02239569

Salzer, M., \& Baron, R. (2016). Well Together - A blueprint for community inclusion: fundamental concepts, theoretical frameworks and evidence. Retrieved from http://www.tucollaborative.org/sdm_downloads/well-together/

Salzer, M. S., Brusilovskiy, E., Prvu-Bettger, J., \& Kottsieper, P. (2014). Measuring community participation of adults with psychiatric disabilities: Reliability of two modes of data collection. Rehabilitation Psychology, 59(2), 211.

Salzer, M. S., Kottsieper, P., \& Brusilovskiy, E. (2015). Intermethod reliability and factors affecting recall with the Temple University Community Participation measure. Journal of Mental Health, 24(4), 189-195. https://doi.org/10.3109/09638237.2015.1036976

Sarason, S.B. (1974). The Psychological Sense of Community: Prospects for a Community Psychology. San Francisco: Jossey-Bass.

Sarason, Seymour B. (1976). Community psychology, networks, and Mr. Everyman. American Psychologist, 31(5), 317-328. Retrieved from https://search-proquestcom.proxy.lib.pdx.edu/docview/614296588/fulltextPDF/568EC550B2564325PQ/1? accountid=13265

Seeman, T. (1996). Social ties and health: The benefits of social integration. Annals of Epidemiology, 6(5), 442-451. Retrieved from https://scholar.google.com/citations?view_op=view_citation\&continue=/scholar\%3 
Fh1\%3Den\%26as_sdt\%3D0,38\%26authuser\%3D1\%26scilib\%3D1\&citilm=1\&citati on_for_view=Xac0OKUAAAAJ:qUcmZB5y_30C\&hl=en\&authuser=1\&oi=p

Segal, S. P., \& Aviram, U. (1978). The Mentally Ill in Community-Based Sheltered Care.

Segal, S. P., Silverman, C. J., \& Temkin, T. L. (2014). Self-help and community mental health agency outcomes: A recovery-focused randomized controlled trial. Psychiatric Services, 61(9), 905-910. https://doi.org/10.1176/ps.2010.61.9.905

Shinn, M., Lehmann, S., \& Wong, N. W. (1984). Social interaction and social support. Journal of Social Issues, 40(4), 55-76. https://doi.org/10.1111/j.15404560.1984.tb01107.x

Shumaker, S. A., \& Brownell, A. (1984). Toward a Theory of Social Support: Closing Conceptual Gaps. Journal of Social Issues (Vol. 40). Retrieved from https://pdfs.semanticscholar.org/fc41/ef531e881f3ea80266ab0dc7b7c47e5861e7.pdf

Stanard, R. P. (1999). The effect of training in a strengths model of case management on client outcomes in a community mental health center. Community Mental Health Journal, 35(2), 169-179. Retrieved from https://link.springer.com/content/pdf/10.1023/A:1018724831815.pdf

Stroul, B. A. (1989). Community support systems for persons with long-term mental illness: A conceptual framework. Psychosocial Rehabilitation Journal, 12(3), 9-26. Retrieved from https://search.proquest.com/docview/1504156855/fulltextPDF/945EB09D367B452F $\mathrm{PQ} / 1$ ?accountid=13265

Talò, C., Mannarini, T., \& Rochira, A. (2014). Sense of community and community participation: A meta-analytic review. Social Indicators Research, 117(1), 1-28. 
https://doi.org/10.1007/s11205-013-0347-2

Tew, J., Ramon, S., Slade, M., Bird, V., Melton, J., \& Le Boutillier, C. (2012). Social factors and recovery from mental health difficulties: A review of the evidence. British Journal of Social Work, 42, 443-460. https://doi.org/10.1093/bjsw/bcr076

The President's New Freedom Commission on Mental Health: Achieving the Promise: Transforming Mental Health Care in America. (2003). Rockville, Maryland.

Toohey, A. M., Mccormack, G. R., Doyle-Baker, P. K., Adams, C. L., \& Rock, M. J. (2013). Dog-walking and sense of community in neighborhoods: Implications for promoting regular physical activity in adults 50 years and older. Health \& Place, 22, 75-81. https://doi.org/10.1016/j.healthplace.2013.03.007

Townley, G. (2015). "It Helps You Not Feel So Bad—Feel Like You Again”: The importance of community for individuals with psychiatric disabilities. Journal of Psychosocial Rehabilitation and Mental Health, 2(2), 113-124. Retrieved from http://link.springer.com/article/10.1007/s40737-015-0036-3

Townley, G, Kloos, B., \& Wright, P. (2009). Understanding the experience of place: Expanding methods to conceptualize and measure community integration of persons with serious mental illness. Health Place, 15(2), 520-531. Retrieved from http://www.sciencedirect.com/science/article/pii/S1353829208001020

Townley, G, Miller, H., \& Kloos, B. (2013). A little goes a long way: The impact of distal social support on community integration and recovery of individuals with psychiatric disabilities. American Journal of Community Psychology. Retrieved from http://onlinelibrary.wiley.com/doi/10.1007/s10464-013-9578-2/full

Townley, Greg, \& Kloos, B. (2009). Development of a measure of sense of community 
for individuals with serious mental illness residing in community settings. Journal of Community Psychology, 37(3), 362-380. https://doi.org/10.1002/jcop.20301

Townley, Greg, \& Kloos, B. (2011). Examining the psychological sense of community for individuals with serious mental illness residing in supported housing environments. Community Mental Health Journal, 47, 436-446. https://doi.org/10.1007/s10597-010-9338-9

Üstün, T. B., Chatterji, S., Bickenbach, J., Kostanjsek, N., \& Schneider, M. (2009). The International Classification of Functioning, Disability and Health: A new tool for understanding disability and health. Disability and Rehabilitation , 25(11-12), 565571. https://doi.org/10.1080/0963828031000137063

Walsh, J., \& Connelly, P. R. (1996). Supportive behaviors in natural support networks of people with serious mental illness. Health \& Social Work, 21(4), 296-303. Retrieved from https://search.proquest.com/docview/1298063504?pqorigsite $=$ gscholar

Ware, N. C., Hopper, K., Tugenberg, T., Dickey, B., \& Fisher, D. (2007). Connectedness and citizenship: Redefining social integration. Psychiatric Services, 58(4), 469-474.

Whitley, R., \& Drake, R. (2010). Recovery: A dimensional approach. Psychiatric Services, 61(12), 1248-1250. Retrieved from http://ps.psychiatryonline.org/doi/abs/10.1176/ps.2010.61.12.1248

Wisdom, J. P., Saedi Auzeen, G., \& Green, C. A. (2009). Another breed of "Service" animals: STARS study findings about pet ownership and recovery From serious mental illness. American Journal of Orthopsychiatry, 79(3), 430-436. https://doi.org/10.1037/aM)16812 
Wong, Yin-Ling I, \& Solomon, P. L. (2002). Community integration of persons with psychiatric disabilities in supportive independent housing: A conceptual model and methodological considerations. Mental Health Services Research, 4(1). Retrieved from http://repository.upenn.edu/spp_papers28.

Wong, Yin-Ling Irene, Stanton, M. C., \& Sands, R. G. (2014). Rethinking social inclusion: Experiences of persons in recovery from mental illness. American Journal of Orthopsychiatry, 84(6), 685-695. https://doi.org/10.1037/ort0000034

Woodward, A. T., Taylor, R. J., Bullard, K. M., Neighbors, H. W., Chatters, L. M., \& Jackson, James, S. (2008). Use of professional and informal support by African Americans and Caribbean Blacks with mental disorders. Psychiatric Services, 59(11), 1292-1298. Retrieved from https://ps.psychiatryonline.org/doi/pdf/10.1176/ps.2008.59.11.1292

Wright, E. R., Wright, D. E., Perry, B. L., \& Foote, C. E. (2007). Stigma and the sexual ssolation of people with serious mental illness. Social Problems, 54(1), 78-98. https://doi.org/10.1525/sp.2007.54.1.78

Yanos, P. T., Felton, B. J., Tsemberis, S., \& Frye, V. A. (2007). Exploring the role of housing type, neighborhood characteristics, and lifestyle factors in the community integration of formerly homeless persons diagnosed with mental illness. Journal of Mental Health, 16(6), 703-717. https://doi.org/10.1080/09638230701496378

Yanos, P. T., Rosenfield, S., \& Horwitz, A. V. (2001). Negative and supportive social interactions and quality of life among persons diagnosed with severe mental illness. Community Mental Health Journal, 37(5), 405-419. Retrieved from https://link.springer.com/content/pdf/10.1023/A:1017528029127.pdf 
Yanos, P. T., Stefanic, A., \& Tsemberis, S. (2011). Psychological community integration among people with psychiatric disabilities and nondisabled community members. Journal of Community Psychology, 39(4), 390-401. https://doi.org/10.1002/jcop.20441

Zimolag, U., \& Krupa, T. (2009). Pet ownership as a meaningful community occupation for people with serious mental illness. American Journal of Occupational Therapy, 63(2), 126-137. https://doi.org/10.5014/ajot.63.2.126 


\section{Chapter 2: Study 1}

The influence of sense of community on the relationship between community participation and mental health for individuals with serious mental illnesses*

*Terry, R., Townley, G., Brusilovskiy, E., \& Salzer, M. S. (2019). The influence of sense of community on the relationship between community participation and mental health for individuals with serious mental illnesses. Journal of Community Psychology, 47(1), 163-175.

\footnotetext{
Abstract

The goal of the current study is to better understand the association between community participation and mental health by investigating sense of community as a potential mediating factor between community participation, psychological distress, and mental health functioning. A survey was administered to 300 adults with serious mental illnesses utilizing community mental health services in the United States in a crosssectional design. Hayes PROCESS macro (model 4, version 2.16; Hayes, 2013) was employed to test all of the hypotheses. Results indicate that sense of community partially mediated the association between community participation and psychological distress, as well as mental health functioning. Implications include contributing to the current knowledge base about the influence of community factors on mental health and informing future interventions aimed at promoting community participation of adults with serious mental illnesses.
} 


\section{Introduction}

In 1963, the Community Mental Health Act instigated a shift in the focus of mental health care policies from psychiatric hospitalizations to prioritizing moving people with serious mental illnesses into the community (Carling, 1995). However, subsequent policies did not support this act, resulting in a disproportionate number of people living in the community without the proper resources from community mental health services to function independently (Carling, 1995). To address this issue, the field of community mental health care has shifted towards promoting community integration, which is the belief that people with psychiatric disabilities should have the same opportunities as individuals without disabilities to live, form relationships, and experience a sense of belonging in their communities (Townley \& Kloos, 2011; Townley, Miller, \& Kloos, 2013; Wong \& Solomon, 2002). Although the deinstitutionalization movement successfully moved people with serious mental illnesses out of psychiatric hospitals and into the community, these actions have not successfully integrated those individuals into all aspects of community life or created inclusive communities (Dewees, Pulice, \& McCormick, 1996; Pinfold, 2000). In fact, people with serious mental illnesses typically report feelings of social isolation and low levels of community engagement (Badger et al., 2003; Dewees, Pulice, \& McCormick, 1996; Pinfold, 2000; Townley, Kloos, \& Wright, 2009).

Previous research demonstrates that locating mental health services in the community is generally beneficial for people with serious mental illnesses, but there remains a lack of understanding about how other community factors, such as community 
participation and sense of community, work together to influence individuals' mental health (Nelson, Lord, \& Ochocka, 2001; Segal, Silverman, \& Temkin, 2010). These factors may play an important role in helping individuals with serious mental illnesses integrate fully into their communities and work toward recovery (Townley \& Kloos, 2009; Yanos, Felton, Tsemberis, \& Frye, 2007). As such, the goal of the current study is to better understand the association between community participation and mental health by investigating sense of community as a potential mediating factor between the two.

\section{Community Participation}

In addition to the challenges noted above, individuals with serious mental illnesses typically have fewer opportunities for meaningful, self-directed participation in their communities (Ware, Hopper, Tugenberg, Dickey, \& Fisher, 2007). Community participation is defined as independent engagement in community-based contexts across any of the following social life domains: domestic life (e.g., cleaning, shopping), interpersonal life (e.g., formal relationships, intimate relationships, family relationships), major life activities (e.g., education and employment), and community, civic, and social life (e.g., politics, religion, culture; WHO, 2001). There has been limited research on aspects of community participation for people with serious mental illnesses beyond domestic life (Salzer, Brusilovskiy, Prvu-Bettger, \& Kottsieper, 2014). However, research suggests that members of this population believe that activities in the other domains are important to them, but that they do not participate in these activities as much as they would prefer (Salzer et al., 2014). As such, it is important to research these components of community participation because forming relationships, performing 
valued social roles, and engaging with the community may combat the negative effects of psychological symptom distress and social isolation.

Past research suggests that community participation has several benefits for people with serious mental illnesses, including promoting a better quality of life and recovery (Badger et al., 2003; Burns-Lynch, Brusilovskiy, \& Salzer, 2016; Kaplan, Salzer, \& Brusilovskiy, 2012). In fact, researchers in the field argue that community participation may be a medical necessity for individuals with disabilities (Salzer \& Baron, 2016). For example, Burns-Lynch, Brusilovskiy, and Salzer (2016) found significant positive correlations between community participation and measures of quality of life and recovery. Specifically, social participation (e.g., getting together in the community, visiting family or friends) had the strongest correlations with quality of life and recovery (Burns-Lynch, Brusilovskiy, \& Salzer, 2016). Furthermore, Kaplan, Salzer, and Brusilovskiy (2012) found that components of participation such as civic engagement, friendship, group membership, and employment were positively associated with greater recovery and quality of life. Additionally, participants who established casual relationships with a larger number of community members, such as store employees and wait staff, had stronger perceptions of belonging and overall life satisfaction (Wieland et al., 2007).

\section{Sense of Community}

Community participation aligns with the core community psychology value of sense of community, recognizing that when people spend more time actively participating in their communities, they are likely to develop a sense of belonging, or connectedness, 
to the community (Talò, Mannarini, \& Rochira, 2014). Sarason (1974) first conceptualized the idea of a psychological sense of community, defining it as the feeling that one belongs to, and participates in, a larger collective of individuals. He asserted that a sense of community is important to overall health and well-being, particularly for individuals who have been marginalized or segregated from community life (Sarason, 1974). Additionally, Sarason theorized that an absence of a sense of community may have a variety of negative consequences, such as feelings of alienation, loneliness, and psychological distress (1974). For people who experience serious mental illnesses, this can be expressed specifically through an increase in the number or severity of psychiatric symptoms (Townley \& Kloos, 2009).

McMillan and Chavis (1986) later proposed a theoretical framework for sense of community that included the following four components: membership, influence, integration and fulfillment of needs, and shared emotional connection. First, membership is characterized by feelings of belonging, emotional security, and identification. Second, influence is the ability for members to influence a group, and vice versa, for a cohesive group to be able to influence members. Third, integration and fulfillment of needs implies that the group is capable of satisfying the physical and psychological needs of its members, which will reinforce members' commitment to the group. Finally, shared emotional connection stems from sharing or identifying with the history of a community through personal investment and interaction with other members of the community.

Past research suggests that people with serious mental illnesses experience health benefits from sense of community and relationships with community members in a 
similar manner as members of the general population (Kloos \& Townley, 2011; Yanos, Stefanic, \& Tsemberis, 2011). In particular, sense of community may play an important role in improving mental health for people with serious mental illnesses. For example, the more that individuals with serious mental illnesses feel that they belong in their neighborhoods and are accepted by neighbors, the less psychiatric distress they report (Kloos \& Townley, 2011). Further, in a study conducted by Gulcur, Tsemberis, Stefanic, and Greenwood (2007), participants who experienced more psychological symptoms reported lower levels of sense of community.

\section{The Relationship Between Community Participation and Sense of Community}

Talò, Mannarini, and Rochira (2014) completed a meta-analytic review to investigate the relationship between sense of community and community participation and found a significant positive correlation between community participation and sense of community. Furthermore, the authors reviewed theoretical discussions regarding sense of community and community participation and found that most researchers argue that these constructs have a circular relationship, such that community participation reinforces sense of community while sense of community boosts community participation. However, previous empirical research suggests that community participation is likely to lead to an increase in sense of community (Chavis, Hogge, McMillan, \& Wandersman, 1986; Prince \& Gerber, 2005). For example, Prince and Gerber (2005) found that while sense of community and community participation were both significantly related to overall life satisfaction in a sample of adults with serious mental illnesses, they suggested 
that community participation is likely to lead to enhanced sense of community rather than the reverse.

\section{Mental Health}

Although symptom management plays a critical role in recovery for people with serious mental illnesses (Corrigan, Salzer, Ralph, Sangster, \& Keck, 2004; Smith, 2000), it is important to recognize that complete mental health encompasses more than just a lack of symptoms; it also includes an overall sense of well-being characterized by positive mental health functioning (Salyers, Bosworth, Swanson, Lamb-Pagone, \& Osher, 2000). People with serious mental illnesses report that management of mental health challenges requires prioritizing the improvement of general health and social functioning in addition to symptom management (Badger et al., 2003). However, the majority of research related to recovery for people with serious mental illnesses focuses solely on reducing symptoms and rarely examines other health-promoting factors. To address this deficiency, the current study operationalizes mental health as both lower psychological distress and better mental health functioning; and these variables are conceptualized as outcomes promoted by community participation and sense of community.

\section{Study Purpose, Research Questions, and Hypotheses}

This study aims to contribute to the current knowledge base regarding the influence of community factors on mental health for individuals with serious mental illnesses. Specifically, the goal of the current study is to investigate sense of community as a potential mediating factor between community participation, psychological distress, and mental health functioning. It is hypothesized that people with serious mental illnesses 
who report higher levels of community participation will report less psychological distress, as well as better mental health functioning, than people with lower levels of participation. Additionally, it is expected that individuals with serious mental illnesses who report higher levels of community participation will report a stronger sense of community compared to those with lower levels of participation. Further, it is expected that people with serious mental illnesses who report a stronger sense of community will also report less psychological distress and better mental health functioning than individuals who report lower levels of sense of community. Finally, it is hypothesized that sense of community will be the primary mechanism responsible for the relationship between community participation, psychological distress, and mental health functioning. That is, sense of community will mediate the relationship between community participation and the proposed outcomes.

\section{Participants}

\section{Method}

The current study utilized data collected from 300 adults with serious mental illnesses using community mental health services in the United States, who were recruited to take part in a larger study examining individual and environmental influences on community participation. Individuals were recruited from 21 mental health service organizations in 15 different states (see Figure 2.1). Participants were recruited via flyers posted in common areas of the partnering mental health organizations and distributed by case managers and other staff members.

Inclusion criteria for this study were as follows: adults between the ages of 18-65; self-reported diagnosis of either schizophrenia-spectrum disorder or major affective 
disorder (e.g., major depression and bipolar); self-reported limitations related to mental illness that occurred in the last 12 months; eligibility for Medicaid or state-equivalent benefit program; and willingness to provide a residential address. Exclusion criteria applied to individuals who were unable to provide informed consent or had a legal guardian.

Demographics. The average participant age was $46(\mathrm{SD}=11.23)$, and $60 \%$ were female. The majority of the participants were White (65\%; Black, 28\%; Other, $7 \%)$. The majority of participants reported a diagnosed mood disorder (230, 77\%), while 129 (43\%) reported a schizophrenia-spectrum disorder. Diagnostic percentages total more than $100 \%$ because participants were asked to report any current diagnoses, and some reported more than one diagnosis. Other sample demographics relevant to the current study include relationship status (64\% single), employment (16\% currently working for pay), and housing situation (57\% reported living in their own apartment, home, or condo). Additionally, a total of 72 participants (24\%) reported having been hospitalized for a mental health or psychiatric issue in the six months prior to being interviewed.

\section{Measures}

Community participation. To measure community participation, a modified 22item version of the Temple University Community Participation Measure (TUCP; Salzer, Brusilovskiy, Prvu-Bettger, \& Kottsieper, 2014) was used. Participants were asked about 22 different areas in which they participated in the last 30 days without assistance from mental health staff (e.g., going to the library, shopping, visiting with friends or family). For the purposes of this study, community participation was operationally defined as the 
total number of different areas in which participation occurred, with possible scores ranging from 0 to 22 (internal reliability alpha $=.71$ ).

Sense of community. In order to assess participants' sense of community, 13 items from the Sense of Community Index-2 (SCI-2; Chavis, Lee, \& Acosta, 2008) were used. Participants were instructed to think about their broader community and respond to each item in terms of how they generally feel about their community, as well as their perceptions of membership, influence, fulfillment of needs, and shared emotional connection (e.g., "Community members and I value the same things"). Participants responded to each statement using a four-point scale ranging from 1 (not at all) to 4 (completely). The scale was analyzed as an average of the 13 items, with the internal reliability in this sample computed as .91 .

Psychological distress. In order to assess the participants' psychological distress, the 25-item Hopkins Symptoms Checklist (HSCL-25; Derogatis, Lipman, Rickels, Uhlenhuth, \& Covi, 1974) was used. Participants were read a list of psychological symptoms and complaints and were asked how much each symptom distressed them in the past week (e.g., "Feeling no interest in things"). Participants responded to each statement using a four-point scale ranging from 1 (not at all) to 4 (extremely). The scale was analyzed as an average of 25 items, and the internal reliability in this sample was .94 .

Mental health functioning. To measure participants' mental health functioning, a 12-item version of the Short-Form Health Survey (SF-12; Ware, Kosinski, \& Keller, 1996) was used. In this measure, participants were asked about their views of their own health and wellness in the past month (e.g., "Have you felt calm and peaceful?"). 
Participants responded to questions using both three-point scales (e.g., limited a lot, limited a little, or not limited at all) and five-point scales (e.g., not at all, a little bit, moderately, quite a bit, and extremely). Scoring software provided by Optum ${ }^{\mathrm{TM}}$ (2016) was used to clean and score SF-12 data. A summary measure from the SF-12 called the mental health component score (MCS) was used for this study. The internal reliability alpha for the MCS was .77.

\section{Design and Procedures}

The current study used survey-based methods and a cross-sectional design. The research protocol included measures of community participation, perceptions of neighborhoods, sense of community, stigma, psychological distress, and quality of life. Data were collected during a phone interview, and research assistants recorded participants' answers electronically into an online survey platform. Participants provided informed consent and obtained a \$20 honorarium for their time. Interviews lasted about one hour on average. The study was approved by the Institutional Review Boards of the sponsoring Universities in addition to review boards within the Departments of Mental Health when required by partnering agencies.

\section{Results}

\section{Preliminary Analyses}

Frequency distributions and summary statistics were examined to confirm that data were normally distributed and fell within a plausible range of values for each variable (see Table 2.1). There was very little missing data in this study. None of the 
variables were missing more than three participant responses (i.e., no more than $1 \%$ missing data on any single variable).

Intraclass correlation coefficients (ICCs) were computed among the primary study variables to assess whether a multi-level design was necessary to address potential bias introduced by the shared variance between participants utilizing services at the same agency or residing in the same state. Given the low ICC values (mean ICC $=.04$ ), and in line with common recommendations in the literature that ICCs below .10 (i.e., $10 \%$ of the total variance in the outcome) are not likely to violate the independence assumption, it was acceptable to proceed with analyses using the general linear model rather than a multi-level design.

Correlational analyses between primary study variables were conducted, and a correlation matrix is presented in Table 2.2. Consistent with past research, race, gender, age, and diagnosis were considered as potential covariates (Davis, Townley, \& Kloos, 2013). Participants' current living situation was also tested as a potential covariate since people who live in their own homes or apartments may have very different experiences with community participation, sense of community, and recovery than participants living in more controlled settings or with family members.

A series of independent samples t-tests and correlational analyses indicated that there were no significant differences in the mediator or outcome variables by race or current living situation, as well as no significant correlations with age. However, there were significant differences by gender and diagnosis for sense of community, psychological distress, and mental health functioning (see Table 2.3 and 2.4). First, sense 
of community was significantly higher for males $(M=2.58, S D=.74)$ than females $(M=$ $2.33, S D=.73), t(296)=-2.87, p<.05$. Second, psychological distress was significantly lower for males $(M=1.89, S D=.60)$ than females $(M=2.23, S D=.65), t(294)=4.50, p$ $<.05$. Third, mental health was significantly higher for males $(M=40.35, S D=10.29)$ than females $(M=37.85, S D=10.65), t(295)=-2.01, p<.05$.

Furthermore, there were significant differences by diagnosis for sense of community, psychological distress, and mental health. Sense of community was significantly higher for participants diagnosed with a schizophrenia-spectrum disorder $(M$ $=2.56, S D=.76)$ compared to individuals without a schizophrenia-spectrum diagnosis $(M=2.33, S D=.71), t(298)=-2.64, p<.05$. Psychological distress was significantly lower for participants diagnosed with a schizophrenia-spectrum disorder $(M=2.00, S D=$ .62) compared to individuals without a schizophrenia-spectrum diagnosis $(M=2.16, S D$ $=.67), t(296)=2.10, p<.05$. Mental health was significantly higher for participants diagnosed with a schizophrenia-spectrum disorder $(M=40.70, S D=8.82)$ compared to individuals without a schizophrenia-spectrum diagnosis $(M=37.38, S D=11.55)$, $t(296.65)=-2.82, p<.05$. Based on these results, gender and diagnosis were included as covariates in the following analyses.

\section{Mediation Analyses}

All of the hypotheses were tested in SPSS Version 24 (IBM Corporation, 2016) using path analysis-based mediation with the Hayes PROCESS macro (model 4, version 2.16; Hayes, 2013). Bias-corrected bootstrapping techniques were employed to test the indirect effects using 5,000 bootstraps. 
Psychological distress. In the first mediation model, community participation was indicated as the predictor variable, sense of community as the mediator, and psychological distress as the outcome variable. Overall, the mediation model was significant, $F(4,290)=13.53, p<.001, R^{2}=.16$. Community participation significantly predicted psychological distress $(b=-.02, \beta=-.11, p<.05)$ and sense of community $(b=$ $.05, \beta=.24, p<.001)$. Sense of community significantly predicted psychological distress $(b=-.23, \beta=-.26, p<.001)$. A test of the indirect effect of community participation on psychological distress through sense of community revealed that participation predicted psychological distress as a function of sense of community (indirect effect $=-.01,95 \%$ BC CI: [-.02- -.01]). These results suggest a partial mediation (see Table 2.5 and Figure 2.2).

Mental health functioning. In the second mediation model, community participation was indicated as the predictor variable, sense of community as the mediator, and mental health functioning as the outcome variable. Overall, the mediation model was significant, $F(4,291)=10.06, p<.001, R^{2}=.12$. Results indicated that community participation significantly predicted mental health functioning $(b=.40, \beta=.13, p<.05)$ and sense of community $(b=.05, \beta=.25, p<.001)$. Next, sense of community significantly predicted mental health functioning $(b=3.50, \beta=.24, p<.001)$. A test of the indirect effect of community participation on mental health functioning through sense of community revealed that participation predicted mental health functioning as a function of sense of community (indirect effect $=.19,95 \%$ BC CI: [.09-.35]). Again, these results suggest a partial mediation (see Table 2.6 and Figure 2.3). 


\section{Discussion}

Community integration has emerged as a priority area among mental health advocates, policy makers, and researchers (Nelson, Lord, \& Ochocka, 2001; Ware et al., 2007; Yanos, 2007). Finding ways to promote community integration and, ultimately, recovery for adults with serious mental illnesses may be especially important as resources in the community and opportunities for participation continue to be limited. As such, the findings from the current study highlight the importance of community-based factors, particularly community participation and sense of community, in facilitating positive mental health outcomes for adults with serious mental illnesses.

\section{Overview of Study Findings}

Psychological distress. The initial goal of the present study was to examine sense of community as a potential mediating factor between community participation and psychological distress. As hypothesized, participants who reported higher levels of community participation (i.e., participation across a greater number of activity areas) also reported higher levels of sense of community and lower levels of psychological distress. Additionally, community participation remained a significant predictor of psychological distress when sense of community was added to the model, suggesting a partial mediation. Furthermore, the results indicated a significant negative indirect effect, suggesting that sense of community acts a meaningful mediator between community participation and psychological distress. The results of this mediation analysis suggest that while community participation is important, the feelings of belonging and acceptance from community members also influence psychological distress. Consistent with past 
research, while being physically present in the community is likely beneficial to recovery, it is also the social and psychological aspects of community integration that primarily results in lower psychological distress (Prince \& Gerber, 2005; Tew et al., 2011; Wong \& Solomon, 2002).

Mental health functioning. In addition to examining their association with psychological distress, the current study also sought to test the role that community factors play in promoting mental health functioning more broadly. In support of the study hypotheses, individuals who reported higher levels of community participation also reported higher levels of sense of community and mental health functioning. Additionally, community participation remained significant after adding sense of community as a mediator, suggesting partial mediation. Furthermore, there was a significant positive indirect effect of sense of community, indicating that sense of community acts as an important mediator of the relationship between community participation and mental health functioning. The results of the present study support past research that suggests the positive influence of community-based factors on the mental health functioning of individuals with serious mental illnesses (Kloos \& Townley, 2011; Tsai \& Rosenheck, 2012).

\section{Limitations and Future Research Directions}

While this study has numerous strengths, several limitations must also be noted. First, this study may not be generalizable to all adults with serious mental illnesses because participants were voluntarily recruited from outpatient mental health services 
organizations. These participants may have experiences that are quite different from those who are not engaged in outpatient mental health services.

Second, the criterion for establishing causality includes covariation between variables, temporal ordering, and elimination of competing explanations (Hayes, 2013; Kline, 2015). The data collected in this study were cross-sectional and observational in design, and therefore can only be used to establish covariation between variables. Future research examining community experiences and mental health should utilize research designs that allow researchers to establish more certain causal associations and eliminate competing explanations, such as experimental manipulation of community participation or longitudinal designs tracking participation patterns over time (Hayes, 2013).

The TUCP, which was used to measure community participation in the current study, recognizes that interpersonal relationships, major life activities, and social, community, and civic life play important roles in recovery, moving beyond the traditional examination of only participation in the domestic life domain (Salzer et al., 2014). While this study focused on independent participation (i.e., activities done without the assistance of mental health staff), it did not differentiate between activities performed with other adults who have mental illnesses and those performed with individuals who do not have a disability. While community integration research has often emphasized the importance of participation in activities that are separated from other individuals with disabilities, other researchers and advocates have argued that definitions of participation should highlight the value of engaging with peers of one's own choosing, which may certainly involve other individuals with disabilities (Cummins \& Lau, 2003; Milner \& 
Kelly, 2009; Pinfold, 2000). Future research should further examine the types of individuals with whom participation occurs and how this may differentially affect mental health outcomes. Similarly, it is important to recognize that individuals may choose not to actively participate in their communities and may cultivate a sense of community by spending time with family members or engaging with online communities (Brusilovskiy, Townley, Snethen, \& Salzer, 2016).

\section{Implications for Research and Practice}

The current study has important implications that contribute to the field of community mental health research and practice. The findings are consistent with the notion that community-based factors, such as community participation and sense of community, are positively associated with mental health outcomes for people with serious mental illnesses (Kloos \& Townley, 2011; Prince \& Gerber, 2005). Specifically, community participation was significantly related to better mental health through increased perceptions of sense of community. Several scholars have discussed the relationship between community participation and sense of community (Chavis, Hogge, McMillan, \& Wandersman, 1986; Prince \& Gerber, 2005), but research has yet to explicitly explore the potential directional relationship between the two constructs. While longitudinal research is needed to confirm the direction of effects, the current study provides provisional evidence that supporting individuals with serious mental illnesses to identify and pursue engagement in community activities may in fact influence their sense of community, and in turn, their mental health outcomes . 
Interestingly, the results of analyses with demographic and diagnostic variables found that individuals who were diagnosed with a schizophrenia-spectrum disorder reported higher levels of sense of community and mental health, and lower levels of psychological distress, compared to individuals without a schizophrenia-spectrum diagnosis. These results suggest that these individuals may be experiencing more sense of community, better mental health, and less psychological distress than individuals with other diagnoses. There is currently a gap in the literature regarding the influence of the type of mental health diagnosis on community-based factors and recovery outcomes. As such, future research and service interventions should continue to explore the ways that individuals with different mental health diagnoses experience a sense of community, as well as how this may relates to their community participation and overall mental health.

The present study also contributes to the current literature by continuing to advocate for a more holistic view of mental health for individuals with serious mental illnesses. Although symptom management remains a fundamental aspect of community mental health services, finding alternative ways to improve mental health that are rooted in community spaces may help offset the many challenges faced by mental health service organizations, including lack of funding, high client caseloads, and service provider burnout (Davidson, O’Connell, Tondora, Styron, \& Kangas, 2006). As adults with serious mental illnesses become more fully integrated into the community and experience improved mental health, they may become less reliant on community mental health services. This could allow community mental health service providers to reduce caseload sizes and spend more time supporting individuals who require more assistance with 
symptom management and adaptive functioning (Davidson et al., 2006). Findings from the current study also inform future interventions that aim to promote community integration among adults with serious mental illnesses. For instance, interventions that promote community participation have been found to benefit individuals more effectively than clinical services alone (Segal, Silverman, \& Temkin, 2010).

\section{Conclusion}

The results of this study suggest that community factors play an important role in mental health outcomes for individuals with serious mental illnesses. Specifically, sense of community acts as a mediator of the relationship between community participation, psychological distress, and mental health functioning. Thus, while participating in community activities is important, it is the feeling that one belongs to and is accepted by a larger group of individuals that may have the strongest impact on mental health. These findings highlight the fact that is it important for individuals with serious mental illnesses to both be in the community and also of the community, with meaningful opportunities to engage in activities, establish relationships with others, and develop feelings of belongingness and acceptance (Cummins \& Lau, 2003; Ware et al., 2007). As such, policy and practice should continue to strive to find ways to promote community integration for people with serious mental illnesses as they actively work towards recovery. 


\section{Figure 2.1}

Location of partnering community mental health organizations with participant recruitment totals.

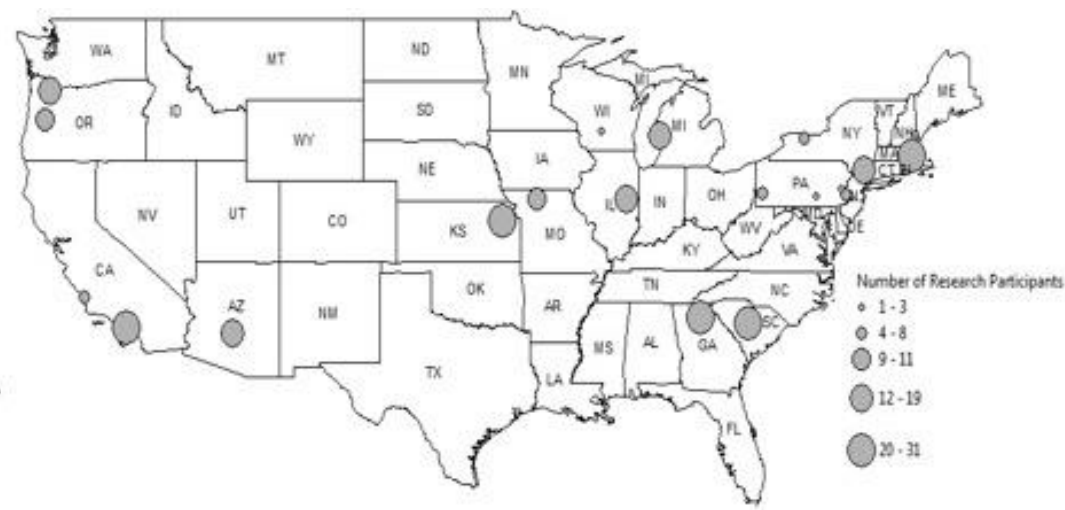


Figure 2.2

Statistical model of the mediation analysis with psychological distress as an outcome.

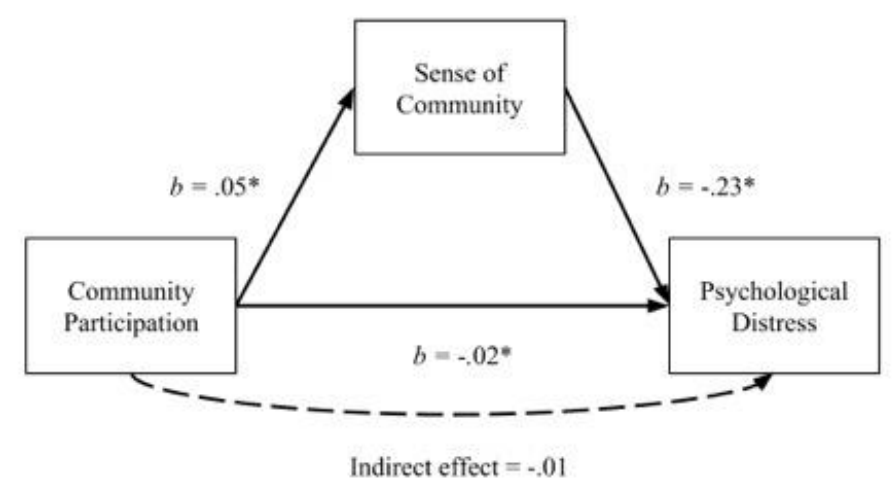


Figure 2.3

Statistical model of the mediation analysis with mental health functioning as an outcome.

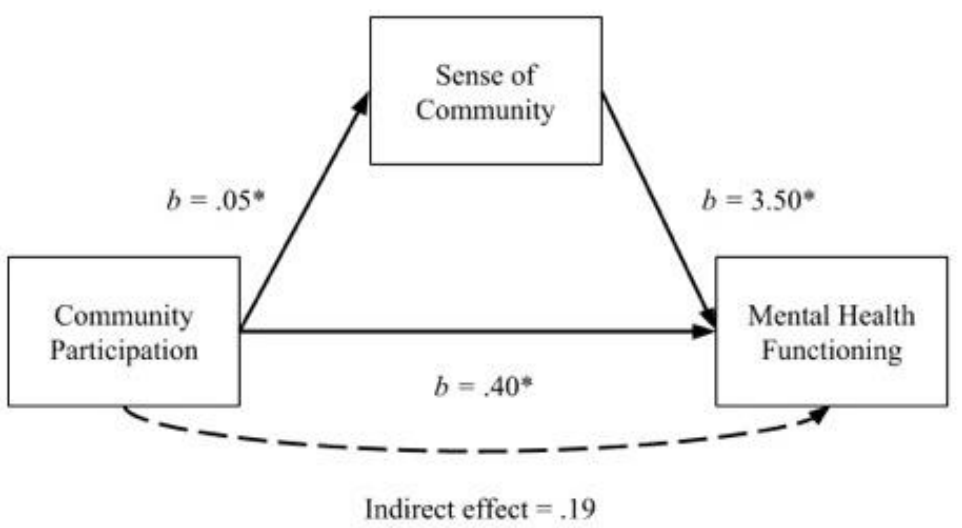




\section{Table 2.1}

Descriptive Statistics

\begin{tabular}{cccccc}
\hline Measure & $\mathrm{N}$ & Min & Max & Mean & SD \\
\hline $\begin{array}{c}\text { Community } \\
\text { Participation }\end{array}$ & 299 & 0 & 22 & 7.56 & 3.41 \\
$\begin{array}{c}\text { Sense of } \\
\text { Community }\end{array}$ & 300 & 1 & 4 & 2.43 & .74 \\
$\begin{array}{c}\text { Psychological } \\
\text { Distress }\end{array}$ & 298 & 1 & 4 & 2.09 & .65 \\
$\begin{array}{c}\text { Mental Health } \\
\text { Functioning }\end{array}$ & 299 & 13 & 71 & 38.79 & 10.59 \\
\hline
\end{tabular}


Table 2.2

Correlation Matrix of Study Variables

\begin{tabular}{|c|c|c|c|c|}
\hline & $\begin{array}{l}\text { Community } \\
\text { Participation }\end{array}$ & $\begin{array}{c}\text { Sense of } \\
\text { Community }\end{array}$ & $\begin{array}{c}\text { Psychological } \\
\text { Distress }\end{array}$ & $\begin{array}{c}\text { Mental Health } \\
\text { Functioning }\end{array}$ \\
\hline $\begin{array}{l}\text { Community } \\
\text { Participation }\end{array}$ & -- & & & \\
\hline $\begin{array}{l}\text { Sense of } \\
\text { Community }\end{array}$ & $.25^{* *}$ & -- & & \\
\hline $\begin{array}{l}\text { Psychological } \\
\text { Distress }\end{array}$ & $-.18 * *$ & $-.32 * *$ & -- & \\
\hline $\begin{array}{l}\text { Mental Health } \\
\text { Functioning }\end{array}$ & $.18 * *$ & $.31 * *$ & $-.61 * *$ & -- \\
\hline
\end{tabular}

Note. $* *$ Correlation is significant at the 0.01 level (2-tailed). 
Table 2.3

Independent Samples T-Test: Outcome Variables by Gender

\begin{tabular}{|c|c|c|c|c|c|c|c|c|c|c|}
\hline & \multicolumn{3}{|c|}{ Female } & \multicolumn{3}{|c|}{ Male } & \multirow[b]{2}{*}{$\mathrm{t}$} & \multirow[b]{2}{*}{$\mathrm{df}$} & \multicolumn{2}{|c|}{$95 \% \mathrm{CI}$} \\
\hline & $\mathrm{M}$ & SD & $\mathrm{n}$ & $\mathrm{M}$ & SD & $\mathrm{n}$ & & & Lower & Upper \\
\hline $\begin{array}{l}\text { Sense of } \\
\text { Community }\end{array}$ & 2.33 & 0.73 & 179 & 2.58 & 0.74 & 119 & $-2.87^{*}$ & 296 & -.42 & -.08 \\
\hline $\begin{array}{l}\text { Psychological } \\
\text { Distress }\end{array}$ & 2.23 & 0.65 & 178 & 1.89 & 0.60 & 118 & $4.50^{*}$ & 294 & 0.19 & 0.49 \\
\hline Mental Health & $\begin{array}{c}37.8 \\
5\end{array}$ & $\begin{array}{c}10.6 \\
5\end{array}$ & 179 & 40.35 & 10.29 & 118 & $-2.01 *$ & 295 & -4.96 & -0.06 \\
\hline
\end{tabular}


Table 2.4

Independent Samples T-Test: Outcome Variables by Diagnosis

\begin{tabular}{|c|c|c|c|c|c|c|c|c|c|c|}
\hline & \multicolumn{3}{|c|}{$\begin{array}{l}\text { Schizophrenia - } \\
\text { Spectrum (No) }\end{array}$} & \multicolumn{3}{|c|}{$\begin{array}{l}\text { Schizophrenia - } \\
\text { Spectrum (Yes) }\end{array}$} & \multirow[b]{2}{*}{$\mathrm{t}$} & \multirow[b]{2}{*}{$\mathrm{df}$} & \multicolumn{2}{|c|}{$95 \% \mathrm{CI}$} \\
\hline & $\mathrm{M}$ & $\mathrm{SD}$ & $\mathrm{n}$ & $\mathrm{M}$ & SD & $\mathrm{n}$ & & & Lower & Upper \\
\hline $\begin{array}{l}\text { Sense of } \\
\text { Community }\end{array}$ & 2.33 & 0.71 & 172 & 2.56 & $\begin{array}{c}0.7 \\
6\end{array}$ & 128 & $-2.64 *$ & 298 & -.40 & -.06 \\
\hline $\begin{array}{l}\text { Psychological } \\
\text { Distress }\end{array}$ & 2.16 & .67 & 172 & 2.00 & .62 & 126 & $2.10 *$ & 296 & .10 & .31 \\
\hline Mental Health & 37.38 & $\begin{array}{c}11.5 \\
5\end{array}$ & 172 & 40.70 & $\begin{array}{c}8.8 \\
2\end{array}$ & 127 & $-2.82 *$ & $\begin{array}{c}296.6 \\
5\end{array}$ & -5.64 & -1.00 \\
\hline
\end{tabular}




\section{Table 2.5}

Summary of Mediation Model 1, with Psychiatric Distress as the Outcome

Direct Effects of Community Participation on Psychological Distress

\begin{tabular}{lrccc} 
& \multicolumn{5}{c}{ Psychological Distress } \\
\hline Predictor & $\mathrm{b}(\mathrm{SE})$ & $\beta$ & $\mathrm{t}$ & $\mathrm{p}$ \\
\hline Intercept & $2.93(.13)$ & -.01 & 22.17 & .00 \\
Sense of Community & $-0.23(.05)$ & -.26 & -4.55 & .00 \\
Community & & & & \\
Participation & $-.02(.01)$ & -.11 & -1.93 & .05 \\
Diagnosis & $-.05(.07)$ & -.04 & -.72 & .47 \\
& & & & \\
Gender & $-0.27(.07)$ & -.20 & -3.53 & .00 \\
\hline
\end{tabular}

Indirect Effect of Community Participation on Psychological Distress Through Sense of Community

Est. SE BootLLCI BootUCLI

\begin{tabular}{lllll}
\hline Sense of & & & & \\
Community & -.01 & .00 & -.02 & -.01 \\
\hline
\end{tabular}

Note. Indirect effect based on 5,000 bootstraps. Eight cases were excluded due to missing data. 
Table 2.6

Summary of Mediation Model 2, with Mental Health Functioning as the Outcome

Direct Effects of Community Participation on Mental Health Functioning

\begin{tabular}{lrrrr} 
& \multicolumn{4}{c}{ Mental Health Functioning } \\
\hline Predictor & $\mathrm{b}(\mathrm{SE})$ & $\beta$ & $\mathrm{t}$ & $\mathrm{p}$ \\
\hline Intercept & $\begin{array}{r}26.02 \\
(2.17)\end{array}$ & .01 & 12.01 & .00 \\
& $3.50(.82)$ & .24 & 4.25 & .00 \\
Sense of Communi & & & & \\
Community & $.40(.18)$ & .13 & 2.25 & .03 \\
Participation & $2.38(1.21)$ & .11 & 1.96 & .05 \\
Diagnosis & $.93(1.22)$ & .04 & .76 & .45 \\
Gender & & &
\end{tabular}

Indirect Effect of Community Participation on Mental Health Functioning Through Sense of Community

\begin{tabular}{lcccc}
\hline & Est. & SE & BootLLCI & BootUCLI \\
\hline $\begin{array}{l}\text { Sense of } \\
\text { Community }\end{array}$ & .19 & .06 & .09 & .35 \\
\hline $\begin{array}{l}\text { Note. Indirect effect based on 5,000 bootstraps. Seven cases were excluded due to } \\
\text { missing data. }\end{array}$
\end{tabular}




\section{References}

Abdallah, C., Cohen, C. I., Miguel Sanchez-Almira, M. D., Reyes, P., \& Ramirez, P. (2009). Community integration and associated factors among older adults with schizophrenia. Psychiatric Services, 60(12), 1642-1648. doi:

$10.1176 /$ ps.2009.60.12.1642

Badger, T. A., McNiece, C., Bonham, E., Jacobson, J., \& Gelenberg, A. J. (2003). Health outcomes for people with serious mental illness: A case study. Perspectives in Psychiatric Care, 39(1), 23-32. doi: 10.1111/j.1744-6163.2003.tb00670.x

Brusilovskiy, E., Townley, G., Snethen, G., \& Salzer, M. S. (2016). Social media use, community participation and psychological well-being among individuals with serious mental illnesses. Computers in Human Behavior, 65, 232-240. doi:

10.1010/j.chb.2016.08.036

Burns-Lynch, W., Brusilovskiy, E., \& Salzer, M.S. (2016). An empirical study of the relationship Between community participation, recovery, and quality of life of individuals with serious mental illnesses. Israel Journal of Psychiatry, 53, 46-55.

Carling, P.J. (1995). Return to Community: Building Support Systems for People with Psychiatric Disabilities. Guilford Press.

Chavis, D. M., Hogge, J. H., McMillan, D. W., \& Wandersman, A. (1986). Sense of community through Brunswik's lens: A first look. Journal of Community Psychology, 14(1), 24-40. doi: 10.1002/1520-6629(198601)14:1\%3C24::AIDJCOP2290140104\%3E3.0.CO\%3B2P

Corrigan, P. W., Salzer, M., Ralph, R. O., Sangster, Y., \& Keck, L. (2004). Examining 
the factor structure of the recovery assessment scale. Schizophrenia Bulletin, 30(4), 1035. doi: 10.1093/oxfordjournals.schbul.a007118

Cummins, R. A., \& Lau, A. L. (2003). Community integration or community exposure? A review and discussion in relation to people with an intellectual disability. Journal of Applied Research in Intellectual Disabilities, 16(2), 145157. doi: 10.1046/j.1468-3148.2003.00157.x

Davis, B. A., Townley, G., \& Kloos, B. (2013). The roles of clinical and nonclinical dimensions of recovery in promoting community activities for individuals with psychiatric disabilities. Psychiatric Rehabilitation Journal, 36(1), 51. doi: 10.1037/h0094749

Davidson, L., O'connell, M., Tondora, J., Styron, T., \& Kangas, K. (2006). The top ten concerns about recovery encountered in mental health system transformation. Psychiatric Services, 57(5), 640-645. doi: $10.1176 /$ ps.2006.57.5.640

Derogatis, L. R., Lipman, R. S., Rickels, K., Uhlenhuth, E. H., \& Covi, L. (1974). The Hopkins Symptom Checklist (HSCL): A self-report symptom inventory. Behavioral Science, 19(1), 1-15. doi: 10.1002/bs.3830190102

Dewees, M., Pulice, R. T., \& McCormick, L. L. (1996). Community integration of former state hospital patients: Outcomes of a policy shift in Vermont. Psychiatric Services. doi: 10.1176/ps.47.10.1088

Hayes, A. F. (2013). Introduction to Mediation, Moderation, and Conditional Process Analysis: A Regression-based Approach. Guilford Press. 
IBM Corporation (2016). IBM SPSS Statistics 24. IBM. Armonk, NY: IBM Corporation.

Kaplan, K., Salzer, M. S., \& Brusilovskiy, E. (2012). Community participation as a predictor of recovery-oriented outcomes among emerging and mature adults with mental illnesses. Psychiatric Rehabilitation Journal, 35(3), 219. doi:

$10.2975 / 35.3 .2012 .219 .229$

Kline, R. B. (2015). The mediation myth. Basic and Applied Social Psychology, 37(4), 202-213. doi: 10.1080/01973533.2015.1049349

Kloos, B., \& Townley, G. (2011). Investigating the relationship between neighborhood experiences and psychiatric distress for individuals with serious mental illness. Administration and Policy in Mental Health and Mental Health Services Research, 38(2), 105-116. doi: 10.1007/s10488-010-0307-y

Nelson, G., Lord, J., \& Ochocka, J. (2001). Empowerment and mental health in community: Narratives of psychiatric consumer/survivors. Journal of Community \& Applied Social Psychology, 11(2), 125-142. doi: 10.1002/casp.619

Pinfold, V. (2000). 'Building up safe havens... all around the world': users' experiences of living in the community with mental health problems. Health \& Place, 6(3), 201-212. doi: 10.1016/S1353-8292(00)00023-X

Prince, P. N., \& Gerber, G. J. (2005). Subjective well-being and community integration 
among clients of assertive community treatment. Quality of Life Research, 14(1), 161-169. doi: 10.1007/s11136-004-2407-1

Salyers, M. P., Bosworth, H. B., Swanson, J. W., Lamb-Pagone, J., \& Osher, F. C. (2000). Reliability and validity of the SF-12 health survey among people with severe mental illness. Medical Care, 38(11), 1141-1150.

Salzer, M.S. \& Baron, R.C. (2016). Well Together - A blueprint for community inclusion: fundamental concepts, theoretical frameworks and evidence. Published by Wellways Australia Limited, Melbourne, Australia.

Salzer, M. S., Brusilovskiy, E., Prvu-Bettger, J., \& Kottsieper, P. (2014). Measuring community participation of adults with psychiatric disabilities: Reliability of two modes of data collection. Rehabilitation Psychology, 59(2), 211. doi:

$10.1037 / \mathrm{a} 0036002$

Sarason, S. B. (1974). The Psychological Sense of Community: Prospects for a Community Psychology. San Francisco: Jossey-Bass, 1974.

Segal, S. P., Silverman, C. J., \& Temkin, T. L. (2010). Self-help and community mental health agency outcomes: A recovery-focused randomized controlled trial. Psychiatric Services, 61(9), 905-910. doi: 10.1176/ps.2010.61.9.905

Smith, M. K. (2000). Recovery from a severe psychiatric disability: Findings of a qualitative study. Psychiatric Rehabilitation Journal, 24(2), 149. doi: 10.1037/h0095105

Talò, C., Mannarini, T., \& Rochira, A. (2014). Sense of community and community 
participation: A meta-analytic review. Social Indicators Research, 117(1), 1-28. doi: 10.1007/s11205-013-0347-2

Tew, J., Ramon, S., Slade, M., Bird, V., Melton, J., \& Le Boutillier, C. (2011). Social factors and recovery from mental health difficulties: a review of the evidence. British Journal of Social Work, 42(3), 443-460. doi:

10.1093/bjsw/bcr076

Townley, G. (2015). “It Helps You Not Feel So Bad-Feel Like You Again”: The importance of community for individuals with psychiatric disabilities. Journal of Psychosocial Rehabilitation and Mental Health, 2(2), 113-124. doi: $10.1007 / \mathrm{s} 40737-015-0036-3$

Townley, G., \& Kloos, B. (2009). Development of a measure of sense of community for individuals with serious mental illness residing in community settings. Journal of Community Psychology, 37(3), 362. doi: 10.1002/jcop.20301

Townley, G., \& Kloos, B. (2011). Examining the psychological sense of community for individuals with serious mental illness residing in supported housing environments. Community Mental Health Journal, 47(4), 436-446. doi: $10.1007 / \mathrm{s} 10597-010-9338-9$

Townley, G., Kloos, B., \& Wright, P. A. (2009). Understanding the experience of place: Expanding methods to conceptualize and measure community integration of persons with serious mental illness. Health \& Place, 15(2), 520-531. doi: 10.1016/j.healthplace.2008.08.011

Townley, G., Miller, H., \& Kloos, B. (2013). A little goes a long way: The impact of 
distal social support on community integration and recovery of individuals with psychiatric disabilities. American Journal of Community Psychology, 52(1-2), 8496. doi: 10.1007/s10464-013-9578-2

Tsai, J., \& Rosenheck, R. A. (2012). Conceptualizing social integration among formerly homeless adults with severe mental illness. Journal of Community Psychology, 40(4), 456-467. doi: 10.1002/jcop.20527

Ware Jr, J. E., Kosinski, M., \& Keller, S. D. (1996). A 12-Item Short-Form Health Survey: Construction of scales and preliminary tests of reliability and validity. Medical Care, 34(3), 220-233.

Ware, N. C., Hopper, K., Tugenberg, T., Dickey, B., \& Fisher, D. (2007). Connectedness and citizenship: Redefining social integration. Psychiatric Services, 58(4), 469474. doi: $10.1176 /$ ps.2007.58.4.469

Wieland, M. E., Rosenstock, J., Kelsey, S. F., Ganguli, M., \& Wisniewski, S. R. (2007). Distal support and community living among individuals diagnosed with schizophrenia and schizoaffective disorder. Psychiatry, 70(1), 1-11. doi: 10.1521/psyc.2007.70.1.1

World Health Organization. (2001). International classification of functioning, disability and health: ICF. World Health Organization.

Wong, Y. L. I., \& Solomon, P. L. (2002). Community integration of persons with 
psychiatric disabilities in supportive independent housing: A conceptual model and methodological considerations. Mental Health Services Research, 4(1), 1328. doi: 10.1023/A:1014093008857

Yanos, P.T. (2007). Beyond "landscapes of despair": The need for new research on the urban environment, sprawl, and the community integration of persons with serious mental illness. Health and Place, 13, (672-676). doi:

10.1016/j.healthplace.2006.10.002

Yanos, P. T., Felton, B. J., Tsemberis, S., \& Frye, V. A. (2007). Exploring the role of housing type, neighborhood characteristics, and lifestyle factors in the community integration of formerly homeless persons diagnosed with mental illness. Journal of Mental Health, 16(6), 703-717. doi: 10.1080/09638230701496378

Yanos, P. T., Stefanic, A., \& Tsemberis, S. (2011). Psychological community integration among people with psychiatric disabilities and nondisabled community members. Journal of Community Psychology, 39(4), 390-401. doi:

10.1002/jcop. 20441 


\title{
Chapter 3: Study 2
}

Exploring the role of social support in promoting community integration: An integrated literature review*

*Terry, R., \& Townley, G. (2019). Exploring the role of social support in promoting community integration: An integrated literature review. American Journal of Community Psychology, 64(3-4), 509-527.

\begin{abstract}
Community integration has emerged as a priority area among mental health advocates, policy makers, and researchers (Townley, Miller, \& Kloos, 2013; Ware et al., 2007). Past research suggests that social support influences community integration for individuals with serious mental illnesses (Davidson et al., 2001; Wong \& Solomon, 2002), but there has not yet been a systematic review on this topic. Therefore, the purpose of this paper is to explore the influence of social support on community integration through a review of the existing literature. An extensive literature search was conducted, resulting in 32 articles that met the search criteria. These articles were organized into three categories: defining community integration, supportive relationships, and mental health services. The search results are analyzed according to the types of support being provided. Article strengths, limitations, implications, and future directions are also addressed. Overall, the findings of this review suggest that social support, which may be provided by a variety of individuals and services, plays an important role in promoting community integration for individuals with serious mental illnesses. Therefore, as community mental health research and practice continues to promote community integration for individuals with serious mental illnesses, the mental health field should
\end{abstract}


emphasize the importance of social support as a key factor influencing community integration.

\section{Introduction}

Although deinstitutionalization has moved individuals with psychiatric disabilities out of hospitals and into the community, a more realistic understanding is that these individuals are "in the community, but not of it" (Ware, Hopper, Tugenberg, Dickey, \& Fisher, 2007, pg. 469). As mental health polices and practice continue to emphasize the importance of community integration, research has shown that individuals with serious mental illnesses often lack opportunities for employment, have fewer meaningful personal relationships, struggle to obtain stable, decent housing, and face discrimination from community members (Carling, 1995; Townley, Brown, \& Sylvestre, 2018; Ware et al., 2007). Previous research suggests that social support has a considerable impact on psychological distress and well-being (Cohen \& Wills, 1985; Leavy, 1983); and scholars have speculated that support provided by a range of sources influences community integration for individuals with serious mental illnesses (Carling, 1990). Therefore, the purpose of this paper is to explore the influence of social support on community integration through a review of the existing literature.

\section{Background and Significance}

Until the mid- $20^{\text {th }}$ century, mental health care in the United States was primarily focused on psychiatric hospitalization, whereby individuals with serious mental illnesses were often admitted indefinitely and isolated from family, friends, and the community (Carling, 1995). The Community Mental Health Act in 1963, enacted during the Kennedy 
administration, instigated a shift in the focus of mental health care policies and prioritized moving people with serious mental illnesses out of psychiatric hospitals and into the community. The Carter administration subsequently passed the Mental Health Systems Act, which was intended to provide federal funding to community mental health service in order to successfully serve individuals that were living in the community. However, this legislation was repealed by the Reagan administration in the Omnibus Budget Reconciliation Act of 1981. Responsibility for caring for individuals with serious mental illnesses was pushed back to states, and federal spending in this area greatly declined. As a result, a disproportionate number of people now live in the community without the proper resources from community mental health services to function independently (Carling, 1995). In response, the field of community mental health care has shifted towards promoting community integration, which is the belief that people with psychiatric disabilities should have the same opportunities as individuals without disabilities to live, form relationships, and experience a sense of belonging in their communities (Townley \& Kloos, 2009; Wong \& Solomon, 2002).

Individuals with serious mental illnesses report that community integration is important to them, but they typically experience social isolation and low community engagement (Badger, McNiece, Bonham, Jacobson, \& Gelenberg, 2008; Townley, Kloos, \& Wright, 2009). Similarly, past research suggests that individuals with serious mental illnesses have smaller support systems, fewer social contacts, and tend to experience nonreciprocal relationships with others (Dewees et al., 1996; Leavy, 1983). Furthermore, their social networks (i.e., interpersonal connections tied to an individual) are typically 
smaller than members of the general population and are characterized by less meaningful, personal relationships (Beels, 1981; Leavy, 1983; Ware et al., 2007). Therefore, individuals with serious mental illnesses are typically more socially isolated and likely experience lower levels of social support than individuals with larger social networks (Beels, 1981; Cohen \& Wills, 1985).

Research suggests that social support positively influences mental health and well-being (for reviews, see Cohen \& Wills, 1985, Leavy 1983). Cohen and Wills (1985) proposed two models to explain how social support may impact well-being: the buffer model and the main effect model. First, social support may act as a buffer between stress and negative outcomes by reducing the reaction of stress, or positively influencing the physiological processes that are occurring. An example of the buffer model is that social support may provide a solution to a stressful problem or encourage healthful behaviors. Second, social support may have positive effects on well-being regardless of the level of stress to which the individual is exposed because it helps them meet important human needs such as security, social contact, and belonging. The positive effects of social support, as posited in the main effect model, likely occur because people have social networks that expose them to consistent and positive social support experiences. Although Cohen and Wills (1985) posited that these models explain the linkages between social support and well-being, these models are likely also relevant to the relationship between social support and community integration.

Past research suggests that social support contributes to community integration for individuals with serious mental illnesses (Carling, 1990; Davidson et al., 2001; Wong \& 
Solomon, 2002). Social support may stem from numerous sources, including family, friends, service providers, or other members of the community (Leavy, 1983). For example, Davidson et al. (2001) identified three dimensions of inclusion (i.e., community integration) for individuals with serious mental illnesses, including friendship, a sense of belonging through meaningful activities, and hopefulness. Additionally, social support can be cultivated through community mental health services such as employment programs or case management. These organizations may provide training in social or occupational skills, opportunities for community engagement, or provide a space to interact with other individuals (Townley, Miller, \& Kloos, 2013). Salzer and Baron (2016) contend that individuals, organizations, and institutions should strive to foster communities that value engagement and participation with individuals with psychiatric disabilities. Finally, proponents of community integration believe that individuals with serious mental illnesses can successfully integrate into the community as long as supportive services are available to them (Townley, 2015).

\section{Theoretical Grounding}

Social support. Most psychologists agree that social support is an important predictor of well-being, and numerous definitions of social support have emerged over the years (Cohen and Wills, 1985; Gottlieb, 1978; Leavy, 1983). For example, Gottlieb (1978) proposed that social support is comprised of informal helping behaviors that are carried out by natural helpers (i.e., friends, neighbors), such as providing companionship or reflecting respect. Later, Beels (1981) broadly defined social support for individuals with schizophrenia as "whatever factors there are in the environment that promote a 
favorable course of the illness" (pg. 60). However, social support that is intended to benefit an individual may also have harmful consequences if the support is not necessary, wanted, or does not match the needs of an individual (Revenson, Schiaffino, Majerovitz, \& Gibofsky, 1991; Shinn, Lehmann, \& Wong, 1984). For example, studies of negative support with individuals with chronic illnesses suggest that it results in harmful outcomes such as depression and anxiety (Ray, 1992; Revenson, Schiaffino, Majerovitz, \& Gibofsky, 1991).

Presently, most scholars acknowledge the presence of three types of support: emotional support (e.g., love or empathy), tangible support (e.g., loaning money), and informational support (e.g., providing advice about money management; House, 1981; Langford, Bowsher, Maloney, \& Lillis, 1997). However, this understanding of social support does not account for social activities, social networks, or the perceptions and quality of support (Leavy, 1983). Although some researchers consider social networks as an acceptable proxy for social support (Beels, 1981; Hammer, 1981), Leavy (1983) contends that examining network frequency or density does not accurately capture the type or quality of support that is provided. Additionally, he argues that social support, which is typically considered at an individual-level perspective, should also be viewed at group, organization and community levels. An examination of social support at multiple ecological level of analysis aligns with community psychology values and practice (Bronfenbrenner \& Morris, 2006; Kloos, Hill, Thomas, Wandersman, \& Elias, 2012).

As such, Leavy (1983) posits that social support should be conceptualized as the range of supportive resources that are available to any given individual. Scholars have 
theorized that social support is best defined in terms of an exchange of resources between participants (i.e., family, health professionals) that are perceived to be beneficial by the recipient or the provider (Shinn, Lehmann, \& Wong, 1984; Shumaker \& Brownell, 1984). While we recognize that there is not currently scholarly consensus regarding the best way to conceptually define social support, this resource perspective aligns with community psychology values and practices. It also provides a framework for assessing supports needed to bolster community integration outcomes among individuals with serious mental illnesses. Accordingly, social support will be conceptualized in this review as a variety of resources (e.g., individuals, services) that may impact community integration.

Community integration. The community mental health field describes community integration as the belief that people with psychiatric disabilities should have the same opportunities to live and interact in the community as community members without psychiatric disabilities (Wong \& Solomon, 2002). Previously, researchers commonly focused on physical or functional aspects of community such as the location of housing or services, or ability to purchase goods at a store (Ware et al., 2007; Wong \& Solomon, 2002). In response, Wong and Solomon (2002) argued that community integration encompasses far more than merely being physically integrated into the community and suggested that the construct should be expanded to include social and psychological aspects of integration. As such, Wong and Solomon (2002) proposed three components of community integration: physical, social, and psychological. 
First, physical integration is the person's use of community resources and involvement in community activities beyond community mental health centers. Second, social integration encompasses a person's social network and the social relationships developed within this network, as well as regular interactions with community members (e.g., neighbors, coworkers, and members of religious or spiritual organizations). Third, psychological integration refers to a person's perceived sense of belonging, community membership, emotional connections with community members, and ability to influence the community. Wong and Solomon (2002) state that all three components of community integration are necessary for individuals with serious mental illnesses to successfully integrate into the community. Therefore, this paper will attempt to identify and incorporate all three aspects of community integration into the review.

While there is potential overlap between social support and these dimensions of community integration, particularly social and psychological integration, an important distinction is that social support is considered in this review as a resource that includes support from both individuals and services, as well as the quality of support.

Alternatively, social integration refers more broadly to the presence of a person's relationships and social interactions (Wong \& Solomon, 2002), while psychological integration focuses on an individual's perceived sense of community and identification with a community, which may or may not include perceptions of social support (Townley \& Kloos, 2011).

\section{Purpose}


Although scholars have completed reviews on the relationship between social support and psychological disorders (e.g., Leavy, 1983), or focused on specific aspects of social support in relation to community integration (e.g., peer support; Davidson, Bellamy, Guy, \& Miller, 2012), no one has comprehensively reviewed the impact of social support on community integration for individuals with serious mental illnesses. It also seems that social support has not been as prominent of a focus in the current literature despite its importance and relevance in bolstering a variety of beneficial outcomes, particularly among members of marginalized groups (e.g., Israel, Farquhar, Schulz, James, \& Parker, 2002; Maton et al., 1996). As such, this review aims to contribute to the current literature and set an agenda for a renewed focus on social support by 1) utilizing a resource-oriented perspective to explore the role of social support in promoting community integration for adults with serious mental illnesses; and 2) providing recommendations for ways that service providers, researchers, and advocates can enhance supports that enable individuals to participate fully in their communities.

\section{Data Collection}

\section{Methods}

Search Strategy. Articles were searched and identified using Google Scholar and EBSCO Host Academic Search Premier. Search terms included variations of community integration, serious mental illness, and social support and are listed below:

- Community integration, community inclusion, social integration

- Serious mental illness, psychiatric disabilities 
- Support, social support, family support, community support, friends, supported employment

A snowballing technique was employed to find additional articles from relevant literature reviews and dissertations. Articles that included these keywords were initially reviewed by titles, abstracts, and occasionally full-text to reduce the total number of articles to only those directly pertaining to this review. Utilizing Leavy's (1983) definition of social support, the construct was operationalized as a range of supportive resources that may impact community integration, including individuals, groups, services, organizations, or communities. Papers that examined community integration as a single construct, or specifically focused on one aspect of community integration (i.e., physical, social, psychological), were included in the review. Additionally, articles focusing on broader constructs that may encompass community integration (e.g., recovery, quality of life, well-being) were examined to determine whether or not they met inclusion criteria for the review. After realizing that Google Scholar and EBSCO Host Academic Search Premier do not include all relevant journals, a few journals (e.g., Canadian Journal of Community Mental Health) were manually searched and two additional articles were added to the review.

Sample. All articles included novel research studies with human subjects. In order to obtain as many relevant articles as possible, there was no predefined time period or limits on geographic location. The population of interest was adults with a major mental illness (e.g., schizophrenia, bipolar disorder, depression). Therefore, studies that recruited individuals with a minor mental illness (e.g., anxiety conditions) or focused on 
mental health more broadly were excluded from the review. Articles that focused on individuals with other disabilities, including intellectual and developmental disabilities, were also excluded from the review. Additionally, articles were excluded if the sample was exclusively individuals with physical injuries or traumatic brain injuries. Studies that sampled from community mental health providers, community members, family members, or friends were included if the research informed the influence of social support on community integration for individuals with serious mental illnesses. Studies focused exclusively on children, individuals who were homeless (with no specified mental illness), or formerly incarcerated individuals were also excluded.

\section{Coding Strategy}

The first author of this review utilized a combination of deductive and inductive coding strategies to review article titles, abstracts, and full text and organize the articles by themes that reflected types of support that influenced community integration. For example, certain categories of support were anticipated prior to beginning the review (e.g., family and friends), while other unanticipated categories of support emerged through the coding process (e.g., pets as a source of support influencing community integration). A list of key information from articles (e.g., sample, methodology, findings) was maintained in an excel spreadsheet, and a column was added to include a support category for each article (e.g., general supports, case management services). For example, articles that reported the results of interventions that paired participants with a community member were categorized into facilitated relationships (Davidson et al., 2001; McCorkle et al., 2008). Although several articles fell under more than one category, the 
author chose to organize the articles by the most prominent topic area. Any questions or concerns about categorizing the articles into certain themes were discussed and agreed upon with the second author throughout the process.

\section{Article Characteristics}

\section{Results}

A total of 32 articles published in 19 journals (see Table 3.1) were included in this review. Article characteristics are described in Table 3.2. The majority of the articles were quantitative $(n=20)$, followed by qualitative $(n=10)$ and mixed-methods $(n=2)$. Articles were published over a broad time period, ranging from 1985 to 2015.

\section{Research Topic Areas}

The 32 articles were organized into three major categories: defining community integration, supportive relationships, and mental health services. The following section summarizes the content in each of these research topic areas.

Defining community integration. Two articles sought to define and understand the concept of social integration (Ware et al., 2007) and community integration (Townley, 2015) by interviewing and observing individuals with serious mental illnesses. These articles were included in the review because participants in both studies discussed the importance of social support in promoting community integration.

First, Ware et al. (2007) concluded that social integration is a process whereby individuals with psychiatric disabilities continuously develop capacities for connectedness and citizenship. Connectedness entails developing and maintaining reciprocal, interpersonal relationships, as well as feeling a sense of belonging in the community. Citizenship refers to the political rights and responsibilities of members of 
our society that are either not offered or expected from individuals with psychiatric disabilities (Ware et al., 2007). Second, Townley (2015) utilized semi-structured qualitative interviews to reveal that participants often listed social support as an important aspect of becoming fully integrated into the community. Participants listed friends, service providers, mental health centers, places of worship, and recreational groups as important providers of social support that help them achieve community integration. For example, participants identified seeing friends and engaging in friendly interactions with service providers as social support experienced in mental health settings (Townley, 2015).

\section{Supportive Relationships}

Articles in this section focused on social support that is provided by relationships with friends, family members, mental health providers, community members, and pets.

General supports. Beal (1999) explored the process of relationship-building and social integration for individuals with serious mental illnesses. She conducted semistructured qualitative interviews with individuals diagnosed with schizophrenia living in the community and their friends. Three important aspects of the relationship between participants and friends emerged in the interviews: the importance of routines to foster opportunities to interact; rules or norms involved in creating friendships; and the process of maintaining these relationships (Beal, 1999).

All of the participants noted that daily routines led to predictable and safe opportunities to interact with others in the community (Beal, 1999). Participants reported that community activities (e.g., using public transportation, going to the grocery store) 
helped them meet and establish relationships with others in the community. As those relationships developed, both participants and their friends reported establishing implicit and explicit boundaries to define the friendship, such as refraining from expressing anger. In order to maintain friendships, both parties identified having the ability to leave an interaction at any time as an important rule. Additionally, participants and their friends noted that being able to both give and receive help, or engage in reciprocity, was imperative to continuing the friendship. The application of these informal rules allowed relationships to flourish and provided participants with more opportunities to engage in the community. Accordingly, Beal (1999) argues that meaningful, personal relationships with others is essential to achieving social integration for individuals with serious mental illnesses.

Beal and colleagues (2005) conducted another study to further explore relationship and community-building processes for individuals with schizophrenia. Two major themes emerged from the interviews: venturing forth and connecting, and facilitators to interaction (Beal et al., 2005). Venturing forth and connecting is defined as the act of moving beyond the service environment and interactions hosted by mental health services and connecting with others in the broader community (Beal et al., 2005). The process of venturing forth and connecting was enabled by objects, relationships, routines, past experiences, and environments that facilitated social interactions. For example, participants reported several facilitating objects, such as coffee, cigarettes, or meals that helped initiate and maintain interactions with others. Most participants preferred that interactions were time-limited and casual. Additionally, family members, 
friends, virtual relationships, and mental health providers were identified as sources of social support. Participants noted the importance of reciprocity in relationships. Overall, the majority of participants believed that the benefits of relationships were limited, such that they did not reduce psychiatric symptoms or reduce hospitalizations. However, participants reported that relationships did connect them to the community and gave them hope for the future (Beal et al., 2005).

Bradshaw, Armour, and Roseborough (2007) conducted semi-structured qualitative interviews with adults with serious mental illnesses to better understand the process of recovery over time. Five themes emerged from the interviews: reintegration into the community, reintegration with family and friends, reintegration with case managers, integration of the self and mental illness, and barriers to integration (Bradshaw et al., 2007). Overall, participants recognized the importance of integrating into the community and desired more opportunities to achieve community integration (Bradshaw, Armour, \& Roseborough, 2007). However, many participants reported difficulties integrating into the community. The majority of participants reported that family members and friends provided both emotional support (i.e., comfort) and tangible support (e.g., cosigning an apartment). Several participants identified friends as people that helped them stay out of psychiatric hospitals and remain integrated in the community. However, participants often reported conflicting feelings in regards to relationships with family. Many participants felt like a burden to family members while simultaneously feeling frustrated when family members struggled to allow them to be independent. 
Participants also reported mixed feelings about support provided by mental health services. For example, some participants reduced their involvement in mental health services because they associated it with mental illness and believed that distance would enable them to experience greater community integration. Nonetheless, the majority of participants reported positive feelings about case managers. Participants felt like they had developed meaningful relationships with their case managers and were reluctant to discontinue service use even though they did not need them anymore. Finally, lack of opportunities to develop relationships in the community, financial struggles, lack of transportation options, housing, and stigma were all identified as barriers to community integration.

Community supports. Townley, Miller, and Kloos (2013) conducted a mixedmethods study to investigate the role that distal support plays in community integration. Distal supports are casual, routine relationships developed with community members at grocery stores, coffee shops, restaurants and other routine activity locations (Wieland et al., 2007). Participants in the study by Townley and colleagues (2013) listed pharmacies, grocery stores, and other stores such as bookstores as the most frequent sources of distal support. Quantitative analyses revealed that traditional supports accounted for $11.8 \%$ of the variance in community integration, with distal supports accounting for an additional $3.1 \%$ of the variance after controlling for traditional supports (Townley et al., 2013).

Next, Townley and Kloos (2011) examined neighborhood factors that influence sense of community (i.e., psychological integration) for individuals with serious mental illnesses. Analyses revealed that support provided by neighbors predicted a significant 
amount of variance in psychological integration. Further, participants in congregate housing (i.e., those living with other individuals who also have mental illnesses) reported higher levels of psychological integration than participants in non-congregate housing (Townley \& Kloos, 2011). This suggests the important role of mental health peers in providing support that encourages community integration.

Pets. Zimolag and Krupa (2009) examined the role of pet ownership in promoting community integration. The results suggested that individuals with serious mental illnesses who are pet owners are more likely to experience psychological and social integration compared to non-pet owners. The authors explain that this is likely due to pet ownership creating opportunities for social interaction in the community and providing a sense of responsibility and belonging that enhances feelings of self-worth and self-esteem (Zimolag \& Krupa, 2009).

Facilitated relationships. Davidson and colleagues (2001) conducted a randomized trial of a nine-month social support program that paired individuals with serious mental illnesses with volunteer partners. Participants and partners were encouraged to develop friendships and participate in community activities on a weekly basis. A small stipend was provided every month to offset the cost of activities. Participants were randomly assigned to three conditions: stipend-only, consumer volunteers (i.e., history of psychiatric disabilities), and community volunteers (i.e., no history of psychiatric disabilities). The researchers conducted semi-structured interviews with a small group of participants once the program was completed to better understand 
participants' social relationships and experiences of community integration before, during, and after the program (Davidson et al., 2001).

In both the consumer and community volunteer conditions, participants reported decreased feelings of isolation and loneliness, expanded social networks, and increased participation in community activities (Davidson et al., 2001). Participants highlighted that the informal contract that participants and partners agreed to - that they would meet on a weekly basis - helped participants overcome social anxieties. The contract seemed to encourage participants and partners to value consistency and practice unconditional acceptance for one another. Finally, participants emphasized reciprocity as an important aspect of the program; compared to mental health providers or family members who may act patronizing or condescending, partners treated them as equals (Davidson et al., 2001).

The next study aimed to better understand the benefits and drawbacks of an intentional friendship program for individuals with serious mental illnesses that pairs individuals with serious mental illnesses with community volunteers (McCorkle et al., 2008). The researchers were also interested in exploring potential differences between volunteers who have been diagnosed with a mental illness and those who have not. Both parties commit to meeting at least four hours a month for at least one year. Clients and volunteers in the program completed semi-structured qualitative interviews (McCorkle et al., 2008).

Clients most frequently reported gaining a friend as a benefit of the program (McCorkle et al., 2008). Partners provided both emotional and tangible support to clients, such as providing transportation. Other benefits included opportunities to engage in 
casual, informal interactions, and participating in community activities. Half of the clients reported drawbacks to the program, but each drawback was highly individualized. For example, one client said that the volunteer had begun to provide advice that contradicted the instructions of a doctor and therapist (McCorkle et al., 2008).

Overall, participants expressed an appreciation for gaining a companion, and there were no reported drawbacks to community volunteers who were not diagnosed with a mental illness (McCorkle et al., 2008). However, clients reported both benefits and drawbacks to being paired with a community volunteer who had been diagnosed with a mental illness. A few clients viewed community volunteers with mental illnesses as role models, but others reported feeling depressed that the volunteers were more successful than them. Additionally, clients reported that consumer volunteers were more aware of the reality of being diagnosed with a mental illness, especially in regards to power and discrimination. Clients also felt like consumer volunteers were more likely to push them to overcome obstacles (McCorkle et al., 2008).

\section{Mental Health Services}

Mental health services are conceptualized as social support for the purposes of this review because they provide supportive resources to individuals with serious mental illnesses (Leavy, 1983). Services provide social support in a variety of ways, including presenting information or training (i.e., informational support), giving clients rides to and from community activities (i.e., tangible support), and allowing clients to disclose traumatic experiences in therapy (i.e., emotional support). Oftentimes, mental health services aim to help individuals successfully integrate into the community by assisting 
them with symptom and medication management, obtaining employment, and securing stable housing (Stroul, 1989). The following articles examine the influence of various mental health services in promoting community integration.

Supported employment. Workplace settings give individuals an opportunity to participate and contribute to society, gain valuable social contacts, and secure a paycheck. (W. A. Anthony \& Blanch, 1987). Consequently, a large portion of mental health research is dedicated to helping individuals with serious mental illnesses find and maintain employment in integrated settings, referred to as supported employment (Drake et al., 1999; Drake, McHugo, Becker, \& Clark, 1996; McFarlane et al., 2000). These services attempt to help individuals with serious mental illnesses obtain competitive employment, which is a job in a mainstream setting that pays minimum wage or more, is not specifically set aside for people with disabilities, and is held independently by the client. Supported employment programs provide services such as searching for employment, contract negotiations, work assessment, and long-term support.

Competitive employment is considered an aspect of community integration in this review because it requires that jobs are held in mainstream settings, which influences important factors such as the use of public transportation or developing relationships with others (e.g., coworkers; Anthony \& Blanch 1987, Banks, Charleston, \& Mank, 2001). Additionally, receiving a paycheck allows individuals to participate in meaningful community activities such as going to a restaurant, watching a movie, or attending a cultural event (Davidson et al., 2001). Finally, the mental health field continually stresses the importance of employment when discussing ways in which individuals with serious 
mental illnesses may successfully integrate into the community (Anthony \& Blanch, 1987; Carling, 1990; Davidson, et al., 2001; Stroul, 1989). As such, the following articles examine the role of supported employment models in obtaining competitive employment for individuals with serious mental illnesses.

The first three articles compared individual placement and support (IPS) to other models of supported employment, including group skills training (Drake et al., 1996), enhanced vocational rehabilitation (Drake et al., 1999), psychosocial rehabilitation, and standard services (Mueser et al., 2004). IPS provides vocational services alongside mental health services and focuses on helping clients find competitive employment, whereas other supported employment model are segregated from mental health services and focus on aspects such as pre-employment training and transitional or step-wise employment opportunities. Overall, findings from multiple studies suggest that IPS is superior at securing competitive employment for individuals with serious mental illnesses, such that participants obtained more competitive jobs, were more likely to be employed over time, worked more hours, and received higher wages compared to participants in other supported employment models (Drake et al., 1996; Drake et al., 1999; Mueser et al., 2004). Additionally, a fourth article reported the results of an IPS program without comparing it to other employment programs; the results suggested that about $50 \%$ of the participants were competitively employed after one year (Block, 1992).

Rural. The fifth article examined competitive employment outcomes for clients in an ACT-IPS program compared to traditional psychiatric and vocational services in rural areas (Gold et al., 2006). Rural areas present several difficulties to implementing 
supported employment services, such as higher rates of poverty, less employment opportunities, and difficulties with communication and travel between services. The findings suggested that clients in the ACT-IPS program were more than twice as likely to be competitively employed than the comparison group over 24 months, $64 \%$ and $26 \%$ respectively (Gold et al., 2006).

FACT and MFG vs. CVR. The sixth article compared family-aided assertive community treatment (FACT) alongside psychoeducational multifamily group treatment (MFG) to conventional vocational rehabilitation (CVR) regarding vocational outcomes (McFarlane et al., 2000). MFG connects multiple families to create a network of supportive individuals who can help clients with various needs related to recovery and community integration. The results showed that there were significantly fewer unemployed participants in the FACT-MFG group (16.2\%) than the CVR group (43.4\%). Additionally, participants in FACT-MFG group held more competitive jobs and were significantly more likely to be employed than CVR participants (McFarlane et al., 2000).

Service Integration. The seventh article examined the influence of service integration on competitive employment for individuals with serious mental illnesses (Cook et al., 2005). Service integration was defined as the following: (1) vocational and psychiatric services at the same location, (2) multidisciplinary teams with clinical and vocational staff who met frequently (i.e., at least three times a week) to discuss clients, (3) and a single case record for each client. The outcomes of interest were competitive employment and whether or not the person worked for 40 or more hours in a month. The study concluded that supported employment programs that had higher levels of integrated 
vocational and psychiatric services resulted in better employment outcomes compared to services that were not integrated, such that participants were more likely to work competitively and to work at least 40 hours per month (Cook et al., 2005).

Housing. Although mental health policies and practice have shifted to supporting individuals with serious mental illnesses to live in the community rather than remaining in psychiatric hospitals, numerous factors have left a significant proportion of individuals either homeless or living in inadequate or substandard housing (Carling, 1990).

Fortunately, the mental health field recognized that supporting individuals to obtain decent housing is essential to recovery and community integration and began providing services for supported housing (Carling, 1990). There are a range of housing situations that may fall under supported housing. The most integrated type of supported housing is typically characterized by independent, scatter-site housing units in the community that allow individuals to take advantage of natural supports and resources beyond mental health services (Carling, 1990; Yanos, Stefanic, \& Tsemberis, 2011). For example, Housing First is an intervention that aims to provide scatter-site housing and support services to individuals experiencing homeless that does not require tenants to prove their sobriety or participate in psychiatric or substance use treatments (Gulcur et al., 2007). The following articles examined the influence of social support on community integration for individuals with serious mental illnesses who live in various types of supported housing.

Kruzich (1985) aimed to identify client, facility, and community characteristics that influence community integration for individuals with serious mental illnesses living 
in residential facilities. Clients were living in one of three housing conditions ranging in levels of care from medical services available 24 hours a day to a facility with no services provided on site. The results suggested that involvement with others outside the facility, social skills training, and facilities that did not provide any medical services on site were positively related to community integration (Kruzich, 1985). Next, Kennedy (1989) aimed to better understand the influence of social support on physical integration (i.e., participating in community activities) for individuals with serious mental illnesses living in various types of residential facilities. The results revealed that emotional support explained a significant amount of variance in physical integration, while tangible and informational support were not significantly associated with integration (Kennedy, 1989). McCarthy and Nelson (1993) interviewed individuals with serious mental illnesses who were previously and currently living in supported housing. The outcomes of interest included quality of life and personal growth, which included aspects of community integration such as participation in community activities. The majority of residents regarded the staff positively and reported that they provided emotional and problem-solving support. However, a few residents reported that some staff members acted condescending or naive. Additionally, both staff and residents reported positive changes such as increases in employment and community activities (McCarthy \& Nelson, 1993).

Yanos, Stefanic, and Tsemberis (2011) examined predictors of psychological integration (i.e., sense of community) for individuals with serious mental illnesses living in supported housing in comparison to neighbors living in the same communities. The 
predictor of interest, neighborhood social capital, assessed individuals' perceptions of neighbors having positive relationships and experiencing closeness in the neighborhood. The analyses revealed that individuals with serious mental illnesses and community members did not significantly differ in psychological integration or perceptions of neighborhood social capital. Furthermore, perceived social capital was positively significantly correlated with psychological integration for both groups (Yanos, Stefanic, $\&$ Tsemberis, 2011).

Gulcur and colleagues (2007) randomly assigned adults with psychiatric disabilities to either Housing First or treatment as usual. Participants were interviewed every six months for two years. Results suggested that placement in Housing First significantly predicted psychological and social integration (Gulcur et al., 2007). Similarly, Yanos, Felton, Tsemberis, and Frye (2007) examined the influence of Housing First on community integration for adults with serious mental illnesses. Participants in Housing First reported higher scores of independence (e.g., self-care, shopping) and occupational functioning (e.g., employment, education) compared to participants in congregate housing over three years (Yanos et al., 2007). Additionally, qualitative interviews based on a smaller sample from the study above revealed that while participants felt that Housing First increased community integration, there were several challenges noted such as with loneliness and the additional responsibilities of independent living (Yanos, Barrow, \& Tsemberis, 2004).

Aubry and colleagues (2015) conducted a randomized controlled trial called the At Home/Chez Soi Housing First demonstration project in which adults with serious 
mental illnesses who were homeless or precariously housed were randomly assigned to either Housing First with Assertive Community Treatment (ACT) support services or treatment as usual (TAU) in five Canadian cities. After one year, Housing First participants were significantly more likely to be in stable housing and show improvements in quality of life and community functioning (e.g., social networks, participation in meaningful activity) than TAU participants (Aubry et al., 2015).

Patterson, Moniruzzaman, and Somers (2014) examined community integration among homeless adults with mental illnesses in Vancouver, BC as part of the larger study described above. Participants were randomized to Housing First (either independent apartments or congregate residence) with support services or to treatment as usual (TAU). While there were no significant improvements in physical integration among Housing First participants compared to TAU, residence in independent apartments was associated with increased psychological integration for participants with less severe needs. The authors explain that one factor that likely contributed to this was the intensive off-site supports available to participants in independent housing, with staff meeting with participants in their neighborhoods to connect them to resources and meaningful activities (Patterson, Moniruzzaman, \& Somers, 2014).

Finally, Ornelas, Martins, Zilhão, and Duarte (2014) completed qualitative interviews with adults with serious mental illnesses in Housing First programs in two cities in Portugal. Overall, participants reported that living in independent, scatter-site units with flexible support services led to increases in community integration such as 
utilizing local resources (e.g., coffee shops, churches), increasing social contacts, and gaining employment (Ornelas et al., 2014).

Consumer-run and self-help organizations. Mental health policies and practice are increasingly recognizing the consumer/survivor model as an important method to support individuals with serious mental illnesses (Trainor et al., 1997). The consumer/survivor model recognizes that individuals with serious mental illnesses have the ability to support one another rather than solely relying on mental health professionals (Borkman, 1976). Trainor and colleagues (1997) examined the role that participating in consumer-run organizations plays in promoting community integration for individuals with serious mental illnesses. Participants ranked consumers, the self, family physicians, and friends as the most supportive individuals in promoting community integration. Additionally, participants reported more social contacts and an increased connection to the community after participating in the organization (Trainor et al., 1997).

Although the results of the previous article suggested that participating in a consumer-run organization may promote community integration, the study was crosssectional and did not have a comparison group. Consequently, Nelson and colleagues (2007) employed a longitudinal design with a comparison group to strengthen these findings. The researchers found that participants who were continuously active in a consumer-run organization reported significantly higher community integration scores after three years than the control group. Additionally, participants in the organization engaged in community activities more frequently, which led to increases in employment and educational activities over time (Geoffrey Nelson et al., 2007). 
Finally, Segal, Silverman, and Temkin (2010) examined the impact of community mental health agencies and self-help agencies (SHA-CMHA) in promoting recovery for individuals with serious mental illnesses. SHAs often involve consumers as decisionmakers regarding program organization and content, and typically focus on social services such as support groups or participating in community activities. In contrast, CMHAs primarily focus on clinical services. The researchers hypothesized that individuals with serious mental illnesses utilizing SHA-CMHA services would have improved social integration scores compared to individuals only using CMHA services. Participants were randomly assigned to either SHA-CMHA or CMHA services and completed self-report quantitative interviews at baseline, one month, three months, and eight months. The analyses revealed that participants in SHA-CMHAs reported significantly higher levels of social integration outcomes than participants in CMHA over time (Segal, Silverman, \& Temkin, 2014).

Case management. Case management services arose after the deinstitutionalization movement to manage and coordinate the various services offered to individuals with psychiatric disabilities (Stanard, 1999). Stanard (1999) examined the effectiveness of a strengths-based model of case management. Unlike other models of case management, the strengths-based model recognizes that individuals can recover from mental illness and become more involved in the community. Clients paired with case managers who received the strengths-based training experienced significantly higher levels of educational and vocational outcomes than clients paired with case managers who did not receive the training (Stanard, 1999). 
Chen (2010) examined the role of case managers in ACT teams who are helping individuals with serious mental illnesses transition from living with family to independently living in the community. First, most participants identified increasing client independence as the main priority of ACT services. The optimal level of client independence was described as individuals living in their own homes, managing all of their daily tasks and responsibilities, and participating in social activities in the community. Services that support clients to reach client independence include assisting with daily tasks, providing training in areas such as daily living, money management, applying to jobs, and finding suitable housing (Chen, 2010).

\section{Discussion}

While scholars have long discussed the important role of family members, friends, peers, and mental health service providers in helping to facilitate connections to community, no systematic review of the types and nature of these supports had previously been conducted. The purpose of the current paper was to examine the role of social support in promoting community integration for individuals with serious mental illnesses through a review of the extant literature. As expected, findings suggest that social support, which may be provided by a variety of resources, plays an important role in promoting community integration for individuals with serious mental illnesses.

\section{Summary of Major Findings}

Past research suggests that social support is associated with higher levels of community integration for individuals with serious mental illnesses (Carling, 1990; Davidson et al., 1999; Segal \& Aviram, 1978). An extensive literature search revealed a 
range of articles that examined social support and community integration. Participants in studies by both Ware et al. (2007) and Townley (2015) emphasized that social support plays an important role in promoting community integration. Numerous sources of social support emerged, including family, friends, community members, pets, and mental health providers. Locations that facilitated support included pharmacies, grocery stores, and other stores. Additionally, several mental health services provided social support that aimed to increase community integration, including supported employment, supported housing, consumer-run and self-help organizations, and case management services. Although numerous sources of social support were identified as contributors to community integration, consensus regarding whether these supports positively or negatively influenced community integration was varied. For example, while friendships likely provide individuals with serious mental illnesses opportunities to participate in the community, engage in social interactions, and develop a sense of belonging, these relationships may not reduce the likelihood of rehospitalization (Beal et al., 2005; Bradshaw, Armour, \& Roseborough, 2007). Additionally, family members may act as a reliable source of support and community integration but may also struggle to allow individuals with serious mental illnesses to gain independence in the community (Beal et al., 2005; Bradshaw, Armour, \& Roseborough, 2007). Finally, while some participants reported mental health providers as a valuable resource to increase community integration, many participants did not discuss them as sources of support or reported negative feelings about the role of health providers in facilitating community integration (Beal et al., 2005; Davidson et al., 2001). 
Findings from this review revealed several non-traditional sources of support that positively influence community integration, including community members, neighbors, facilitated relationships, and pets. For example, Townley, Miller, and Kloos (2013) found that distal supports accounted for a significant amount of variance in community integration even after controlling for traditional supports. Additionally, mental health programs that paired individuals with serious mental illnesses with a volunteer resulted in increases in both social support and community integration (Davidson et al., 2001; McCorkle et al., 2008). Furthermore, pet ownership is associated with social and psychological integration for individuals with serious mental illnesses who are living in the community (Zimolag \& Krupa 2009).

Past research suggests that individuals with serious mental illnesses often experience relationships that are one-sided, such as family members providing shelter, or mental health professionals providing therapy (Dewees et al., 1996; Leavy, 1983). Similarly, participants highlighted the importance of reciprocity in relationships in several of the articles (Beal et al., 2005; Bradshaw, Armour, \& Roseborough, 2007; Ware et al., 2007). Reciprocity occurs when individuals have the opportunity to both give and receive help in relationships. For example, relationships that allowed participants to contribute to interactions, such as providing money, objects, advice, or support were profoundly valued and appreciated (Beal et al., 2005; Bradshaw, Armour, \& Roseborough, 2007).

In addition to specific sources of support from individuals' social networks, a variety of service programs also provide support that facilitates community integration. 
For example, individuals with serious mental illnesses who engage in supported employment programs with highly integrated services are more likely to obtain competitive employment and remain employed over time (Cook et al., 2005). Individuals who are competitively employed are achieving community integration goals by participating in community activities and establishing social contacts with co-workers and other people they interact with while working (Anthony \& Blanch, 1987; Banks, Charleston, \& Mank, 2001).

Other mental health services such as supported housing, consumer-run and selfhelp organizations, and case management also contribute to enhanced community integration for individuals with serious mental illnesses. For example, Segal, Silverman, and Temkin (2010) found that participants who utilized both community mental health and self-help services were more socially integrated than participants who only used community mental health services. Furthermore, case managers provide numerous supportive services (e.g., money management) that help individuals with serious mental illness develop skills and capacities that facilitate their integration into the community (Chen, 2010).

\section{Contextual Characteristics across Articles}

Ecological levels of analysis. Leavy (1983) conceptualized social support as a range of supportive resources that are available to individuals at any given time across different contexts and life domains. Articles included in this review represented multiple ecological levels of analyses. Microsystems were represented in articles that examined relationships with friends and family members (e.g., Beal et al., 2005; Bradshaw, 
Armour, \& Roseborough, 2007). Additionally, studies that focused on supported employment, consumer-run organizations, and case management aligned with the organizational-level of analysis (e.g., Chen, 2010; Drake et al., 1999). A few articles either examined or discussed the importance of focusing on the locality level to identify supportive activity settings, such as coffee shops and recreational centers (e.g., Gold et al., 2006; Townley, Miller, \& Kloos, 2013). Articles did not directly examine the role of the macrosystem but occasionally addressed social and cultural factors that influence social support and community integration (e.g., mental health stigma and discrimination) in the discussion sections (e.g., Chen, 2010). Furthermore, several articles examined the influence of time needed to develop relationships (e.g., Beal et al., 2005) and obtain competitive employment (e.g., Cook et al. 2005). Finally, a few studies explored proximal processes that occur as individuals develop relationships and integrated into the community, such as meeting for coffee weekly (e.g., Beal et al., 2005).

Methodology. A variety of methodological strategies were employed across the primary review categories. The majority of articles reported quantitative results; however, there were a notable number of qualitative studies. The majority of the qualitative and mixed-methods research were organized into either defining community integration or supportive relationships, whereas the majority of the quantitative research was found in the mental health services section. These findings are understandable because most of the qualitative studies were interested in understanding the experiences of individuals with serious mental illnesses (i.e., process-oriented), while the quantitative studies were 
generally more interested in demonstrating that services impacted community integration (i.e., outcome-oriented).

Although research should always be driven by the research question, there are benefits and limitations to both quantitative and qualitative research. As such, future research in each of the review categories should consider utilizing different methodologies depending on the research question. Qualitative data may provide a contextual richness to the results of an intervention that is likely not captured by quantitative data alone (for example, see Davidson et al., 2001), whereas quantitative data may be more likely to persuade funders and policy makers to develop or continue services.

Additionally, the majority of articles were cross-sectional in nature. Future research should employ longitudinal methods to examine social support and community integration for individuals with serious mental illnesses over time. For example, it would be interesting to learn if clients and volunteers continued friendships after the supported socialization programs were completed. Furthermore, only one article utilized participatory action research methods (Trainor et al., 1997). Participatory action research is increasingly employed by community psychologists because the methodology is wellaligned with community psychology values (Balcazar et al., 2004). Future research should expand the use of participatory action research methods to understand the importance of social support in promoting community integration for individuals with serious mental illnesses. 
Overall, most of the studies examined social support and community integration from the perspective of individuals with serious mental illnesses. Additionally, most of the research utilized self-report measures, with the exception of supported employment articles that examined competitive employment outcomes (e.g., Drake et al., 1996). Although it is positive that most of the articles collected data from individuals with serious mental illnesses, many researchers encourage utilizing multiple perspectives to fully understand an area of research (Hesse-Biber \& Leavy, 2017). Future research needs to continue to interview other individuals that have perspectives on social support and community integration, such as family, friends, or mental health providers.

Terminology. Researchers in the mental health field have not yet agreed on a consistent set of terminology to examine social support and community integration; therefore, both constructs were measured in a variety of ways. Some articles defined social support as the types of support that individuals might receive (e.g., emotional, tangible, informational; Townley, Miller, Kloos, 2013), while other articles operationalized social support as the availability of individuals that provide support (e.g., choosing friends, Beal, 1999). Finally, several articles did not specifically state that social support was a variable of interest; rather, social support emerged as an important aspect of community integration (e.g., Bradshaw, Armour, Roseborough, 2007).

Community integration was also measured differently across studies. Several articles operationalized community integration using the definition by Wong and Solomon (2002) which includes physical, social, and psychological integration (e.g., Yanos et al., 2007). Other articles did not explicitly state that they were measuring 
community integration but measured a construct that can be identified as an aspect of community integration (e.g., sense of community; Townley \& Kloos, 2011). Multiple quantitative measures of community integration were employed, including the Social Integration Scale (Segal \& Aviram, 1978), Psychological Integration Scale (Perkins, Florin, Rich, Wandersman, \& Chavis, 1990), and the Community Integration Measure (McColl, Davies, Carlson, Johnston, \& Minnes, 2001). Additionally, while competitive employment was included as a measure of community integration, it is important to note that those studies did not examine other important indicators of community integration. Overall, finding ways to increase communication and encourage consensus among researchers working across different disciplines and settings may enhance the current state of research and enhance the likelihood that findings will have an impact on mental health policy and practice. We hope that this review calls attention to the need for a renewed focus on social support and community integration, and in particular a focus on the importance of shared conceptualization and measurement of these constructs.

\section{Limitations of the Review}

Several limitations of this review must be addressed. First, although an extensive literature search was conducted, there is a possibility that relevant articles are not included in this review. Social support and community integration were defined and operationalized in a variety of ways by researchers and across disciplines; and articles may not have appeared in the search results because they did not include the primary keywords used in this review. However, the selected keywords were searched in a variety of combinations, and articles that did not explicitly mention social support or community 
integration were reviewed to ensure that all relevant articles were included. Finally, relevant articles may have been excluded because they were not in English or not electronically available.

Second, this review does not consider differences in geographic location. Although location of the studies may influence individuals with serious mental illnesses' experiences of social support and community integration, most articles did not report the location or provide specific place-based information. Additionally, all of the articles were conducted in the United States or Canada, with the exception of one article completed in Portugal (Ornelas et al., 2014). Therefore, social support and community integration may not be generalizable to individuals with serious mental illnesses in countries not represented in this review.

Third, the findings overwhelming generalize to cultures that value independence in society. For example, while most people might include living independently as an aspect of community integration, multigenerational households are the norm in other cultures (Chen, 2010). Future research should explore the ways in which cultural differences may impact social support and community integration for individuals with serious mental illnesses.

\section{Implications and Future Directions}

Individuals with serious mental illnesses continuously identified social support as important to achieving community integration (Townley, 2015; Ware et al., 2007). However, participants across studies generally reported relatively small social networks and less personal and meaningful relationships than the general population, similar to 
past research (Beels, 1981; Dewees, Pulice, \& McCormick, 1996). There are several individual sources of support that influence community integration for individuals with serious mental illnesses, such as friends, family members, and community members. However, substantial work remains in light of the overall low levels of support reported across the reviewed studies.

Friendships that allow for reciprocal interactions and unconditional acceptance may be more successful than relationships that are unidirectional or based on dependency (Beal, 1999; Beal et al., 2005; Davidson et al., 2001). Additionally, optimal interactions are generally casual, consistent, and time-limited. Family members are particularly important for individuals with serious mental illnesses, especially for individuals that are transitioning to living on their own (Chen, 2010). Families should provide support to family members who are diagnosed with a serious mental illness while also recognizing the importance and benefit of opportunities to become more independent and integrate into the community (Chen, 2010). Natural supports (e.g., friends) are important because these individuals are potentially abundant in the community and not limited by the constraints of more formal community support services (e.g., lack of funding, service provider burnout, and high client caseloads; Davidson et al., 2006).

Mental health providers should encourage clients to participate in a variety of activities in the community, including taking walks in the park, going to stores, or grabbing coffee. These casual, routine interactions with community members positively influence community integration (Beal et al., 2005; Townley, Miller, \& Kloos, 2013). Neighbors are also important community members (Townley \& Kloos, 2011), and 
individuals with serious mental illnesses should consider engaging in interactions and forming relationships with their neighbors. Community centers and neighborhood associations can facilitate these types of interactions by hosting block parties, street fairs, neighborhood cleanups, and other social events. Finally, pets may also act as sources of social support that positively influence community integration (Zimolag \& Krupa, 2009). Mental health providers should engage in discussions with clients about potential interest and readiness in adopting a pet.

Overall, there is a gap in the literature regarding the role of coworkers and significant others in facilitating community integration. Although some studies provided opportunities for participants to report coworkers or significant others as sources of support (e.g., Bradshaw, Armour, \& Roseborough, 2007), other studies solely examined the influence of only one source of support (e.g., friends; Beal, 1999). A lack of supportive relationships with coworkers is likely due to the fact that unemployment is common among individuals with serious mental illnesses, even though the majority of people report that they would like to be employed (Drake et al., 1996). Additionally, many individuals with serious mental illnesses report that they would like to be in a romantic relationship but lack opportunities to meet potential or suitable partners, listing barriers such as financial struggles or lack of transportation (Wright et al., 2007). Furthermore, relationships with coworkers or significant others are likely negatively impacted by stigma and discrimination (Banks, Charleston, \& Mank, 2001; Wright et al., 2007). 
There are considerable benefits to engaging in these types of relationships for the general population (Cohen \& Wills, 1985) and these benefits may apply to individuals with serious mental illnesses. For example, Royce-Davis (2001) found that individuals with psychiatric disabilities cited both spouses and coworkers as sources of support that positively influenced community participation. Therefore, mental health services should support clients as they attempt to develop relationships with coworkers and significant others; and future research should examine these types of relationships and their influence on community integration more closely. In particular, an examination of ways to remove barriers to the formation of these types of relationship is a vital direction for research moving forward.

There were several mental health services that provided social support that influenced community integration for individuals with serious mental illnesses identified in the review. Supported employment models that emphasized providing integrated services and helping clients obtain competitive employment were more successful at employing clients in integrated work settings than more traditional approaches (e.g., Drake et al., 1999; Cook et al., 2005). Therefore, individuals with serious mental illnesses who are interested in obtaining competitive employment should seek out these types of employment programs, and mental health policy should continue to fund supported employment models. Additionally, housing sites should provide activities such as social skills training and social events. These activities may increase social support within housing sites, boost residents' social skills and self-worth, and encourage residents to participate in the community (Kruzich, 1985, Townley \& Kloos, 2011). Furthermore, 
case managers should recognize the strengths and capabilities of clients, emphasize the importance of community integration, and support them in identifying and taking action toward participating more fully in their communities (Chen, 2010, Stanard, 1999).

As mental health policies and advocates continue to highlight the importance of community integration (Townley, Kloos, \& Wright, 2009), it is encouraging to find that services are engaging in practices that support clients in achieving community integration goals. Several participants across studies acknowledged that service use positively influenced their ability to engage in the community settings (Bradshaw, Armour, \& Roseborough, 2007; Segal, Silverman, \& Temkin, 2010). However, relying on services as primary sources of support may hinder individuals' ability to increase social contacts in the community and also contribute to the narrow range of social networks that are typically reported (Beels, 1981; Ware et al., 2007). Ultimately, ensuring that individuals with serious mental illnesses are able to choose between various sources of support is important to achieving optimal levels of community integration. Future studies should investigate how various sources of social support (e.g., community members, services) can help or hinder community integration for adults with serious mental illnesses. Additionally, although the mental health field is increasingly recognizing the importance of peer support (for reviews, see Davidson et al., 1999, Davidson et al., 2012), there were few articles that examined consumer-run and self-help organizations. A potential explanation is that mental health providers often do not recommend consumerrun or self-help organizations to clients and therefore clients do not engage with these organizations (Davidson et al., 1999). Additionally, research may not conceptualize these 
organizations as a source of social support or a predictor of community integration. As such, articles in this area may not have appeared in the search results. However, the findings from this review suggest that involvement in consumer-run and self-help organizations positively influence community integration for individuals with serious mental illnesses (Nelson et al., 2007; Segal, Silverman, \& Temkin, 2010; Trainor et al., 1997). Furthermore, these types of organizations were preferred by individuals with serious mental illnesses (Trainor et al., 1997). Therefore, mental health providers should recommend consumer-oriented organizations to clients, and future research should continue to examine ways in which these organizations support individuals as they integrate into the community.

Finally, much work remains in combatting social isolation among individuals with serious mental illnesses. While the majority of individuals with serious mental illnesses prefer living in the community, they often report feelings of loneliness and difficulty forming relationships with others (Davidson et al., 2001). Past research has suggested that mental illness is the cause of social isolation for individuals with psychiatric disabilities, arguing that symptoms and a deficit in social skills make it difficult for individuals to maintain relationships and integrate into the community (Davidson \& McGlashan, 1997). Some participants across studies included in the review did report that symptoms, side effects of medication, and embarrassment about diagnosis hindered participants' ability to developing meaningful relationships and integrate into the community (e.g., Beal et al. 2005; Davidson et al., 2001). However, there are other important social, political, and cultural factors that contribute to community integration 
barriers, such as lack of opportunities, poverty, and mental health stigma (Beal et al., 2005; Davidson et al., 2001; Dewees, Pulice, \& McCormick, 1996; Sylvestre, Notten, Kerman, Polillo, \& Czechowski, 2018). These macro-structural issues must be a stronger focus of research, practice, and policy moving forward rather than placing all of the onus on individuals with serious mental illness to achieve community integration outcomes on their own.

\section{Conclusion}

"People need each other... especially when you have an illness, you really need the support." (Davidson et al., 2001, pg. 280)

As the participant's comment above reflects, while social support is important for everyone, it is especially important for individuals with serious mental illnesses. Past research has shown that social support influences mental health, well-being, and quality of life (Cohen \& Wills, 1985; Leavy, 1983). The findings from this review suggest that social support plays a significant role in promoting community integration for individuals with serious mental illnesses. This review also contributes to the literature by identifying and analyzing a range of social supports that influence community integration for this population. The community mental health field should strive to help individuals with serious mental illnesses become both in the community and of the community by supporting these individuals as they participate in community activities, establish relationships with others, and obtain stable employment and housing (Cummins \& Lau, 2003; Ware et al., 2007). 


\section{Table 3.1}

Journals Included in the Integrative Literature Review

American Journal of Community Psychology (2)

American Journal of Occupational Therapy

American Journal of Orthopsychiatry

American Journal of Psychiatry

Archives of General Psychiatry

Community Mental Health Journal (6)

Canadian Journal of Community Mental Health (2)

European Journal of Homelessness

International Journal of Social Psychiatry

Journal of Community Psychology (2)

Journal of Consulting and Clinical Psychology (2)

Journal of Mental Health

Journal of Psychosocial Rehabilitation and Mental Health

Journal of Social Issues

Psychiatric Rehabilitation Journal (2)

Psychiatric Services (3)

Psychiatry (2)

Qualitative Social Work

Schizophrenia Bulletin

Note. Journals with more than one article included in the review are indicated in parenthesis. 
Table 3.2

Article

Characteristics

\begin{tabular}{|c|c|c|c|c|c|}
\hline Author & Year & Sample & Methods & Location & Findings \\
\hline Aubry et al. & 2015 & $\begin{array}{l}950 \text { high need } \\
\text { homeless or } \\
\text { precariously housed } \\
\text { individuals assigned } \\
\text { to either Housing } \\
\text { First or treatment as } \\
\text { usual }\end{array}$ & Quantitative & $\begin{array}{l}\text { United } \\
\text { States }\end{array}$ & $\begin{array}{l}\text { Housing First } \\
\text { participants were } \\
\text { significantly more likely } \\
\text { to be in stable housing } \\
\text { and show improvements } \\
\text { in quality of life and } \\
\text { community functioning } \\
\text { than TAU participants. }\end{array}$ \\
\hline Beal & 1999 & $\begin{array}{l}\text { Nine individuals } \\
\text { diagnosed with } \\
\text { schizophrenia; } \\
\text { identified a total of } \\
22 \text { individuals as } \\
\text { friends }\end{array}$ & Qualitative & Canada & $\begin{array}{l}\text { Major themes included } \\
\text { the importance of } \\
\text { routines to foster } \\
\text { opportunities to interact; } \\
\text { rules or norms involved } \\
\text { in creating friendships; } \\
\text { and the process of } \\
\text { maintaining friendships. }\end{array}$ \\
\hline Beal et al. & 2005 & $\begin{array}{l}\text { Seven individuals } \\
\text { diagnosed with } \\
\text { schizophrenia }\end{array}$ & Qualitative & Canada & $\begin{array}{l}\text { Major themes included } \\
\text { venturing forth and } \\
\text { connecting and } \\
\text { facilitators to } \\
\text { interaction. }\end{array}$ \\
\hline Block & 1992 & 14 individuals & Quantitative & Canada & $\begin{array}{l}50 \% \text { of participants were } \\
\text { competitively employed } \\
\text { after one year. }\end{array}$ \\
\hline $\begin{array}{l}\text { Bradshaw, } \\
\text { Armour, \& } \\
\text { Roseborough }\end{array}$ & 2007 & $\begin{array}{l}44 \text { individuals } \\
\text { utilizing services } \\
\text { from a community } \\
\text { mental health center }\end{array}$ & Qualitative & $\begin{array}{l}\text { United } \\
\text { States }\end{array}$ & $\begin{array}{l}\text { Major themes included } \\
\text { reintegration into the } \\
\text { community, with family } \\
\text { and friends and case } \\
\text { managers, integration of } \\
\text { the self and mental } \\
\text { illness, and barriers to } \\
\text { integration. }\end{array}$ \\
\hline Chen & 2010 & $\begin{array}{l}24 \text { case managers } \\
\text { employed by } 10 \\
\text { ACT teams }\end{array}$ & Qualitative & $\begin{array}{l}\text { United } \\
\text { States }\end{array}$ & $\begin{array}{l}\text { Results suggested that } \\
\text { participants aimed to } \\
\text { help clients manage their } \\
\text { mental illness, increase } \\
\text { independence, and } \\
\text { develop social } \\
\text { connections in the } \\
\text { community. }\end{array}$ \\
\hline
\end{tabular}


1,273 individuals

Cook et al. 2005 $\begin{aligned} & \begin{array}{l}\text { interested in } \\ \text { obtaining } \\ \text { employment }\end{array}\end{aligned}$

Davidson et al. 2001

21 individuals utilizing mental health services

Drake,

McHugo,

Becker, \&

Clark

Drake et al.

1999

152 individuals

utilizing intensive case management services

143 individuals; comparison groups included statewide survey from 1,536 individuals and 29 individuals from the mental health centers but not enrolled in the study

Gold et al. 2006

143 individuals

183 participants $(82$

Gulcur

2007

Housing First, 101

treatment as usual)

159 individuals

living in either

Kennedy

1989

supervised

community

residences,
Quantitative

United States

Quantitative

United States

Supported employment services that were integrated with psychiatric services resulted in better employment outcomes compared to services that are not integrated.

In both the consumer and community volunteer conditions, participants reported decreased feelings of isolation and loneliness, expanded social networks, and increased participation in community activities.

Participants in the IPS program were significantly more likely to be competitively employed over participants in the GST program.

Participants in the IPS program were significantly more likely to be competitively employed over participants in the EVR program.

Participants in the ACTIPS program were

United significantly more likely States to be competitively employed over participants in traditional services.

Placement in Housing

United First significantly Quantitative States predicted psychological and social integration.

Emotional support explained a significant Quantitative

United amount of variance in physical integration, while tangible and 
supportive housing, or single-room occupancy

87 individuals

living in three different housing conditions that ranged from a high

Kruzich

McCarthy \& Nelson

34 interviews with residents and staff in seven supported housing programs.

Mixedmethods Quantitative 24 hours licensed nurse available) to a facility with no services provided on site

McCorkle, Dunn, Mui Wan, \& Gagne

Nine individuals, 12 volunteers

Qualitative

United

States

United

McFarlane et al.

200069 individuals

Quantitative States

United $\begin{array}{llll}\text { Mueser et al. } 2004 \quad 204 \text { individuals } \quad \text { Quantitative } & \begin{array}{l}\text { United } \\ \text { States }\end{array}\end{array}$

informational support were not significantly associated with community integration.

Involvement with others outside the facility, social skills training, and United facilities that did not provide medical services on site were positively related to community integration.

The majority of residents reported that they provided emotional and problem-solving support. Staff and residents reported increased employment and participation in community activities.

Benefits included gaining a friend, receiving emotional and tangible support, engaging in casual interactions, and participating in community activities.

Participants in FACTMFG program held more competitive jobs and were more likely to be employed than participants in the CVR program.

Participants in the IPS program were significantly more likely to obtain competitive employment than participants in the PSR program or standard services. 


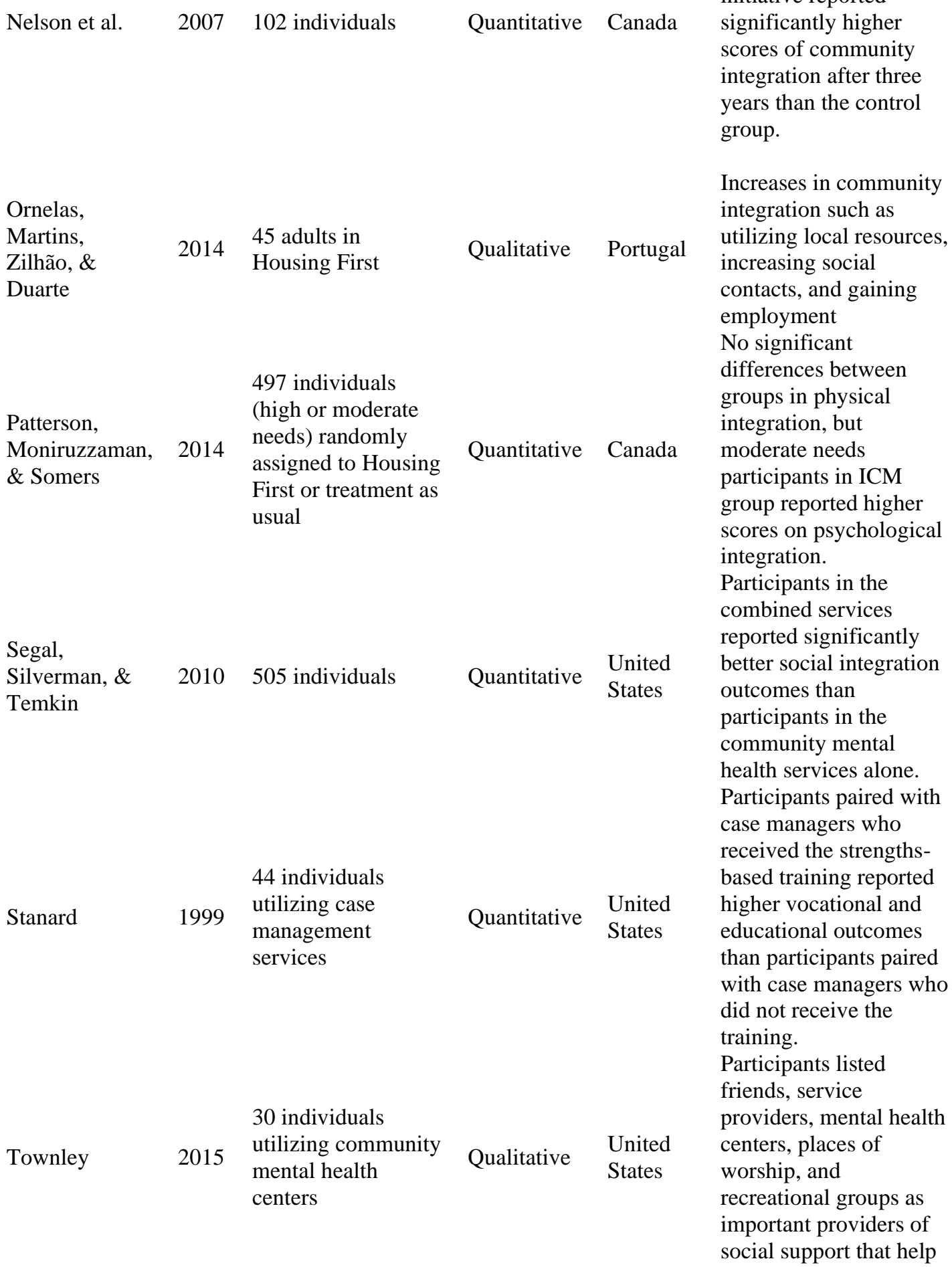

Participants who were continuously active in a consumer survivor initiative reported significantly higher scores of community integration after three years than the control

integration such as increasing social contacts, and gaining employment groups in physical integration, but erate needs participants in ICM group reported higher scores on psychological integration.

Participants in the combined services antly outcomes than participants in the community mental health services alone. cipants paired with case managers who based training reported utilizing case management services social support that help 
them achieve

community integration.

Townley \&
Kloos
Townley,
Miller, \&
Kloos

Trainor,
Shepherd,
Boydell, Leff,
\& Crawford

Ware, Hopper, Tugenberg, Dickey, \& Fisher

Yanos, Barrow, \& Tsemberis

Yanos,

Stefanic, \& Tsemberis

Zimolag \& Krupa
402 residents in support housing utilizing mental health services

300 clients utilizing community mental health services

Sample size for relevant research findings is unclear; responses from two studies $(\mathrm{n}=439, \mathrm{n}$ $=194$ )

56 individuals, eight ethnographic visits at five service centers

80 participants (46

in Housing First, 34 in treatment as usual)

123 individuals; 60 individuals with serious mental illnesses and 63 community members without a severe mental illness

\section{9 clients from} three ACT teams; pet owners $(n=20)$ and non-pet owners $(\mathrm{n}=39)$
Mixed- United methods States

Quantitative Canada

Qualitative

United States

Support provided by neighbors predicted a significant amount of variance in psychological integration.

Distal supports accounted for a significant amount of variance in community integration even after controlling for traditional supports. Participants reported more social contacts and an increased connection to the community after participating in the organization.

Social integration is defined as a process, where individuals with serious mental illness continuously develop capacities for connectedness and citizenship. Increased community Qualitative United integration, but States challenges noted such as with loneliness Individuals with SMI and community members did not significantly differ in psychological community integration, or perceptions of neighborhood social capital.

Participants who are pet owners were more likely to experience

Quantitative Canada psychological and social integration compared to non-pet owners. 


\section{References}

Abdallah, C., Cohen, C. I., Sanchez-Almira, M., Reyes, P., \& Ramirez, P. (2009). Community integration and associated factors among older adults with schizophrenia. Psychiatric Services, 60(12), 16-64. Retrieved from https://ps.psychiatryonline.org/doi/pdf/10.1176/ps.2009.60.12.1642

Anthony, W. A., \& Blanch, A. (1987). Supported employment for persons who are psychiatrically disabled: An historical and conceptual perspective. Psychosocial Rehabilitation Journal, 11(2), 5-23. Retrieved from https://search-proquestcom.proxy.lib.pdx.edu/docview/1504152173/fulltextPDF/B9256567386A43DFPQ/1 ?accountid= 13265

Anthony, W, Rogers, E., \& Farkas, M. (2003). Research on evidence-based practices: Future directions in an era of recovery. Community Mental Health Journal. Retrieved from http://link.springer.com/article/10.1023/A:1022601619482

Anthony, WA. (1993). Recovery from mental illness: The guiding vision of the mental health service system in the 1990s. Psychosocial Rehabilitation Journal, 16(4), 521538. Retrieved from http://psycnet.apa.org/journals/prj/16/4/11/

Anthony, WA. (2000). A recovery-oriented service system: Setting some system level standards. Psychiatric Rehabilitation Journal, 24(2), 159-168. Retrieved from http://psycnet.apa.org/journals/prj/24/2/159/

Aubry, T., \& Myner, J. (1996). Community integration and quality of life: A comparison of persons with psychiatric disabilities in housing programs and community residents who are neighbours. Canadian Journal of Community Mental Health, 
15(1), 5-20. https://doi.org/10.7870/cjcmh-1996-0001

Badger, T. A., McNiece, C., Bonham, E., Jacobson, J., \& Gelenberg, A. J. (2003). Health outcomes for people with serious mental illness: A case study. Perspectives in Psychiatric Care, 39(1), 23-32. https://doi.org/10.1111/j.1744-6163.2003.tb00670.x

Balcazar, F. E., Taylor, R. R., Keilhorner, G. W., Tamley, K., Benziger, T., Carlin, N., \& Johnson, S. (2004). Participatory action research: General principles and a study with a chronic health condition. In In L.A. Jason, C.B. Keys, Y.S. Suarez-Balcazar, R.R. Taylor, \& M.I. Davis (Eds). Participatory Community Research: Theories and Methods in Action. (pp. 17-35). Washington D.C.: American Psychological Association.

Banks, B., Charleston, T. G., \& Mank, D. (2001). Workplace supports, job performance, and intergration outcomes for people with psychiatric disabilities. Psychiatric Rehabilitation Journal, 24(4), 389-396. Retrieved from https://search-proquestcom.proxy.lib.pdx.edu/docview/1347253418/fulltextPDF/6D9724A99D184D76PQ/ 1 ? accountid $=13265$

Basset, T., Faulkner, A., Repper, J., \& Stamou, E. (2010). Lived Experience Leading The Way Peer Support in Mental Health. Nottingham.

Beal, G. (1999). The constitution of community: How individuals diagnosed with schizophrenia and their friends achieved community. Psychiatry, 62(2), 173-186. https://doi.org/10.1080/00332747.1999.11024863

Beal, G., Veldhorst, G., McGrath, J.-L., Guruge, S., Grewal, P., DiNunzio, R., \& Trimnell, J. (2005). Constituting community: Creating a place for oneself. 
Psychiatry, 68(3), 199-211. https://doi.org/10.1521/psyc.2005.68.3.199

Beels, C. C. (1981). Social support and schizophrenia. Schizophrenia Bulletin, 7(1), 5872. https://doi.org/10.1093/schbul/7.1.58

Berkman, L., Glass, T., Brissette, I., \& Seeman, T. (2000). From social integration to health: Durkheim in the new millennium. Social Science \& Medicine, 51(6), 843857. Retrieved from https://scholar.google.com/citations?view_op=view_citation\&continue=/scholar\%3 Fh1\%3Den\%26as_sdt\%3D0,38\%26authuser\%3D1\%26scilib\%3D1\&citilm=1\&citati on_for_view=Xac0OKUAAAAJ:hC7cP41nSMkC\&hl=en\&authuser=1\&oi=p

Blazer, D. G. (1982). Social support in an elderly community population. American Journal of Epidemiology, 115(5), 684-694. https://doi.org/10.1093/oxfordjournals.aje.a113351

Bond, G. R., Salyers, M. P., Rollins, A. L., Rapp, C. A., \& Zipple, A. M. (2004). How evidence-based practices contribute to community integration. Community Mental Health Journal, 40(6), 569-588. https://doi.org/10.1007/s10597-004-6130-8

Bradshaw, W., Armour, M. P., \& Roseborough, D. (2007). Finding a place in the world: The experience of recovery from severe mental illness. Qualitative Social Work, 6(1), 27-47. https://doi.org/10.1177/1473325007074164

Braun, V., \& Clarke, V. (2006). Using thematic analysis in psychology. Qualitative Research in Psychology, 3(2), 77-101. Retrieved from http://eprints.uwe.ac.uk/11735/2/thematic_analysis_revised_-_final.pdf

Brusilovskiy, E., Townley, G., Snethen, G., \& Salzer, M. S. (2016). Social media use, 
community participation and psychological well-being among individuals with serious mental illnesses. Computers in Human Behavior, 65, 232-240.

https://doi.org/10.1016/j.chb.2016.08.036

Burns-Lynch, W., Brusilovskiy, E., \& Salzer, M. S. (2016). An empirical study of the relationship between community participation, recovery, and quality of life of individuals with serious mental illnesses. Israel Journal of Psychiatry, 53(1), 46-55. Retrieved from https://cdn.doctorsonly.co.il/2016/08/09_Burns-Lynch_AnEmpirical-Study.pdf

Carling, P.J. (1995). Return to Community: Building Support Systems for People with Psychiatric Disabilities. Guilford Press.

Carling, Paul J. (1990). Major mental illness, housing, and supports: The promise of community integration. American Psychologist, 45(8), 969-975. https://doi.org/10.1037/0003-066X.45.8.969

Chavis, D. M., \& Wandersman, A. (1990). Sense of community in the urban environment: A catalyst for participation and community development. American Journal of Community Psychology, 18(1), 55-81. https://doi.org/10.1007/BF00922689

Chen, F.-P. (2010). Assisting adults with severe mental illness in transitioning from parental homes to independent living. Community Mental Health Journal, 46, 372380. https://doi.org/10.1007/s10597-009-9263-y

Cobb, S. (1976). Social support as a moderator of life stress. Psychosomatic Medicine, 38(5), 300-314. Retrieved from 
https://pdfs.semanticscholar.org/10ec/c3df00f4472cbdfc5509c77d43ecc85193da.pdf

Cohen, C. I., \& Sokolovsky, J. (1978). Schizophrenia and social networks: Ex-patients in the inner city. Schizophrenia Bulletin, 4(4), 546-560.

Cohen, S., \& Wills, T. A. (1985). Stress, social support, and the buffering hypothesis. Psychological Bulletin, 98(2), 310-357.

Cook, J. A., Lehman, A. F., Drake, R., McFarlane, W. R., Gold, P. B., Leff, H. S., ... Grey, D. D. (2005). Integration of psychiatric and vocational services: A multisite randomized, controlled trial of supported employment. American Journal of Psychiatry, 162(10), 1948-1956. https://doi.org/10.1176/appi.ajp.162.10.1948

Corin, E., \& Lauzon, G. (1992). Positive withdrawal and the quest for meaning: The reconstruction of experience among schizophrenics. Psychiatry, 55(3), 266-278. https://doi.org/10.1080/00332747.1992.11024600

Corrigan, P. W., \& Phelan, S. M. (2004). Social support and recovery in people with serious mental illnesses. Community Mental Health Journal, 40(6), 513-523. https://doi.org/10.1007/s10597-004-6125-5

Corrigan, P. W., \& Watson, Amy, C. (2002). Understanding the impact of stigma on people with mental illness. World Psychiatry. Retrieved from https://www.ncbi.nlm.nih.gov/pmc/articles/PMC1489832/pdf/wpa010016.pdf

Cummings, S. M., \& Kropf, N. P. (2009). Formal and informal support for older adults with severe mental illness. Aging \& Mental Health, 13(4), 619-627. https://doi.org/10.1080/13607860902774451

Cummins, R., \& Lau, A. (2003). Community integration or community exposure? A 
review and discussion in relation to people with an intellectual disability. Journal of Applied Research in .... Retrieved from http://onlinelibrary.wiley.com/doi/10.1046/j.1468-3148.2003.00157.x/full

Davidson, L. (2005). More fundamentally human than otherwise. Psychiatry, 68(3), 243249. Retrieved from http://web.a.ebscohost.com.proxy.lib.pdx.edu/ehost/pdfviewer/pdfviewer?vid=1\&si d=7fbff5cb-6651-40cb-9347-1a279950de49\%40sessionmgr4010

Davidson, L., Bellamy, C., Guy, K., \& Miller, R. (2012). Peer support among persons with severe mental illnesses: A review of evidence and experience. World Psychiatry, 11(2), 123-128. https://doi.org/10.1016/j.wpsyc.2012.05.009

Davidson, L., Chinman, M., Kloos, B., Weingarten, R., Stayner, D., \& Tebes, J. K. (1999). Peer support among individuals with severe mental illness: A review of the evidence. Clinical Psychology: Science and Practice, 6(2), 165-187. Retrieved from https://s3.amazonaws.com/academia.edu.documents/44465989/Peer_Support_Amon g_Individuals_With_Seve20160406-203791e7a6po.pdf?AWSAccessKeyId=AKIAIWOWYYGZ2Y53UL3A\&Expires=152286 8305\&Signature=StSN5GLL8oFZUnq Y1pI\%2B VZzqNQg\%3D\&response-contentdisposition $=$ inli

Davidson, L., Haglund, K. E., Stayner, D. A., Rakfeldt, J., Chinman, M. J., \& Kraemer Tebes, J. (2001). "It was just realizing...that life isn't one big horror": A qualitative study of supported socialization. Psychiatric Rehabilitation Journal, 24(3), 275292. https://doi.org/10.1037/h0095084 
Davidson, L., \& McGlashan, T. H. (1997). The varied outcomes of schizophrenia. The Canadian Journal of Psychiatry, 42(1), 34-43. https://doi.org/10.1177/070674379704200105

Davidson, L., O’Connell, M., Tondora, J., Styron, T., \& Kangas, K. (2006). The top ten concerns about recovery encountered in mental health system transformation. Psychiatric Services, 57(5), 640-645. https://doi.org/10.1176/ps.2006.57.5.640

Davidson, L., Stayner, D. A., Nickou, C., Styron, T. H., Rowe, M., \& Chinman, M. L. (2001). "Simply to be let in": Inclusion as a basis for recovery. Psychiatric Rehabilitation Journal, 24(4), 375-388. Retrieved from https://search-proquestcom.proxy.lib.pdx.edu/docview/1347253334/fulltextPDF/7D1D6248E6BA4C57PQ/ 1 ?accountid $=13265$

Dewees, M., Pulice, R., \& McCormick, L. (1996). Community integration of former state hospital patients: Outcomes of a policy shift in Vermont. Psychiatric Services. Retrieved from http://psycnet.apa.org/psycinfo/1996-06687-006

Drake, R. E., McHugo, G. J., Bebout, R. R., Becker, D. R., Harris, M., Bond, G. R., \& Quimby, E. (1999). A randomized clinical trial of supported employment for innercity patients with severe mental disorders. Archives of General Psychiatry, 56(7), 627. https://doi.org/10.1001/archpsyc.56.7.627

Drake, R. E., McHugo, G. J., Becker, D. R., \& Clark, R. E. (1996). The New Hampshire study of supported employment for people with severe mental illness. Journal of Consulting and Clinical Psychology, 64(2), 391-399. Retrieved from https://search.proquest.com/docview/614315911/fulltextPDF/E30068843D5247E6P 
Q/1?accountid=13265

Farkas, M., Gagne, C., Anthony, W., \& Chamberlin, J. (2005). Implementing recovery oriented evidence based programs: Identifying the critical dimensions. Community Mental Health Journal, 41(2), 141-158. Retrieved from http://link.springer.com/article/10.1007/s10597-005-2649-6

Felton, B., \& Shinn, M. (1992). Social integration and social support: Moving "Social Support" beyond the individual level. Journal of Community Psychology, 20(2), 103-115. Retrieved from http://web.a.ebscohost.com.proxy.lib.pdx.edu/ehost/pdfviewer/pdfviewer?vid=1\&si d=3dd58681-b925-473c-b885-7853d92e1ee8\%40sessionmgr4010

Gold, P. B., Meisler, N., Santos, A. B., Carnemolla, M. A., Williams, O. H., \& Keleher, J. (2006). Randomized trial of supported employment integrated with assertive community treatment for rural adults with severe mental illness. Schizophrenia Bulletin, 32(2), 378-395. https://doi.org/10.1093/schbul/sbi056

Granerud, A., \& Severinsson, E. (2006). The struggle for social integration in the community - the experiences of people with mental health problems. Journal of Psychiatric and Mental Health Nursing, 13(3), 288-293. https://doi.org/10.1111/j.1365-2850.2006.00950.x

Greene, J. C., \& Caracelli, V. J. (1997). Defining and describing the paradigm issue in mixed-method evaluation. New Directions for Evaluation, 1997(74), 5-17. https://doi.org/10.1002/EV.1068

Greene, J. C., Caracelli, V. J., \& Graham, W. F. (1989). Toward a conceptual framework 
for mixed-method evaluation designs. Educational Evaluation and Policy Analysis Fall, 11(3), 255-274. Retrieved from https://journals.sagepub.com/doi/pdf/10.3102/01623737011003255?casa_token=g6 Q7jY9QNqAAAAAA:xGL3SSFuvWRGnE3zgkhd8EQZGKcH5gNqnnb3LHJY4Z_O3JfyULT57YmYaoIncpAnInATVhVNO2e

Hammer, M. (1981). Social supports, social networks, and schizophrenia. Schizophrenia Bulletin, 7(1), 45-57.

Harding, C. M., Zubin, J., \& Strauss, J. S. (1987). Chronicity in schizophrenia: Fact, partial fact, or artifact? Psychiatric Services, 38(5), 477-486. https://doi.org/10.1176/ps.38.5.477

Harding, C., \& Zahniser, J. (1994). Empirical correction of seven myths about schizophrenia with implications for treatment. Acta Psychiatrica Scandinavica, 90, 140-146. Retrieved from http://www.psychodyssey.net/wpcontent/uploads/2012/05/Empirical-correction.pdf

Hawkley, L. C., \& Cacioppo, J. T. (2010). Loneliness matters: A theoretical and empirical review of consequences and mechanisms. Annals of Behavioral Medicine : A Publication of the Society of Behavioral Medicine, 40(2), 218-227. https://doi.org/10.1007/s12160-010-9210-8

Headey, B. (2003). Pet ownership: Good for health? Medical Journal of Australia, 179(9), 460-461. Retrieved from www.mja.com.au

Heaney, Catherine, A., \& Israel, Barbara, A. (2008). Social networks and social support. In K. Glanz, B. K. Rimer, \& K. Viswanath (Eds.), Health behavior and health 
education: Theory, research, and practice (4th ed., pp. 189-210). San Francisco: Jossey-Bass. Retrieved from http://iums.ac.ir/files/hshesoh/files/beeduhe_0787996149(1).pdf\#page=227

Hendryx, M., Green, C. A., \& Perrin, N. A. (2009). Social support, activities, and recovery from serious mental illness: STARS study findings. The Journal of Behavioral Health Services \& Research, 36(3), 320-329. Retrieved from https://link.springer.com/content/pdf/10.1007\%2Fs11414-008-9151-1.pdf Hennings, B. A. (1999). Are consumers going to the dogs (and cats and birds)? New Directions for Mental Health Services, 1999(83), 45-49. https://doi.org/10.1002/yd.23319998307

Hesse-Biber, S., \& Leavy, P. (2010). The Practice of Qualitative Research. Sage. Retrieved from https://scholar.google.com/scholar?hl=en\&as_sdt=0\%2C $38 \& q=$ the+practice+of $+q u$ alitative+research+hesse+biber\&btnG=

Horwitz, A. V, Reinhard, S. C., \& Howell, S. (1996). Caregiving as reciprocal exchange in families with seriously mentally ill members. Journal of Health and Social Behavior, 37(37), 149-162. Retrieved from http://www.jstor.org/stable/2137270 House, J. S. (1981). Work stress and social support. Reading, Mass.: Addison-Wesley. Israel, B. A., Farquhar, S. A., Schulz, A. J., James, S. A., \& Parker, E. A. (2002). The relationship between social support, stress, and health among women on Detroit's east side. Health Education \& Behavior, 29(3), 342-360. https://doi.org/10.1177/109019810202900306 
Jones, D. R., Macias, C., Barreira, P. J., Fisher, W. H., Hargreaves, W. A., \& Harding, C. M. (2004). Prevalence, severity, and co-occurrence of chronic physical health problems of persons with serious mental illness. Psychiatric Services, 55(11), 12501257. Retrieved from http://ps.psychiatryonline.org/doi/abs/10.1176/appi.ps.55.11.1250

Kaplan, K., Salzer, M. S., \& Brusilovskiy, E. (2012). Community participation as a predictor of recovery-oriented outcomes among emerging and mature adults with mental illnesses. Psychiatric Rehabilitation Journal, 35(3), 219-229. https://doi.org/10.2975/35.3.2012.219.229

Kaplan, K., Salzer, M. S., Solomon, P., Brusilovskiy, E., \& Cousounis, P. (2011). Internet peer support for individuals with psychiatric disabilities: A randomized controlled trial. Social Science \& Medicine, 72(1), 54-62. https://doi.org/10.1016/J.SOCSCIMED.2010.09.037

Kawachi, I., \& Berkman, L. F. (2001). Social ties and mental health. Journal of Urban Health: Bulletin of the New York Academy of Medicine, 78(3). Retrieved from https://link.springer.com/content/pdf/10.1093/jurban/78.3.458.pdf

Kennedy, C. (1989). Community integration and well-being: Toward the goals of community care. Journal of Social Issues, 45(3), 65-77. https://doi.org/10.1111/j.1540-4560.1989.tb01555.x

Kline, R. B. (2015). The mediation myth. Basic and Applied Social Psychology, 37(4), 202-213. https://doi.org/10.1080/01973533.2015.1049349

Kloos, B, \& Townley, G. (2011). Investigating the relationship between neighborhood 
experiences and psychiatric distress for individuals with serious mental illness. Administration and Policy in Mental Health and Mental Health Services Research, 38(2), 105-116. Retrieved from http://link.springer.com/article/10.1007/s10488010-0307-y

Kloos, Bret, Zimmerman, S. O., Scrimenti, K., \& Crusto, C. (2002). Landlords as partners for promoting success in supported housing: "It takes more than a lease and a key." Psychiatric Rehabilitation Journal, 25(3), 235-244. Retrieved from https://search-proquestcom.proxy.lib.pdx.edu/docview/1347253476/fulltextPDF/C3191BE677FD44FEPQ/ 1 ?accountid $=13265$

Kostanjsek, N. (2011). Use of The International Classification of Functioning, Disability, and Health (ICF) as a conceptual framework and common language for disability statistics and health information systems. BMC Public Health, 11(4). https://doi.org/10.1186/1471-2458-11-S4-S3

Kraut, R., Kiesler, S., Boneva, B., Cummings, J., Helgeson, V., \& Crawford, A. (2002). Internet paradox revisited. Journal of Social Issues, 58(1), 49-74. https://doi.org/10.1111/1540-4560.00248

Kraut, R., Patterson, M., Lundmark, V., Kiesler, S., Mukophadhyay, T., \& Scherlis, W. (1998). Internet paradox: A social technology that reduces social involvement and psychological well-being? American Psychologist , 53(9). Retrieved from https://scholar.google.com/citations?user=HKGYvu4AAAAJ\&hl=en\&oi=sra\#d=gs_ md_cita- 
$\mathrm{d} \& \mathrm{u}=\% 2$ Fcitations\%3Fview_op\%3Dview_citation\%26hl\%3Den\%26user\%3DHKG Yvu4AAAAJ\%26citation_for_view\%3DHKGYvu4AAAAJ\%3Au5HHmVD_uO8C $\% 26$ tzom\%3D420

Kruzich, J. M. (1985). Community integration of the mentally ilI in residential facilities. American Journal of Community Psychology, 13(5), 553-564. Retrieved from https://s3.amazonaws.com/academia.edu.documents/46229950/bf009232672016060 4-11909ii3rjn.pdf?AWSAccessKeyId=AKIAIWOWYYGZ2Y53UL3A\&Expires=15196981 04\&Signature=yW076Wtoz8UW\%2FfN7spiCyZHFDig\%3D\&response-contentdisposition=inline \%3B filename\%3DCommunity_in

Langford, C. P. H., Bowsher, J., Maloney, J. P., \& Lillis, P. P. (1997). Social support: A conceptual analysis. Journal of Advanced Nursing, 25(1), 95-100. https://doi.org/10.1046/j.1365-2648.1997.1997025095.x

Leavy, R. L. (1983). Social support and psychological disorder: A review. Journal of Community Psychology, 11(1), 3-21. https://doi.org/10.1002/15206629(198301)11:1<3::AID-JCOP2290110102>3.0.CO;2-E

Lester, H., \& Gask, L. (2006). Delivering medical care for patients with serious mental illness or promoting a collaborative model of recovery? British Journal of Psychiatry, 188(5), 401-402. Retrieved from http://www.improvingchroniccare. Machin, K., \& Repper, J. (2013). Recovery: a carer's perspective. Retrieved from http://citeseerx.ist.psu.edu/viewdoc/download?doi=10.1.1.688.2639\&rep=rep1\&typ e=pdf 
Maton, K. I., Teti, D. M., Corns, K. M., Vieira-Baker, C. C., Seattle, J. R. L., Karen, W., ... Keating, D. P. (1996). Cultural specificity of support sources, correlates and contexts: Three studies of African-American and Caucasian youth. American Journal of Community Psychology, 24(4), 551-587. Retrieved from https://s3.amazonaws.com/academia.edu.documents/46431330/bf025067962016061 2-12045-

18yxc6f.pdf?AWSAccessKeyId=AKIAIWOWYYGZ2Y53UL3A\&Expires $=155772$ 2849\&Signature=fpj\%2FV\%2B6wFScZFKIRrXYUFWSv52I\%3D\&responsecontent-disposition=inline $\% 3 \mathrm{~B}$ filename\%3DCultural_

Mattsson, M., Topor, A., Cullberg, J., \& Forsell, Y. (2008). Association between financial strain, social network and five-year recovery from first episode psychosis. Social Psychiatry and Psychiatric Epidemiology, 43(12), 947-952. https://doi.org/10.1007/s00127-008-0392-3

McColl, M. A., Davies, D., Carlson, P., Johnston, J., \& Minnes, P. (2001). The community integration measure: Development and preliminary validation. Archives of Physical Medicine and Rehabilitation, 82(4), 429-434. https://doi.org/10.1053/apmr.2001.22195

Mccorkle, B. H., Dunn, E. C., Mui Wan, Y., \& Gagne, C. (2009). People with Serious Mental Illness Compeer Friends: a Qualitative Study of a Volunteer Friendship Programme for. International Journal of Social Psychiatry, 55(291), 291-305. https://doi.org/10.1177/0020764008097090

Mccorkle, B. H., Sally, A. E., Ae, R., Dunn, E. C., Lyass, A., Yu, A., \& Wan, M. (2008). 
Increasing social support for individuals with serious mental illness: Evaluating the compeer model of intentional friendship. Community Mental Health Journal, 44(5), 359. https://doi.org/10.1007/s10597-008-9137-8

McFarlane, W. R., Dushay, R. A., Deakins, S. M., Stastny, P., Lukens, E. P., Toran, J. W., \& Link, B. (2000). Employment outcomes in family-aided assertive community treatment. American Journal of Orthopsychiatry, 70(2), 203-214. Retrieved from https://search.proquest.com/docview/1038624044/fulltextPDF/A54A0F5C7E1742A EPQ/1 ?accountid=13265

McMillan, D., \& Chavis, D. (1986). Sense of community: A definition and theory. Journal of Community Psychology, 14(1), 6-23. Retrieved from http://mc7290.bgsu.wikispaces.net/file/view/McMillan_1986.pdf

Mechanic, D., \& Rochefort, D. A. (1990). Deinstitutionalization: An appraisal of reform. Annual Review of Sociology, 16, 301-328. Retrieved from https://about.jstor.org/terms

Morgan, D. L. (1998). Practical strategies for combining qualitative and quantitative methods: Applications for health research. Qualitative Health Research, 3, 362-376. Retrieved from https://journals-sagepubcom.proxy.lib.pdx.edu/doi/pdf/10.1177/104973239800800307

Naslund, J. A., Grande, S. W., Aschbrenner, K. A., \& Elwyn, G. (2014). Naturally occurring peer support through social media: The experiences of individuals with severe mental illness using YouTube. PLoS ONE, 9(10), 1-9. https://doi.org/10.1371/journal.pone.0110171 
Nations, U. (2006). United Nations convention on the rights of persons with disabilities. Retrieved from http://www.un.org/esa/socdev/enable/rights/convtexte.htm

Nelson, G, Lord, J., \& Ochocka, J. (2001). Empowerment and mental health in community: Narratives of psychiatric consumer/survivors. Journal of Community \& Applied Social Psychology. Retrieved from http://onlinelibrary.wiley.com/doi/10.1002/casp.619/full

Nelson, Geoffrey, Ochocka, J., Janzen, R., Trainor, J., Goering, P., \& Lomotey, J. (2007). A longitudinal study of mental health consumer/survivor initiatives: Part Voutcomes at 3-year follow-up. Journal of Community Psychology, 35(5), 655-665. https://doi.org/10.1002/jcop.20171

Norbeck, J. S., Lindsey, A. M., \& Carrieri, V. L. (1981). The development of an instrument to measure social support. Nursing Research, 30(5), 264-269. https://doi.org/10.1097/00006199-198109000-00003

Norbeck, J. S., Lindsey, A. M., \& Carrieri, V. L. (1983). Further development of the Norbeck Social Support Questionnaire. Nursing Research,32(1), 4-9. https://doi.org/10.1097/00006199-198301000-00002

Organization, W. H. (2001). International classification of functioning, disability and health: ICF.

Orth-Gomér, K., \& Johnson, J. V. (1987). Social network interaction and mortality. Journal of Chronic Diseases, 40(10), 949-957. https://doi.org/10.1016/00219681(87)90145-7

Perkins, D. D., Florin, P., Rich, R. C., Wandersman, A., \& Chavis, D. M. (1990). 
Participation and the social and physical environment of residential blocks: Crime and community context. American Journal of Community Psychology, 18(1), 83115. https://doi.org/10.1007/BF00922690

Pinfold, V. (2000). "Building up safe havens all around the world”: Users' experiences of living in the community with mental health problems. Health \& Place, 6, 201-212. Retrieved from http://www.sciencedirect.com/science/article/pii/S135382920000023X

Prince, P. N., \& Gerber, G. J. (2005). Subjective well-being and community integration among clients of assertive community treatment. Quality of Life Research, 14(1), 161-169. https://doi.org/10.1007/s11136-004-2407-1

Robson, D., \& Gray, R. (2007). Serious mental illness and physical health problems: A discussion paper. International Journal of Nursing Studies, 44(3), 457-466. Retrieved from https://www.sciencedirect.com/science/article/pii/S0020748906002306

Royce-Davis, J. C. (2001). "It's the Day-to-Day Living That Matters": The meaning and process of community in the lives of a couple with significant psychiatric disabilities. American Journal of Community Psychology, 29(6), 807-832. Retrieved from https://link.springer.com/content/pdf/10.1023/A:1012957014209.pdf

Ryan, G. W., Health, R., \& Russell Bernard, H. (2003). Techniques to identify themes. Field Methods, 15(1), 85-109. https://doi.org/10.1177/1525822X02239569

Salzer, M., \& Baron, R. (2016). Well Together - A blueprint for community inclusion: fundamental concepts, theoretical frameworks and evidence. Retrieved from 
http://www.tucollaborative.org/sdm_downloads/well-together/

Salzer, M. S., Brusilovskiy, E., Prvu-Bettger, J., \& Kottsieper, P. (2014). Measuring community participation of adults with psychiatric disabilities: Reliability of two modes of data collection. Rehabilitation Psychology, 59(2), 211.

Salzer, M. S., Kottsieper, P., \& Brusilovskiy, E. (2015). Intermethod reliability and factors affecting recall with the Temple University Community Participation measure. Journal of Mental Health, 24(4), 189-195. https://doi.org/10.3109/09638237.2015.1036976

Sarason, S.B. (1974). The Psychological Sense of Community: Prospects for a Community Psychology. San Francisco: Jossey-Bass.

Sarason, Seymour B. (1976). Community psychology, networks, and Mr. Everyman. American Psychologist, 31(5), 317-328. Retrieved from https://search-proquestcom.proxy.lib.pdx.edu/docview/614296588/fulltextPDF/568EC550B2564325PQ/1? accountid=13265

Seeman, T. (1996). Social ties and health: The benefits of social integration. Annals of Epidemiology, 6(5), 442-451. Retrieved from https://scholar.google.com/citations?view_op=view_citation\&continue=/scholar\%3 Fhl\%3Den\%26as_sdt\%3D0,38\%26authuser\%3D1\%26scilib\%3D1\&citilm=1\&citati on_for_view=Xac0OKUAAAAJ:qUcmZB5y_30C\&hl=en\&authuser=1\&oi=p

Segal, S. P., \& Aviram, U. (1978). The Mentally Ill in Community-Based Sheltered Care.

Segal, S. P., Silverman, C. J., \& Temkin, T. L. (2014). Self-help and community mental health agency outcomes: A recovery-focused randomized controlled trial. 
Psychiatric Services, 61(9), 905-910. https://doi.org/10.1176/ps.2010.61.9.905

Shinn, M., Lehmann, S., \& Wong, N. W. (1984). Social interaction and social support. Journal of Social Issues, 40(4), 55-76. https://doi.org/10.1111/j.15404560.1984.tb01107.x

Shumaker, S. A., \& Brownell, A. (1984). Toward a Theory of Social Support: Closing Conceptual Gaps. Journal of Social Issues (Vol. 40). Retrieved from https://pdfs.semanticscholar.org/fc41/ef531e881f3ea80266ab0dc7b7c47e5861e7.pdf

Stanard, R. P. (1999). The effect of training in a strengths model of case management on client outcomes in a community mental health center. Community Mental Health Journal, 35(2), 169-179. Retrieved from https://link.springer.com/content/pdf/10.1023/A:1018724831815.pdf

Stroul, B. A. (1989). Community support systems for persons with long-term mental illness: A conceptual framework. Psychosocial Rehabilitation Journal, 12(3), 9-26. Retrieved from https://search.proquest.com/docview/1504156855/fulltextPDF/945EB09D367B452F $\mathrm{PQ} / 1$ ?accountid=13265

Talò, C., Mannarini, T., \& Rochira, A. (2014). Sense of community and community participation: A meta-analytic review. Social Indicators Research, 117(1), 1-28. https://doi.org/10.1007/s11205-013-0347-2

Tew, J., Ramon, S., Slade, M., Bird, V., Melton, J., \& Le Boutillier, C. (2012). Social factors and recovery from mental health difficulties: A review of the evidence. British Journal of Social Work, 42, 443-460. https://doi.org/10.1093/bjsw/bcr076 
The President's New Freedom Commission on Mental Health: Achieving the Promise:

Transforming Mental Health Care in America. (2003). Rockville, Maryland.

Toohey, A. M., Mccormack, G. R., Doyle-Baker, P. K., Adams, C. L., \& Rock, M. J. (2013). Dog-walking and sense of community in neighborhoods: Implications for promoting regular physical activity in adults 50 years and older. Health \& Place, 22, 75-81. https://doi.org/10.1016/j.healthplace.2013.03.007

Townley, G. (2015). “It Helps You Not Feel So Bad-Feel Like You Again”: The importance of community for individuals with psychiatric disabilities. Journal of Psychosocial Rehabilitation and Mental Health, 2(2), 113-124. Retrieved from http://link.springer.com/article/10.1007/s40737-015-0036-3

Townley, G, Kloos, B., \& Wright, P. (2009). Understanding the experience of place: Expanding methods to conceptualize and measure community integration of persons with serious mental illness. Health Place, 15(2), 520-531. Retrieved from http://www.sciencedirect.com/science/article/pii/S1353829208001020

Townley, G, Miller, H., \& Kloos, B. (2013). A little goes a long way: The impact of distal social support on community integration and recovery of individuals with psychiatric disabilities. American Journal of Community Psychology. Retrieved from http://onlinelibrary.wiley.com/doi/10.1007/s10464-013-9578-2/full

Townley, Greg, \& Kloos, B. (2009). Development of a measure of sense of community for individuals with serious mental illness residing in community settings. Journal of Community Psychology, 37(3), 362-380. https://doi.org/10.1002/jcop.20301

Townley, Greg, \& Kloos, B. (2011). Examining the psychological sense of community 
for individuals with serious mental illness residing in supported housing environments. Community Mental Health Journal, 47, 436-446. https://doi.org/10.1007/s10597-010-9338-9

Üstün, T. B., Chatterji, S., Bickenbach, J., Kostanjsek, N., \& Schneider, M. (2009). The International Classification of Functioning, Disability and Health: A new tool for understanding disability and health. Disability and Rehabilitation , 25(11-12), 565571. https://doi.org/10.1080/0963828031000137063

Walsh, J., \& Connelly, P. R. (1996). Supportive behaviors in natural support networks of people with serious mental illness. Health \& Social Work, 21(4), 296-303.

Retrieved from https://search.proquest.com/docview/1298063504?pqorigsite $=$ gscholar

Ware, N. C., Hopper, K., Tugenberg, T., Dickey, B., \& Fisher, D. (2007). Connectedness and citizenship: Redefining social integration. Psychiatric Services, 58(4), 469-474.

Whitley, R., \& Drake, R. (2010). Recovery: A dimensional approach. Psychiatric Services, 61(12), 1248-1250. Retrieved from http://ps.psychiatryonline.org/doi/abs/10.1176/ps.2010.61.12.1248

Wisdom, J. P., Saedi Auzeen, G., \& Green, C. A. (2009). Another breed of "Service" animals: STARS study findings about pet ownership and recovery From serious mental illness. American Journal of Orthopsychiatry, 79(3), 430-436. https://doi.org/10.1037/aM)16812

Wong, Yin-Ling I, \& Solomon, P. L. (2002). Community integration of persons with psychiatric disabilities in supportive independent housing: A conceptual model and 
methodological considerations. Mental Health Services Research, 4(1). Retrieved from http://repository.upenn.edu/spp_papers 28.

Wong, Yin-Ling Irene, Stanton, M. C., \& Sands, R. G. (2014). Rethinking social inclusion: Experiences of persons in recovery from mental illness. American Journal of Orthopsychiatry, 84(6), 685-695. https://doi.org/10.1037/ort0000034

Woodward, A. T., Taylor, R. J., Bullard, K. M., Neighbors, H. W., Chatters, L. M., \& Jackson, James, S. (2008). Use of professional and informal support by African Americans and Caribbean Blacks with mental disorders. Psychiatric Services, 59(11), 1292-1298. Retrieved from https://ps.psychiatryonline.org/doi/pdf/10.1176/ps.2008.59.11.1292

Wright, E. R., Wright, D. E., Perry, B. L., \& Foote, C. E. (2007). Stigma and the sexual ssolation of people with serious mental illness. Social Problems, 54(1), 78-98. https://doi.org/10.1525/sp.2007.54.1.78

Yanos, P. T., Felton, B. J., Tsemberis, S., \& Frye, V. A. (2007). Exploring the role of housing type, neighborhood characteristics, and lifestyle factors in the community integration of formerly homeless persons diagnosed with mental illness. Journal of Mental Health, 16(6), 703-717. https://doi.org/10.1080/09638230701496378

Yanos, P. T., Rosenfield, S., \& Horwitz, A. V. (2001). Negative and supportive social interactions and quality of life among persons diagnosed with severe mental illness. Community Mental Health Journal, 37(5), 405-419. Retrieved from https://link.springer.com/content/pdf/10.1023/A:1017528029127.pdf

Yanos, P. T., Stefanic, A., \& Tsemberis, S. (2011). Psychological community integration 
among people with psychiatric disabilities and nondisabled community members.

Journal of Community Psychology, 39(4), 390-401.

https://doi.org/10.1002/jcop.20441

Zimolag, U., \& Krupa, T. (2009). Pet ownership as a meaningful community occupation for people with serious mental illness. American Journal of Occupational Therapy, 63(2), 126-137. https://doi.org/10.5014/ajot.63.2.126 


\title{
Chapter 4: Study 3
}

Exploring the influence of social support on community participation for adults with serious mental illnesses

\begin{abstract}
Community support services are consistently faced with organizational and societal challenges, such as insufficient funding, fluctuating political climate, and overwhelming needs from clients (Davidson et al., 2006). As researchers, advocates, and policies continue to emphasize the importance of community inclusion (Salzer \& Baron, 2016), it is important to understand and strengthen the natural ties that individuals with serious mental illnesses have in the community (e.g., friends, neighbors). Therefore, the current study identified and explored the association between social support and community participation for adults with serious mental illnesses living independently in community settings. To assess social support and community participation, participants completed a survey followed by semi-structured qualitative questions with a third of the sample. Quantitative data were analyzed using SPSS and qualitative data were analyzed in Microsoft Word using thematic analysis (Braun \& Clarke, 2006; IBM Corporation, 2017). Family, friends, and neighbors were most frequently identified as sources of support. However, spouses, religious leaders, and pets provided higher levels of emotional support. Average total support was significantly related to the amount of community participation reported. Additionally, qualitative analysis revealed several themes that shed light on the relationship between social support and community participation, such as families spending time together, mental health challenges can be barriers to participation, and the desire to do activities with others. These findings
\end{abstract}


provide insight about the role of natural supports (e.g., spouses, family, neighbors) in promoting community participation and inform interventions aimed at increasing social support and community participation. 


\section{Introduction}

The Community Mental Health Act of 1963, passed during the Kennedy administration, intended to move people with serious mental illnesses from overcrowded state-run psychiatric hospitals to community settings (Carling, 1995). As a result, the deinstitutionalization movement began, and an overwhelming number of individuals requiring supportive services began living in the community. Subsequently, the Mental Health Systems Act of 1980, signed by President Carter, aimed to provide funding for these community-based services. However, the Reagan administration ultimately repealed any funding allocated to community support services. Therefore, as the number of people requiring mental health services in the community increased, there was insufficient capacity to provide them with adequate support (Carling, 1995). Furthermore, the individual, family, and community were required to take on more responsibilities for their treatment and recovery (Pinfold, 2000).

An additional consequence of the deinstitutionalization movement is that many people with serious mental illnesses have not experienced full integration into the community or had opportunities to reside in inclusive communities (Dewees et al., 1996; Pinfold, 2000). Individuals with serious mental illnesses often report feelings of social isolation, loneliness, and difficulties engaging with the community in meaningful ways (Badger, McNiece, Bonham, Jacobson, \& Gelenberg, 2008; Dewees, Pulice, \& McCormick, 1996; Pinfold, 2000; Townley, Kloos, \& Wright, 2009). In response to these challenges, researchers and advocates argue that individuals with serious mental illnesses have the right to community inclusion, which is conceptualized as an equal opportunity 
for everyone to participate in the community, including people with serious mental illnesses (Davidson, 2005; Nelson, Lord, \& Ochocka, 2001; Salzer \& Baron, 2016). Indeed, policy makers and researchers alike have stated that community inclusion is a fundamental human right (Salzer \& Baron, 2016; UN Convention, 2006).

Social support and community participation are important aspects of community inclusion. For example, Salzer and Baron (2016) contend that individuals, organizations, and institutions should strive to foster communities that value engagement and participation with individuals with disabilities. Additionally, Davidson and colleagues (2001) identified three important dimensions of inclusion for individuals with serious mental illnesses, including friendship, a sense of belonging through meaningful activities, and hopefulness. Finally, Ware and colleagues (2007) assert that social integration (i.e., community inclusion) occurs when individuals with serious mental illnesses achieve connectedness through social relationships and sense of community and citizenship through participation in responsibilities afforded to all citizens. Although previous studies have theorized that social support contributes to community inclusion, research has yet to empirically investigate the role of social support in promoting community participation. Therefore, the goal of the proposed study is to identify and categorize individuals who provide social support to people with serious mental illnesses, followed by an exploration of the association between social support and community participation for members of this population.

\section{Social Support}


The majority of research on social support suggests that it positively influences mental health and well-being (for reviews, see Cohen \& Wills, 1985; Leavy, 1983). While there are numerous definitions of social support in the literature, most scholars agree that support can be categorized into three primary types: emotional (e.g., empathy), tangible (e.g., providing transportation), and informational support (e.g., giving advice; House, 1981; Langford, Bowsher, Maloney, \& Lillis, 1997). However, social support may produce harmful consequences if the support is not necessary, wanted, or does not match the needs of an individual (Shinn et al., 1984).

Informal vs. formal supports. Individuals with serious mental illnesses receive support from formal and informal supports (Walsh \& Connelly, 1996). Informal, or natural, supports are relationships with others that occur in everyday life, such as friends, family members, co-workers, and neighbors. Formal supports may include therapists, case managers, or peer workers. Whereas formal supports are often restricted by the traditional work environment (e.g., available only during business hours, constrained by billing requirements and limited funding), natural supports are not limited by these restrictions (Walsh \& Connelly, 1996). Additionally, natural supports are more available and accessible to develop relationships with in the community. The limitations of formal supports are especially relevant for community support services, which continually face challenges such as lack of funding, service provider burnout, and high client caseloads that influence their ability to provide sufficient support to their clients (Davidson et al., 2006). 
Natural supports who are close with individuals with serious mental illnesses, such as family and friends, likely also have more insights into the individual's interests, beliefs, and capabilities (Machin \& Repper, 2013). These insights may aid in identifying activities that they may be most interested in. Further, natural supports tend to have more opportunities to invite individuals with serious mental illnesses to participate in community activities and events that foster inclusion and acceptance than formal supports (Kloos, Zimmerman, Scrimenti, \& Crusto, 2002).

Additionally, individuals with serious mental illnesses report that reciprocity is important to maintaining positive relationships with others (Beal et al., 2005; Bradshaw et al., 2007; Ware et al., 2007). Reciprocity in relationships is characterized by opportunities to both give and receive support from others. Oftentimes, individuals with serious mental illnesses experience relationships that are one-sided, such as mental health professionals providing them with therapeutic care (Beal et al., 2005; Ware et al., 2007). Individuals with serious mental illnesses also typically have limited social currency, such as resources and personal attributes that allow individuals to connect and contribute to relationships (Padgett, Henwood, Abrams, \& Drake, 2008; Ware et al., 2007). Additional barriers to engaging in reciprocal social activities include higher rates of unemployment and more frequent hospitalizations (Morgan, Burns, Fitzpatrick, Pinfold, \& Priebe, 2007).

There are likely more opportunities for individuals to engage in norms of reciprocity with natural supports than with formal supports who rely on economic exchanges (Beal et al., 2005; Horwitz, Reinhard, \& Howell, 1996). For example, individuals with serious mental illnesses report that contributing to interactions, such as 
providing money or advice, were profoundly valued and appreciated in relationships with natural supports (Beal et al., 2005; Bradshaw, Armour, \& Roseborough, 2007). Additionally, while it is normative for an individual to give a gift to a sibling who provides comfort and advice, such an exchange is typically discouraged in the context of more formal supportive relationships (Horwitz, Reinhard, \& Howell, 1996).

Non-traditional supports. In addition to the traditional natural supports described above, research has identified non-traditional natural supports such as distal supports and pets. Distal supports are defined as casual relationships developed with community members during routine activities such as purchasing coffee or walking to a bus stop (Wieland et al., 2007). Examples of distal supports include bartenders, librarians, and grocery store clerks (Townley, Miller, \& Kloos, 2013). Distal supports may play a particularly important role for individuals with serious mental illnesses who do not have positive relationships with traditional supports such as friends or family. For example, caregiving for individuals with serious mental illnesses is associated with family disruptions, psychological distress, economic costs, and negative impacts on mental and physical health (Solomon \& Draine, 1995). Family members may distance themselves from individuals with serious mental illness because of these negative outcomes.

Emerging research also suggests that pets provide a source of social support for individuals with serious mental illnesses (Hennings, 1999; Wisdom, Saedi Auzeen, \& Green, 2009; Zimolag \& Krupa, 2009). For example, Wisdom and colleagues (2009) conducted a mixed-methods study examining pet ownership and recovery for individuals 
with serious mental illnesses over a two year period. Four themes emerged from the qualitative analyses, including pets providing empathy and "therapy", pets acting as family, pets fostering social connections with others, and pets increasing participants' self-efficacy and sense of empowerment (Wisdom et al., 2009).

Types of support provided. In the general population, research suggests that emotional support is the most commonly exchanged form of support, followed by informational and tangible support (Burke, 2010, Kaniasty \& Norris, 2000). Similarly, Walsh and Connelly (1996) demonstrated that individuals with serious mental illnesses most frequently identify emotional support, following by material (e.g., food, money) and instrumental (e.g., providing transportation) support provided by natural supports. Additionally, Bradshaw and colleagues (2007) reported that the majority of participants thought that family members and friends provided both emotional support (i.e., comfort) and tangible support (e.g., cosigning an apartment) while investigating the process of recovery over time. While family and friends provide primarily emotional support to individuals with serious mental illnesses, research suggests that distal supports primarily provide tangible or instrumental support (Townley, Miller, Kloos, 2013; Walsh \& Connelly, 1996). Distal supports are likely different from other natural supports because they are more casual, less personal, and may not provide the same level or frequency of support as family members or friends (Townley, Miller, Kloos, 2013). Additionally, tangible support is considered the easiest type to identify and report (House, 1981).

\section{Community Participation}


Community participation is defined as independent engagement in communitybased contexts across any of the following social life domains: domestic life (e.g., cleaning, shopping), interpersonal life (e.g., formal relationships, intimate relationships, family relationships), major life activities (e.g., education and employment), and community, civic, and social life (e.g., politics, religion, culture; WHO, 2001). Past research suggests that community participation has numerous benefits for people with serious mental illnesses, including promoting a better quality of life and recovery (Badger et al., 2003; Burns-Lynch, Brusilovskiey, \& Salzer, 2016; Kaplan et al., 2012).

Although research has primarily focused on domestic aspects of community participation, individuals with serious mental illnesses report that other domains of participation are important to them (Granerud \& Severinsson, 2006; Salzer, Brusilovskiy, Prvu-Bettger, \& Kottsieper, 2014). For example, Salzer and colleagues (2014) found that areas such as using public transportation, running errands, shopping at the grocery store, and entertaining or visiting family and friends have the highest reported levels of participation and are also among the most important activities reported by individuals with serious mental illness. Additionally, studies have typically focused on independent participation (i.e., activities done without the assistance of mental health staff) without identifying whether activities are performed with specific types of individuals (e.g., friends, family members, peers). Discovering with whom individuals with serious mental illnesses engage in activities will increase our understanding of community participation and may inform recommendations to both natural supports and service providers. For example, peers with mental health challenges may act as important sources of support 
because they are more aware of individuals' experiences with mental illness and may be able to encourage or inspire individuals to overcome barriers to community participation (Carling, 1995; Davidson, Bellamy, Guy, \& Miller, 2012; McCorkle et al., 2008).

\section{The Role of Natural Supports in Facilitating Community Participation}

Research suggests that social relationships connect people with serious mental illnesses to the broader community and increase their community participation (Beal et al., 2005; Bradshaw et al., 2007; Davidson, et al., 2001). Bradshaw and colleagues (2007) reported that several participants singled out friends as people that helped them reintegrate into the community. For example, one participant spoke about a friend lending their car and teaching them how to parallel park (Bradshaw et al., 2007). Additionally, Royce-Davis (2001) found that individuals with serious mental illnesses cited both spouses and coworkers as sources of support that positively influenced community participation. Furthermore, positive social interactions were associated with higher levels of satisfaction with social life and increased engagement in leisure activities in a study by Yanos, Rosenfield, and Horwitz (2001).

However, individuals have reported both negative and positive experiences when family members have attempted to help them become more integrated into the community (Bradshaw et al., 2007; Davidson, et al., 2001). For example, Beal et al. (2005) found that participants had positive feelings towards family members, stating that they were a reliable source of support that were capable of connecting them to community activities. In contrast, participants in another study reported that family 
members struggled to allow them to become more independent, such as allowing them to move out (Bradshaw, Armour, \& Roseborough, 2007).

According to previous studies, distal supports also positively contribute to community participation (Beal, 1999; Beal et al., 2005; Corin \& Lauzon, 1992; Townley et al., 2013). For example, Townley, Miller and Kloos (2013) found that distal supports accounted for a unique amount of variance in community inclusion while controlling for more traditional supports (i.e., family, friends). Finally, a study examining the relationship between pet ownership and community inclusion found that participants who were pet owners were more likely to engage in meaningful activities and experience social integration compared to non-pet owners (Zimolag \& Krupa, 2009). Thus, both traditional (e.g., friends, family) and non-traditional (e.g., distal supports, pets) sources of informal social support are important to consider as potential facilitators of community participation.

It is generally recognized that individuals with serious mental illnesses typically report smaller social networks (i.e., social relationships tied to an individual) compared to individuals in the general population (Dewees et al., 1996; Leavy, 1983; Ware, Hopper, Tugenberg, Dickey, \& Fisher, 2007). However, research has yet to explore how other characteristics of social relationships (e.g., contact frequency, length of relationship) influence community participation for individuals with serious mental illnesses. Research among individuals in the general population suggests that higher levels of contact can have both positive and negative effects, including providing more social support (Heaney \& Israel, 2008) or increasing risk-taking behaviors (Berkman et al., 2000). Additionally, 
previous studies suggests that frequency of contact with natural supports predicts mortality in both the general population and also among older adults, such that higher frequency of contact with natural supports is associated with lower levels of mortality (Blazer, 1982; Orth-Gomér \& Johnson, 1987).

\section{Study Purpose and Research Questions}

There is consensus in research and practice that social support and community participation are important components of community inclusion and beneficial to individuals with serious mental illnesses (Davidson, 2005; Nelson, Lord, \& Ochocka, 2001; Salzer \& Baron, 2016). However, there is a dearth of literature regarding specific characteristics of social relationships and their association with community participation. As such, the current study aimed to contribute to the current knowledge base regarding the influence of social support on community participation for adults with serious mental illnesses by examining the following:

Research Question 1: Who are the primary sources of social support for adults with serious mental illnesses?

Research Question 2: What levels of each type of support (e.g., emotional, tangible) do these sources of support provide to adults with serious mental illnesses?

Research Question 3: How does social support provided by natural supports (e.g., family, friends, and neighbors) relate to community participation for adults with serious mental illnesses?

The current study is primarily exploratory and descriptive, and numerous gaps in the literature limit the ability to develop specific hypotheses regarding associations 
between social support and community participation. In general, I expect that participants will report a wide range, but a relatively small number, of social support providers compared to the general population. I also expect that support provided by natural supports will be positively associated with community participation. Collectively, findings from this research will enhance our understanding of social support among individuals with serious mental illnesses and shed light on the underexamined role that natural supports may play in bolstering community participation.

\section{Methods}

\section{Participants}

The current study utilized data collected from 50 participants utilizing mental health services and living in independent supportive housing maintained by Cascadia Behavioral Healthcare in Portland, Oregon. Cascadia Behavioral Healthcare is a private nonprofit organization that provides services to people experiencing mental illness and addiction challenges in Oregon. Participants were recruited in person, via recruitment flyers sent to all residents and posted in community rooms informing them of the project and providing my contact information (see Appendix A). On-site housing managers were also informed of the project and provided interested clients with recruitment flyers.

Inclusion criteria for the proposed study were adults between the ages of 18-65 who lived in one of the participating housing sites and self-reported a diagnosis of a serious mental illness (e.g., bipolar disorder, major depression, or schizophrenia-spectrum disorders). Additionally, participants must have identified as the heads of household living at one of the housing sites. Exclusion criteria applied to clients who were unable to 
provide informed consent or who had a legal guardian. No residents were excluded based on these criteria. Convenience sampling was used to reach the desired number of participants.

Housing sites. Participants were recruited from a total of five independent supportive housing sites. The housing sites are apartment-style units which are integrated into the surrounding neighborhood and not connected to mental health services. Initially, two housing sites were chosen in a meeting with the Vice President of Housing and the Director of Property Management and Compliance. The initial housing sites were selected based on size (larger site being preferred), location, resident demographics (specifically, race and gender), and availability of the housing manager to assist with research as needed. Additional housing sites were chosen via email correspondence with the Director of Property Management and Compliance and the Senior Portfolio Managers. The additional housing sites were chosen based on size, availability, and preferences of the Director and Senior Portfolio Manager. However, several sites had to be excluded due to their participation in another research study occurring at the same time as this data collection.

\section{Measures}

The survey included demographic questions along with measures of social support and community participation. Additionally, every third participant was asked semi-structured qualitative questions (see Appendix B).

Community participation. A modified 22-item version of the Temple University Community Participation Measure (TUCP; Salzer, Brusilovskiy, Prvu-Bettger, \& 
Kottsieper 2014) was used to measure community participation. Participants were asked about 22 different areas in which they participated in the last 30 days without assistance from mental health staff (e.g., going to the library, shopping, visiting with friends or family), whether they view their participation in each area as important, and whether they participated in each area as frequently as they wish. Four items about participating in mental health activities were removed in order to focus on participation in community activities. The survey measures independent activity (i.e., without mental health staff) in order to assess the activities that participant choose to engage in without assistance from mental health organizations. Participants' responses to the 22 TUCP items were used to calculate the following: 1) amount of participation, calculated as the sum of participation days across all 22 items; 2) breadth of participation, or total number of important participation areas with at least one day of participation completed; and 3) sufficiency of participation, or the percentage of important activity areas where participation occurred as much as the person desired. Past studies have demonstrated that the scale has good reliability and validity (Burns-Lynch et al., 2016; Salzer et al., 2014; Salzer, Kottsieper, \& Brusilovskiy, 2015).

A previous study by Salzer, Kottsieper, and Brusilovskiy (2015) demonstrated intermethod reliability by comparing the TUCP to a similar diary checklist. Results showed significant Spearman correlations for participation areas ranging from 0.20 to 0.89. In addition, Salzer, Brusilovskiy, Prvu-Bettger, \& Kottsieper (2014) assessed testretest reliability by comparing the measure at two time points within 24 to 72 hours. The analyses found significant Pearson correlations for days of participation in each area at 
Time 1 and 2 ranging from 0.27 to 0.85 . The internal reliability (i.e., Cronbach's alpha) for the amount of participation was 0.68 in a previous study (Terry, Townley, Brusilovskiy, \& Salzer, 2019). In the current study, the internal reliability (i.e., Cronbach's alpha) for the amount of participation was .60 , breadth of participation was .59 , and sufficiency of participation was .79. Finally, to provide evidence for validity, studies have reported significant correlations between community participation and constructs that theoretically should be related to participation, including lower levels of impairment (Terry et al., 2019), and higher levels of recovery and quality of life (BurnsLynch et al., 2016).

Social support. A revised 10-item Norbeck Social Support Questionnaire was used to measure social support (NSSQ; Norbeck, Lindsey, \& Carrieri, 1981). Participants are asked to list the first names or initials of up to 24 individuals who provide support to them and the relationship they have with that person (e.g., friend, father, spouse). Participants are then asked to report the amount of support available from each person using a 5-point scale ranging from 0 (not at all) to 4 (a great deal). A sample item is, “How much does this person make you feel liked or loved?”. Additionally, participants are asked about the length of relationship and frequency of contact for each person on a scale of $1-5$.

Psychometric testing suggests that the scale has good reliability and validity (Norbeck, Lindsey, \& Carrieri, 1981; Norbeck, Lindsey, \& Carrieri, 1983). Test-retest reliability was assessed by comparing the measure at two time points, one week apart. There were significant Pearson correlations for the support and network scales at Time 1 
and 2, ranging from 0.86 to 0.92 . Correlations between the support subscales and two subscales (i.e., Need for Inclusion and Need for Affection) from the Fundamental Interpersonal Relations Orientation Behavior (FIRO-B; Schutz, 1958) was utilized to demonstrate construct validity. The analyses resulted in significant Pearson correlations between the two measures ranging from 0.17 to 0.26 . Norbeck et al. (1981) recommends calculating correlations to assess reliability rather using the coefficient alpha. As such, Spearman correlations were conducted between the subscales; correlations were significantly positively correlated with values ranging from 0.84 to 0.98 .

Five items were added to the measure based on the research questions guiding this study. The items asked how much each person provides support in the following participation areas: employment; education; romantic relationships; parenting; and leisure and recreational activities.

Qualitative interviews. Semi-structured qualitative questions were asked immediately after the survey for every third participant (see Appendix A). The questions attempted to broaden our understanding of the role of social support in influencing community participation and unpack whether or not participants engage in community activities with certain types of individuals (e.g., family members, peers). An example question is "Which of these activities do you prefer to do with others?".

\section{Design and Procedures}

The current study utilized a quantitative survey followed by qualitative follow-up questions, to better understand the association between social support and community participation for adults with serious mental illnesses. The inclusion of both quantitative 
and qualitative methodology allowed for triangulation of findings across data sources and strengthened the results from either method alone (Greene \& Caracelli, 1997; Greene, Caracelli, \& Graham, 1989; Hesse-Biber \& Leavy, 2010). Further, qualitative interviews allowed participants to voice their own opinions and experiences regarding the constructs of interest, and also helped to contextualize and assist with the interpretation of quantitative results (Morgan, 1998).

The consent form (see Appendix B) and procedures were approved by the Portland State University IRB. The interviews were conducted in the community rooms at the housing sites. Housing managers agreed that the community rooms were the best option to conduct interviews and confirmed that the rooms are not frequently used by residents during the day. Additionally, the housing managers informed all residents that interviews would be taking place in the community room during the study period. The consent form also indicated that participant could complete the interview in a more private location (i.e., private office or personal unit) if they felt uncomfortable. Most of the community rooms had a door to close for privacy. There were two housing sites that did not have a door to close. A couple of residents from these locations asked to complete the interview in a private office, which was readily available. There were also a few instances in which residents entered the community room while an interview was being conducted. Each time, the interview was paused and the resident was asked to come back later after the interview was completed.

I read each question aloud, and participants' responses were recorded electronically on a laptop. Surveys ranged from about 14 minutes to 134 minutes (about 
two hours) in length, with an average of 32 minutes. A few surveys were significantly longer than average due to a high number of reported supports (i.e., up to 24 individuals) and/or participants taking breaks (e.g., to smoke, go to the bathroom, or answer a phone call). The qualitative interviews were completed in 10 to 30 minutes, and participants' responses were recorded using a digital audio recorder. Participants received $\$ 10$ for completing the survey, and an additional $\$ 5$ if they were selected to complete the qualitative interviews. The qualitative interviews were transcribed during the data collection phase, typically within one to two weeks after the interview was conducted. Any identifying language was removed from the transcriptions. Initial thoughts and impressions were added as memos during the transcription.

\section{Data Analysis and Results}

\section{Sample Demographics}

Survey sample. The sample included 48 participants. The average participant age was $52(S D=11.34)$. Forty-seven percent of participants identified as women, $49 \%$ identified as men, and $4 \%$ reported prefer not to say or prefer to self-describe. Most participants were White (60.4\%), 18.8\% were Black, 6.3\% Latino or Hispanic, $4.2 \%$ Native American, 4.2\% Asian, and 6.3\% other. Participants primarily reported a diagnosed mood disorder $(n=23,47.9 \%)$, followed by schizophrenia-spectrum $(n=11$, $22.9 \%)$ anxiety disorder $(n=11,22.9 \%)$, and other $(n=3,6.3 \%)$. Most of the participants were single $(56.3 \%)$, followed by in a relationship $(22.9 \%)$, currently married $(2.1 \%)$, separated $(4.2 \%)$, divorced $(8.3 \%)$, and widowed $(6.3 \%)$. In regards to education, 4.2\% completed less than nine years of school; $14.6 \%$ completed 9-12 years of school but 
did not graduate; $29.2 \%$ were high school graduates or obtained a GED; $39.6 \%$ completed some college, vocational, trade, or business school; $6.3 \%$ were associate or vocational graduates; $4.2 \%$ were college graduates; and $2.1 \%$ obtained a Master's degree or equivalent.

Twenty-nine percent of participants were currently working for pay, with an average of 17.20 hours of work per week. The average income for participants was $\$ 746.62$ per month. More than half of the participants had a biological child (58\%), but only $17 \%$ reported having a biological child under the age of 18 .

Qualitative interview sample. The average age of participants who completed the follow-up questions was $55(S D=8.22)$. Forty percent identified as women and $60 \%$ men. Most participants were White (60\%), 20\% were Black, 6.7\% Latino or Hispanic, 6.7\% Asian, and $6.7 \%$ other. Participants primarily reported a diagnosed mood disorder $(9,60 \%)$ followed by a schizophrenia-spectrum disorder $(3,20 \%)$, and an anxiety disorder $(3,20 \%)$. Most of the participants were single (66.7\%), 20\% were divorced, $6.7 \%$ were in a relationship, and $6.7 \%$ were separated. In regards to education, $6.7 \%$ completed less than nine years of school; $13.3 \%$ completed $9-12$ years of school but did not graduate; $20 \%$ were high school graduates or obtained a GED; $33.3 \%$ completed some college, vocational, trade, or business school; $6.7 \%$ were associate or vocational graduates; $13.3 \%$ were college graduates; and 6.7\% have a Master's degree or equivalent. Thirty-three percent of participants were currently working for pay, with an average of 15.38 hours of work per week. The average income for participants was 
$\$ 831.47$ per month. More than half of the participants had a biological child $(60 \%)$, but only $20 \%$ reported having a biological child under the age of 18 .

\section{Preliminary Analyses}

Descriptive analyses were conducted on all variables to detect outliers and errors in data entry. There were two outliers for the breadth of participation, but the outliers were retained because the values occurred within a plausible range for the variable. There were additional outliers for emotional support, tangible support, and total support. These outliers occurred because two participants identified more individuals as supports $(M=$ 20.5) compared to the rest of the sample $(M=5.28)$. These outliers were also retained because the values occurred within a plausible range for the variables. There was no more than 5\% missing data on any single variable. All data were analyzed in SPSS Version 25 (IBM Corporation, 2017).

Frequency distributions and summary statistics were examined to determine whether the data were normally distributed and fell within a plausible range of values for each variable (see Tables 4.1 to 4.3 ). Tests of skewness and kurtosis revealed that emotional support, tangible support, and total support were positively skewed.

Additionally, the values were outside of the range of acceptable values according to guidelines that absolute skewness values lower than three and absolute kurtosis values lower than 10 are acceptable (Kline, 2011). Therefore, statistical tests for data that is normally distributed and nonparametric tests for data that are not normally distributed were conducted. Analyses were also conducted with the outliers removed to investigate 
whether the outliers were significantly influencing the results. When the outliers were removed, the skewness and kurtosis values were within an acceptable range.

Scores on number of individuals in support network, length of relationship, and frequency of contact were combined to create a composite variable called total network. Additionally, scores on the emotional and tangible support questions were summed to create emotional support and tangible support variables, and then combined into a total support variable. The summed scores of emotional, tangible, and total support were used to compare results to a previous study with the general population (Norbeck, 1995).

When scoring the NSSQ, Norbeck, Lindsey, and Carrieri (1981) recommended abstaining from calculating average scores because the results are biased against individuals who report larger networks. However, House and Kahn (1985) argue that the variability in network size introduces measurement error. As such, some researchers calculate the average scores to account for the potential error. Gigliotti and Samuels (2011) conducted psychometric tests and concluded that average emotional support and average total support are not influenced by network size. However, average tangible support is influenced by network size. Respondents tend to report lower tangible support because certain support categories (e.g., children, pets) are often unable to provide tangible support. Therefore, the average emotional support and average total support were used for the following analyses, while tangible support was summed rather than averaged. Correlational analyses between primary study variables were performed, and a correlation matrix is presented in Table 4.4. 
Demographic analyses. A series of t-tests, ANOVAs, and correlations were conducted to test for associations between participant characteristics (race, gender, age, and diagnosis) and the primary study variables. There were significant differences by age and gender for the support variables. First, Spearman's correlation indicated that age was significantly negatively correlated with tangible support $r_{s}(46)=-.37, p<.05$, such that older participants reported less tangible support. Second, an independent samples t-test revealed that women reported significant higher average total support $(M=24.22, S D=$ 2.70) than men $(M=21.87, S D=3.82), t(44)=2.42, p<.05$. There were no significant differences in support variables by race or diagnosis. Additionally, there were no significant differences by race, gender, age or diagnosis for the community participation variables.

\section{Primary Analyses}

Research Question 1: Who are the primary sources of support for adults with serious mental illnesses?

In total, participants identified 240 individuals as supports, with an average of 5.28 supports $(S D=4.30)$. In comparison, a previous study with the general population found the average number of supports to be $10.75(S D=5.80$; Norbeck, 1995). The average total network score (i.e., number of supports, length of relationship, contact frequency) for participants in the current study was $49.21(\mathrm{SD}=37.22)$, compared to $96.75(S D=54.55)$ in the general population. Overall, participants with serious mental illnesses in the current study identified fewer individuals as supports and reported lower total network scores than members of the general population (Norbeck, 1995). 
Family or relatives were identified most often as supports $(f=92,38 \%$ of the 240 total supports reported by participants), followed by friends $(f=52,22 \%)$, neighbors $(f=$ $33,14 \%)$, pets $(f=17,7 \%)$, counselor or therapist $(f=12,5 \%)$; spouse or partner $(f=11$, $5 \%)$; healthcare providers $(f=11,5 \%)$; work or school associates $(f=4,1 \%)$; and minister, priest, rabbi, or other religious leaders $(f=2,1 \%)$. Examples of other supports $(f$ $=6,2 \%$ ) included housing manager or case worker (see Figure 4.1 and 4.2).

Participants reported an average emotional support score of $85.64(S D=71.70)$, while tangible support was $31.68(S D=29.26)$, and average total support was $117.32(S D$ $=100.06)$. Comparatively, the general population reported an average emotional support of $123.25(S D=73.95)$; an average tangible support of $54.20(S D=34.70)$; and an average total support of $176.50(S D=105.02$; Norbeck, 1995). Thus, participants in this study reported lower scores on emotional, tangible, and total support than members of the general population.

Loss. Less than half of participants $(n=22,46 \%)$ reported losing relationships due to moving, job changes, separation, divorce, death or another reason. Participants reported losing relationships with spouses or partners, family or relatives, or friends in the past year. Participants reported losing one to four individuals. The majority of these participants reported losing one individual $(n=13,59 \%)$ who provided no support $(n=$ $8,36 \%$ ). In comparison, about $40 \%$ of individuals in the general population study reported losing relationships in the last year (Norbeck, 1995). Additionally, these individuals reported losing an average of $2.30(S D=1.20)$ units of support on a scale of 0 to 4 . Therefore, a higher percentage of participants in the current study reported losing 
relationships compared to the previous study, but they did not report losing a higher amount of support from those individuals.

Research Question 2: What levels of each type of support (e.g., emotional, tangible, total) do these sources of support provide to adults with serious mental illnesses?

The type of support (i.e., average emotional, tangible, average total) provided by each category of individuals was examined to identify whether certain individuals provide higher levels of each type of support than others.

First, spouses or partners provided the highest levels of average emotional support $(M=18.64, S D=2.06)$, followed by pets $(M=18.15, S D=3.34)$, friends $(M=17.53, S D$ $=2.64)$, religious leaders $(M=17.50, S D=3.54)$, healthcare providers $(M=17.17, S D=$ $2.57)$, counselor or therapist $(M=16.93, S D=2.61)$, family or relatives $(M=16.58, S D=$ $3.14)$, work or school associates $(M=15.00, S D=5.00)$, other supports $(M=14.75, S D=$ 6.13), and neighbors $(M=14.30, S D=4.03$; see Table 4.5).

Second, family or relatives provided the highest levels of tangible support $(M=$ $12.00, S D=9.90)$, followed by friends $(M=7.23, S D=14.07)$, neighbors $(M=4.56, S D$ $=10.92)$, spouse or partner $(M=2.02, S D=3.83)$, pets $(M=1.85, S D=4.28)$, healthcare providers $(M=1.02, S D=2.65)$, counselor or therapist $(M=0.92, S D=3.06)$, other supports $(M=0.67, S D=2.60)$, work or school associates $(M=0.35, S D=1.91)$, and religious leaders $(M=0.29, S D=1.47$; see Table 4.6).

Third, spouse or partners provided the highest levels of average total support $(M=$ $27.45, S D=2.97)$, followed by religious leaders $(\mathrm{M}=24.50, \mathrm{SD}=6.36)$, friends $(M=$ 
$24.22 S D=4.46)$, pets $(M=23.12, S D=4.59)$, family or relatives $(M=23.04, S D=$ 3.91), healthcare providers $(M=21.78, S D=4.99)$, neighbors $(M=21.35, S D=5.65)$, other $(M=20.37, S D=9.14)$, counselor or therapist $(M=20.11, S D=3.98)$, and work or school associates $(M=18.50, S D=5.63$; see Table 4.7).

Research Question 3: How does social support provided by natural supports relate to community participation for adults with serious mental illnesses?

Quantitative. Average emotional support, tangible support, and average total support were recalculated to only include natural supports (i.e., excluding health care providers, counselors or therapists). Tangible support provided by natural supports was positively skewed, so non-parametric tests were used for analyses of this type of support. Correlational analyses were conducted between support and community participation variables (see Table 4.8). Average total support was significantly related to the amount of community participation, $r(48)=0.29, p<.05$, such that higher levels of average total support was associated with a higher number of participation days. There were no significant correlations between average emotional support, tangible support, and community participation amount, breadth, or sufficiency.

Additionally, when asked how often each of their natural supports provides support in a specific participation area, participants reported the highest levels of average support in parenting $(M=3.15, S D=1.29)$, followed by leisure and recreational activities $(\mathrm{M}=3.13, \mathrm{SD}=1.38)$, education $(M=3.10, S D=1.41)$, relationships $(M=2.86, S D=$ 1.20) and employment $(M=2.86, S D=1.40)($ see Table 4.9). 
Qualitative. After the qualitative interviews were transcribed, theoretical thematic analysis was used to identify and analyze patterns of meaning, or themes, regarding how natural supports who provide support influence community participation (Braun \& Clarke, 2006; Ryan, Health, \& Bernard, 2003). Semantic coding was utilized to describe, summarize, and interpret themes in the dataset. Braun and Clarke (2006) outlined six steps that acted as a guide to the qualitative analysis: getting to know the data, developing codes, identifying, reviewing, and defining themes, and producing the report.

First, I listened to the interviews and read the transcripts several times to correct any errors and become familiarized with the data. Initial memos and codes were also developed at this time. The transcripts were in a Word document, and I used the highlighter and comment tools to record memos and codes. Then, I reviewed the research question and began to develop relevant codes. Codes were then extracted and placed in a list. Relevant codes were grouped together, and themes emerged from these groups. Next, I reread the transcripts to ensure that the themes accurately reflected participants' responses. Finally, I discussed both the codes and themes with a colleague through a peer debriefing process, which will be discussed further below.

Peer debriefing. The purpose of the peer debrief was to review initial coding of interview data, discuss any biases present, and improve the reliability and credibility of the analysis. Peer debriefing is often recommended to improve trustworthiness in qualitative research (Lincoln \& Guba, 1985; Barber \& Walczak, 2009). 
Additionally, peer debriefing provides a second opinion from an outside researcher regarding the meaning and interpretation of the data (Barber \& Walczak, 2009). The person chosen for the peer debrief was another graduate student on my research team. This person was familiar with both the research topic and qualitative research. We met in person to conduct the review. I chose three interview transcripts for her to review (20\%, as recommended by Barber \& Walczak, 2009). First, she highlighted text that was relevant to the research question, wrote memos, and produced codes. She then reviewed the memos and codes that I had created. After that, we reviewed the transcripts together, compared and discussed the codes, and resolved any disagreements in coding. Later, I sent the themes and several quotes for each theme to her via email. She reviewed the document, suggested removing a theme, and provided a few alternative names for themes. I accepted these changes.

Analyses revealed the following themes: 1) families spend time together; 2) neighbors provide social interaction and tangible support, but may not lead to community participation; 3) friends support community participation; 4) pets provide emotional support and encourage physical activity, but may not lead to community participation; 5) mental health challenges can be barriers to participation; and 6) desire to do activities with others.

\section{Families spend time together}

The majority of participants discussed their families during the interviews. Participants were asked for examples of activities they do with family members. About half of the participants responded that the family "gets together". Examples of getting 
together included going to the park, going to the beach, attending weddings or reunions, camping, celebrating holidays, going to church, and eating at restaurants. Additionally, many participates relied on family members for tangible support that was required for community participation. For example, one participant commented that his brother supports him by "helping me find jobs at times, or he'll help me out financially or by giving me a ride when I need it, to go get food or maybe take in my bottle deposits." Other activities included going to the grocery store, fixing the car, going to the hospital, and shopping.

Additionally, many of the participants noted the importance of family in supporting community participation. For example, one participant believed that his family provided more support for community participation, even though he actively participated in activities with an organization for his ethnic group. He stated, "The ethnic group - yes I'm part of it, but in the end we all go home...I'm very gratified that I have local family and we are close." Another participant explained that due to her children and grandchildren, she's "always got something to do".

\section{Neighbors provide social interaction and tangible support, but may not lead to community participation}

Most of the participants discussed relationships with neighbors that involved conversing with neighbors. For example, one participant explained, "I get together often with neighbors here at [housing site] and we sit and talk...we listen to music together, we take short walks." A few participants relied on neighbors for tangible support or to run errands. A participant described that, "If I need laundry money...he'll give it to me, or 
any groceries, or [if I] need a ride, he's there...[he] makes sure I'm staying healthy." Other activities with neighbors included watching TV or movies, playing video games, and smoking. However, participants rarely mentioned participating in activities with neighbors in the broader community, such as eating out, going to a movie, or going to a park. Two participants reported leaving the housing site with a neighbor to go to the grocery store, but explained that it was only because the neighbor had a car.

\section{Friends support community participation}

Participants who spoke about friends often mentioned going out to eat or shopping with friends. For example, one participant described activities that she does with a friend:

Go to McDonalds, go to Taco Bell, go to the Dollar Tree, go to Winco...go shopping, go to Clackamas Town Center, go see a movie, go out to lunch, or brunch, or dinner or whatever...go out for dessert, anything like that.

Additionally, a few participants spoke about outdoor activities with friends, including going to the park, going to the river, going camping, and riding ATVs on the beach. Finally, a few participants spoke about going to church. These participants had friends who were exclusively considered "church friends". These friends sometimes provided transportation to and from church, and they occasionally went out to eat lunch after church.

Pets provide emotional support and encourage physical activity, but may not lead to community participation 
Several participants owned pets, either cats or dogs. Participants who owned dogs reported typically taking them for walks once or twice day. Most participants described their pets as support animals. For example, a participant stated that his dog is supportive because she "doesn't judge you or talk back". Additionally, a participant explained that:

She's just always excited whenever I come back or even when I've been outside for two minutes. If I come back inside, she's really excited to see me...she's really smart and just always seems to know when I need, not a hug, but a cuddle. However, there was no evidence provided by participants that pet ownership led to community participation. Participants never reported leaving the housing site or surrounding neighborhood with their pet.

\section{Mental health challenges can be barriers to participation}

Participants also mentioned challenges with community participation due to mental illness or concerns about stigma, even though family, friends, or neighbors extended invitations. For example, one participant explained that a friend "invites me, but I struggle so badly with the agoraphobia and being sick that...it's hard for me to accept". Another participant described a friendship that he thought was "really cool", but after visiting the friend and his wife, he said:

I tell people [friend and wife] I hear voices, I used to hear voices, and then feel bad and I don't want to hang out with anybody for like five days cuz I feel likeoh no they probably [sighs] think I'm a psycho.

However, a few participants were grateful that neighbors or family members had experiences with mental illnesses and were able to provide support. For example, one 
participant explained that her daughter provided the most support with community participation because "when we [her and her daughter] get out together, I think cuz we can relate, you know, both of us have struggles with our mental health." Another participant mentioned that a neighbor is a "big support...cuz he deals with the same things as I do".

\section{Desire to do activities with others}

Participants overwhelming responded with a desire to do activities with others when asked about the support they need to participate more actively in the community. A few participants wanted family members to be more active. For instance, one participant explained, "my mom and my sister, if they had more time and energy and the ability to go out and do things with me, that would be good."

Some participants wanted to attend activities with a friend. A participant stated, "Sometimes I like to go out to the art museum, and I like to have somebody else with me when I go there...it's more fun when you got somebody else." Another participant thought that a friend would help reduce their anxiety about going to new places, explaining that:

Sometimes it's hard for me to go to somewhere for the first time if I've never been there, and I've never even seen the place. I'd like someone to be there with me as like a support, like someone to talk to, someone I know, and it makes it a little easier. 
Finally, one participant explained that, "it would have to be someone initiating it with me though... and putting the invite there, and also...I want to say tenacious about it, well yeah...yeah because sometimes it will take a couple no's before the yes..."

\section{Discussion}

This study responds to recent calls for the field of community psychology to reconnect with its community mental health roots (Townley, Brown, \& Sylvestre, 2018) and continues a growing emphasis on promoting community inclusion in the mental health field (Salzer \& Baron, 2016). In particular, the current study advances our understanding of natural supports, which are abundant in the community and not limited by the many constraints of more formal community support services. If individuals receive support from friends, family, and members of the community, they may have more opportunities to participate in the community and ultimately achieve greater levels of community inclusion.

\section{Overview of Study Findings}

Quantitative. The current study explored the association between social support and community participation among individuals with serious mental illnesses. Below, findings will be discussed according to the types and levels of support provided, as well as the relationship between natural supports and community participation.

Types of support. Participants reported a range of individuals as supports, including family members, spouses or partners, friends, neighbors, pets, counselors, health care providers, work or school associates, and religious leaders. Individuals with serious mental illnesses have identified these types of individuals as supports in previous 
studies (e.g., Beal et al., 2005; Walsh \& Connelly, 1996). Consistent with past research, family and friends were identified most often (Beal et al., 2005; Bradshaw, Armour, \& Roseborough, 2007), followed by neighbors, pets, counselor or therapist, spouse or partner, and healthcare providers. Work or school associates and religious leaders were more seldomly reported. Participants in the current study reported a smaller number of supports and lower scores on emotional, tangible, and total support compared to adults without mental illnesses in the general population (Norbeck, 1995), which is in line with previous findings in the mental health literature (Dewees et al., 1996; Leavy, 1983; Ware et al., 2000).

Levels of support. Next, the levels of each type of support (i.e., emotional, tangible, and total) provided by the supports discussed above were examined. First, spouses or partners provided the highest levels of average emotional support, followed by pets, friends, religious leaders, healthcare providers, counselors or therapists, family or relatives, work or school associates, other supports, and neighbors.

Spouses or partners, pets, and religious leaders were rated relatively high in emotional support $(f=11,17$, and 2 , respectively) compared to the frequency with which they were reported. These results indicate that these sources of support are perceived to provide higher levels of emotional support compared to other sources. Participants may perceive the quality of emotional support that those types of support provide as more significant than other sources of support. Therefore, it is possible that the quality of emotional support provided by a few individuals (or pets) is more important than the number of relationships a person has. This possibility has been discussed in social 
support literature for the general population. For example, the Social Support Questionnaire developed by Sarason, Levine, Basham, \& Sarason, 1983) measures the perceived number of supportive individuals and the satisfaction with available social support. This research distinguishes number of supports from satisfaction with support and suggests that the ideal number of supportive individuals and availability of social support likely varies across people and is influenced by many factors, such as personality and life experiences.

Additionally, while participants frequently identified family or relatives, and neighbors as sources of support ( $f=92$ and 33, respectively), the emotional support provided by these individuals was rated lower than that of other sources of support. Findings suggest that family or relatives and neighbors exist in participants' lives, but may not provide high levels of emotional support compared to other sources of support. Individuals with serious mental illnesses have reported negative experiences with family in previous studies. For example, participants have reported that family members act condescendingly toward them, or oppose their desire to live independently (Beal et al., 2005; Bradshaw, Armour, \& Roseborough, 2007; Chen, 2010; Davidson et al., 2001). Furthermore, family or relatives and neighbors may provide types of support that were not represented in the survey, such as providing advice.

Second, family or relatives provided the highest levels of tangible support, followed by friends, neighbors, pets, healthcare providers, counselor or therapist, other supports, work or school associates, and religious leaders. Consistent with past research, participants reported lower levels of tangible support compared to emotional support 
(Walsh \& Connelly, 1996). Notably, these results are also influenced by the number of individuals in each support category since the tangible support variable was summed rather than averaged. However, it makes sense that family or relatives, friends, and neighbors provide more tangible support than other sources due to their greater availability and closer proximity to the individual. Healthcare providers, counselors, or therapists have limited ability to provide tangible support (e.g., such as loaning money) given the professional constrains of their roles (Davidson, O'Connell, et al., 2006; Walsh \& Connelly, 1996). Additionally, work and school associates, and religious leaders may be similarly limited in their roles.

Interestingly, participants reported that pets provided more tangible support than several other sources. In unpacking the two questions included in the survey to measure tangible support, most participants reported lower scores when asked about their pet's ability to provide immediate help, while several participants reported higher scores when asked about their pet's ability to provide help if they were confined to bed for several weeks. Based on conversations during data collection, I believe that participants may have endorsed this question based on their belief that a pet could provide emotional support in that situation, even though the item was intended to assess perceptions of tangible support.

Third, spouse or partners provided the highest levels of average total support, followed by religious leaders, friends, pets, family or relatives, healthcare providers, neighbors, other supports, counselor or therapist, and work or school associates. Similar to findings pertaining to average emotional support, spouses or partners, religious leaders, 
and pets were rated relatively high compared to the frequency with which they were reported. These results are likely due to the high quality of support perceived from these sources of support. Additionally, friends, family or relatives, and neighbors were frequently reported and provided a notable amount of both emotional and tangible support. Finally, healthcare providers, counselors or therapists, work or school associates, and other supports were rated lower on total support compared to other sources. This could be due to the low frequency with which each of these support categories were reported. However, family, friends, and neighbors are likely more available for interactions, closer in proximity, and may have known the participants for extended periods of time compared to the other types of support (Walsh \& Connelly, 1996).

Social support and community participation. Finally, associations between support (i.e., emotional, tangible, total) provided by natural supports (e.g., family, friends and neighbors) and community participation were examined. There was a significant positive correlation between average total support and amount of participation, such that higher levels of average total support were associated with a higher number of participation days. This result suggests that if individuals receive higher levels of support (i.e., emotional and tangible), they may participate in community activities more often. Participants who have higher levels of support may frequently engage in certain activities with others, including going to the grocery store or going to a church, synagogue, or place of worship. There were also a few activities that require relationships with others, such as spending time with friends or family in each other's homes. Finally, if 
participants receive an adequate amount of social support, then they may feel more comfortable engaging in activities alone or with others.

While average total support was significantly correlated with the amount of participation, there were no significant correlations between social support and the breadth or sufficiency of participation. Therefore, although social support is associated with the number of participation days, social support does not significantly influence the variety of activities or number of activities that are important and sufficient. In some cases, natural supports may be willing or available to assist participants in completing more essential daily activities, but are not able or interested in attending more optional activities in the community, such as going to a concert. For example, many participants reported going to the grocery store several times a week, but they participated in few additional activities. Participants also reported insufficient participation across many of the activity areas even though many of these activity areas were rated as important to them. Participants likely confront numerous barriers to community participation that may not be adequately offset by social support, including poor physical or mental health, lower socioeconomic status, accessibility issues, and concerns about mental health stigma. In addition to these more substantive reasons, the non-significant findings could also be the result of the small sample (discussed in more detail below) along with restricted ranges of breadth and sufficiency of participation. For example, for breadth of participation in the current study, participants reported engaging in an average of 6.44 activities that were important to them, compared to 9.34 activities in a previous study (Salzer et al., 2014). 
When asked about the level of support that individuals receive in specific participation areas, participants reported the highest levels of support with parenting. Most individuals, regardless of whether they have a serious mental illness or not, require some support with parenting. This may be particularly true for individuals with serious mental illness because they face several barriers to parenting, including discrimination in child welfare cases, lack of confidence or motivation, and higher levels of parenting stress (Fox, 1999; Kaplan, Solomon, Salzer, \& Brusilovskiy, 2014). Education and employment support scores were likely lower both because only $29 \%$ of participants were employed, and because of the average age of participants $(M=52)$, with several stating that they were retired. Although many of the participants were single (56\%), several participants were not interested in dating and chose not to answer the question pertaining to support with romantic relationships. Several participants were older and had been in previously unsuccessful marriages or relationships. Additionally, participants may have felt uncomfortable discussing romantic relationships with a stranger, especially a young woman. Nevertheless, sexuality and intimacy among individuals with serious mental illnesses remains an under-examined research area that warrants additional attention in future studies (Ecker, Cherner, Rae, \& Czechowski, 2018).

Qualitative. Although the survey data produced few significant findings, the qualitative interviews allowed me to learn more about participants' experiences with social support and community participation. For example, participants discussed examples of activities that they completed with natural supports, including going to the park, going to the beach, or seeing a movie. Theoretical thematic analysis and semantic 
coding were used to identify and analyze themes regarding how natural supports influence community participation (Braun \& Clarke, 2006; Ryan, Health, \& Bernard, 2003). Six themes emerged from this analysis. Overall, participants reported natural supports such as friends, family, neighbors, and pets. Participants reported engaging in numerous community activities with family and friends, but did not report participating in community activities with neighbors or pets. Several participants mentioned a desire to engage in more activities with others. Finally, mental health challenges emerged as barriers to community participation. Themes are discussed further along with quantitative findings in the implications for research and practice section.

\section{Limitations and Future Directions}

Although the current study has many strengths, several limitations must be addressed. First, given the recruitment strategy, findings may have limited generalizability beyond adults with serious mental illnesses who live in independent supportive housing. These individuals' experiences may differ from people with serious mental illnesses who are living in other housing situations (e.g., living with family, experiencing homelessness) or individuals who are not utilizing mental health services. Additionally, convenience sampling was used to select housing sites and recruit participants. As such, the sample may not be representative of the residents of each housing site or residents of supportive housing across Portland, Oregon. Finally, data were collected in an urban area; future research should explore how individuals with serious mental illnesses experience social support and community participation in nonurban and rural areas. 
Another limitation is that the method of data collection (one-on-one interviews) may have resulted in response bias. Participants may have responded to questions in ways that they perceived as socially desirable. Additionally, a couple of participants commented that they were nervous to answer questions while the audio recorder was on. Future studies should consider other methods of recording data (e.g., taking notes, allowing participants to write out responses, etc.) to address these potential concerns. Finally, the extended survey length (up to 134 minutes) due to a higher number of reported supports may have resulted in survey fatigue. Given the average number of supports $(M=5.28)$, researchers may wish to limit the number of supports that a participant can report in future studies with individuals with serious mental illnesses.

The current study consisted of a relatively small sample. A post hoc power analysis revealed that the study may have been under-powered to detect significant associations between variables; at least 82 individuals were necessary to detect a medium effect size (0.30; Erdfelder et al., 1996). Thus, it may be that additional associations between social support and community participation exist, but the current study was under-powered to detect them. For example, although the relationship between social support and breadth of participation were not significant, the positive correlations between the constructs suggest higher levels of social support may be associated with higher levels of breadth of participation. Average emotional support and average total support were non-significant and negatively associated with sufficiency of participation, suggesting that higher levels of social support may be associated with lower levels of participation sufficiency. Future studies should collect data from larger samples to 
address this limitation and further explore the relationship between social support and community participation.

The cross-sectional design of the study can only be used to establish covariation between variables. Thus, we cannot conclude from the current study that higher levels of social support lead to higher levels of community participation (Kline, 2015). A third variable (e.g., symptom severity, location of housing) might influence the relationship between average total support and amount of participation, or the direction of the relationship between support and participation may be reversed. For example, if housing sites are close to resources and activities (e.g., grocery store, parks, museums), then individuals with serious mental illnesses may participate in activities more often. This is especially relevant for individuals with serious mental illnesses who do not have access to a vehicle. Relatedly, past research has found that individuals with serious mental illnesses living in urban areas report higher levels of community participation compared to those living in non-urban areas (Townley, Brusilovskiy, \& Salzer, 2016). Longitudinal research would strengthen the results of this study and allow for more robust conclusions about the possible nature and direction of any influence between variables.

Additionally, people who participate in the community may develop relationships with individuals participating in similar activities, such as making friends while volunteering or engaging in a hobby. However, participants in the qualitative interviews discussed social anxiety related to leaving their apartment. Although some participants reported being able to participate in activities with family or friends, many participants discussed the desire to participate in more activities with others. Oftentimes, mental 
health services will host activities in the community, such as going to the movies or attending a sports event, but clients are usually separated from the general public and are supervised by mental health staff. These activities provide interaction between clients, and may introduce clients to new interests or hobbies, but rarely result in clients meeting people outside of service recipients. Additionally, clients may not be able to choose the date and time, mode of transportation, or the activity itself. Mental health services may consider these activities as community participation, but the participation does not indicate community inclusion.

Although the current study identified a range of individuals as supports, such as friends, neighbors, and healthcare providers, the analyses did not examine the relationships between individuals who provide support and types of support received (i.e. emotional, tangible, total). For example, if a participant has close relationships with several family members, then they might not seek support from neighbors. Alternatively, if a participant has a spouse or partner, then they may not rely on family members as much. Future research should examine social support based on the availability of individuals who can provide support, and the amount of support those individuals provide.

In the future, research should examine social support and community participation using participatory action research methods with individuals with serious mental illnesses. Participatory action research provides individuals with lived experience of the research phenomenon with opportunities to participate more meaningfully in the research process, such as choosing relevant research questions, learning research methodology, 
and validating results. For example, individuals with serious mental illnesses likely have unique perspectives regarding the definition of social support, the importance of social support in relation to community participation, and relevant examples of social support in their daily lives. Additionally, while the community participation scale is utilized across the United States, opportunities to participate likely vary considerably across communities. For instance, while administering the scale, participants occasionally commented that an activity seemed odd, such as going to a theater or cultural event.

Overall, a participatory action research project could engage with individuals with serious mental illnesses in a community to understand their perspectives and experiences with social support and community participation. Based on this information, researchers and participants might collectively develop a research protocol that is more relevant and applicable to the community than the measures that were used in the current study. As a result, the findings might be more useful in enacting changes for residents, rather solely benefiting the researcher, or resulting in organizational changes in Cascadia that are not easily perceived by residents.

Finally, there are individual, community, and societal level factors that act as barriers to community participation, such as symptom distress, poor physical health, low socioeconomic status, lack of employment opportunities, inadequate access to healthcare, transportation barriers, and mental health stigma (Bradshaw, Armour, \& Roseborough, 2007; Dewees, Pulice, \& McCormick, 1996). A few participants explained during the qualitative interviews that having little spending money, not owning a car, and physical or mental health issues were barriers to participation. Future research, interventions, and 
policy efforts should continue to investigate how to reduce these barriers to social support and community participation for individuals with serious mental illnesses.

\section{Implications for Research and Practice}

The current study has important implications for research and practice. Collectively, findings from the current study enhanced our understanding of social support among individuals with serious mental illnesses and shed light on the underexamined role that natural supports play in bolstering community participation.

Family or relatives were the primary individuals who participants reported $(f=$ 92), and the majority of participants reported at least one family member or relative as a source of support $(n=38)$. Quantitative results indicated that family or relatives provided more tangible support than other sources of support. Participants also noted that family provided tangible support, such as loaning money or providing transportation, during the qualitative interviews. Additionally, many participants discussed the importance of family in supporting community participation compared to other sources of support. Participants who mentioned family as supports reported participating in many different activities, such as going to the park, going to the beach, attending weddings or reunions, camping, celebrating holidays, going to church, and eating at restaurants. Therefore, mental health practitioners should encourage clients to engage with family around community participation goals if these relationships are indeed supportive ones.

Participants also frequently reported friends as sources of support $(f=52, n=$ 21). According to the survey, friends provided higher levels of support compared to several other sources of support. Participants who identified friends as supports discussed 
participating in a range of activities during the qualitative interviews, including shopping, eating out, going to church, and engaging in outdoor activities. Practitioners should work with clients to develop friendships that may enhance opportunities for community participation. Although several participants identified neighbors as sources of support $(f$ $=33, n=12$ ), participants did not report engaging in community activities with them during the qualitative interviews. According to these participants, neighbors provided social interaction and occasionally tangible support. Interestingly, past research suggests that support from neighbors is positively associated with sense of community and negatively associated with loneliness (Kriegel, Townley, Brusilovskiy, \& Salzer, 2020; Townley and Kloos, 2011). Therefore, while neighbors may positively influence individuals' perceptions of community acceptance and social connection, this may not directly result in increased community participation. Future research employing a longitudinal design should continue to investigate the role of neighbors in promoting community inclusion.

Although many participates owned pets $(n=13)$ and spoke very positively of them, there was no clear evidence that pets led to community participation. The quantitative results indicated that pets provided higher levels of average emotional support compared to most of the other sources of support. Similarly, participants in the qualitative interviews identified pets as providing emotional support. Participants also reported taking dogs for daily walks in the surrounding neighborhood. Although the current study did not find evidence that pet ownership is associated with community participation, emotional support and physical activity associated with pet ownership may 
result in positive benefits, such as improvements in health and well-being (Headey, 2003).

All of the participants identified a range natural supports during the survey, including family, friends, neighbors, and pets. However, participants reported lower numbers of supports compared to the general population $(M=5.28$ and 10.75 , respectively). Further, many of the participants who completed qualitative interviews expressed a desire for companionship in order to participate in community activities. Past interventions have paired individuals with serious mental illnesses with community volunteers and demonstrated meaningful increases in both social support and community participation (Davidson et al., 2001; McCorkle et al., 2008). Additionally, participants mentioned that natural supports were not always understanding of their mental health challenges. Natural supports may benefit from education on mental health challenges, stigma, and other potential barriers to participation. Finally, case managers can encourage clients to form relationships with community members if they are interested.

Recommendations for increasing natural support may include cultivating new interests and hobbies, collaborating with family members, and identifying community resources (Machin \& Repper, 2013). Further exploring the potential role of natural, distal supports (e.g., baristas, librarians, grocery store clerks, and pharmacists) in supporting participation may be a particularly fruitful area for future research and practice (Townley et al., 2013).

A few participants highlighted family or friends with mental illnesses, also known as peers, as individuals who support them with community participation during the 
qualitative interviews. While much of the research focuses on peers as professional supports (e.g., peer support specialists), research also suggests that peers acting as natural supports is associated with friendship and a sense of belonging for individuals with serious mental illnesses (Basset et al., 2010). Future research should investigate whether peers in a natural support role (e.g., family, friend, or neighbor) increase community participation for individuals with serious mental illnesses. Additionally, interventions have successfully demonstrated the role of volunteers who are peers, and volunteers who are not in increasing social support and community inclusion (McCorkle et al, 2008). Replication research is needed to further examine the effectiveness of s programs in a variety of community contexts.

Although individuals with serious mental illnesses generally receive support from both formal and natural supports (Walsh \& Connelly, 1996), research suggests that certain individuals may leverage formal and informal supports differently (Cummings \& Kropf, 2009). For example, Cummings and Kropf (2009) found that older adults with serious mental illnesses received the majority of support from formal services in areas such as physical health and psychiatric distress, whereas other areas such as money management and self-care were largely initiated by natural supports.

In the current study, there were significant differences by age and gender for the support variables. As participants' age increased, scores on tangible support decreased, suggesting that older participants are receiving lower levels of tangible support. In the general population, research suggests that older individuals have smaller social networks compared to younger individuals (Vaux, 1995). Additionally, as individuals with serious 
mental illnesses age, their parents, who are often provide tangible support, may pass away or decrease in their ability to provide care (Cook, Lefley, Pickett, \& Cohler, 1994; Cummings \& Kropf, 2009). These factors might influence the lower levels of tangible support reported by older participants.

Additionally, women reported higher levels of average total support compared to men. In the general population, there are mixed findings about gender differences in social support (Schwarzer \& Leppin, 1989; Vaux, 1995). More recently, femininity has been associated with seeking and receiving more emotional support, especially from women (Reevy \& Maslach, 2001). Overall, few studies have examined the role of age or gender, and social support for adults with serious mental illnesses. Future research should examine whether these personal characteristics influence social support, and in turn, community participation for individuals with serious mental illnesses.

Finally, future research needs to continue to investigate the role of social media in relation to social support and community participation for individuals with serious mental illnesses. Social media is well suited for individuals with serious mental illnesses because the user can participate from home and has control over entering and exiting the platform, which has been identified as an important component of successful relationships (Beal, 1999; Beal et al., 2005; Naslund, Grande, Aschbrenner, \& Elwyn, 2014). Additionally, individuals with serious mental illnesses may utilize social media to connect with natural supports who live far away or who are not accessible due to not owning a car. Individuals may also use social media to learn about community events and activities and coordinate meetings with individuals in the community (Brusilovskiy, Townley, Snethen, \& Salzer, 
2016). However, there are mixed findings about the potentially harmful effects of internet use, such as increased social isolation, exposure to incorrect information, disclosure of personal information, and decreased well-being (Kaplan, Salzer, Solomon, Brusilovskiy, \& Cousounis, 2011; Kraut et al., 2002, 1998).

\section{Conclusion}

The findings from this study suggest a variety of individuals provide support to individuals with serious mental illnesses, with some evidence that natural supports (e.g., family and friends) are associated with community participation. Specifically, support provided by natural supports was positively associated with the number of participation days reported by participants. This is important because as individuals with serious mental illnesses spend more time in the community, they may experience greater levels of community inclusion. Additionally, activities such as sharing a meal with a friend, seeing a movie with a relative, or going to the park with a partner might reduce loneliness and contribute to recovery and positive mental health outcomes (Davidson et al., 2001). Family, friends, and other natural supports should continue to support individuals with serious mental illnesses as they engage with the community. Policy and practice should encourage the role of natural supports in increasing community participation, and promoting community inclusion. 
Table 4.1

Descriptive Statistics with All Supports

\begin{tabular}{|c|c|c|c|c|c|c|c|c|c|}
\hline \multirow[b]{2}{*}{ Measure } & \multirow[b]{2}{*}{$N$} & \multirow[b]{2}{*}{ Min } & \multirow[b]{2}{*}{ Max } & \multirow[b]{2}{*}{$M$} & \multirow[b]{2}{*}{$S D$} & \multicolumn{2}{|c|}{ Skewness } & \multicolumn{2}{|c|}{ Kurtosis } \\
\hline & & & & & & Statistic & SE & Statistic & SE \\
\hline Emotional & 47 & 19 & 419 & 85.64 & 71.70 & 3.12 & 0.35 & 11.84 & 0.68 \\
\hline \multicolumn{10}{|l|}{ Emotional } \\
\hline (average) & 47 & 9 & 20 & 16.64 & 2.63 & -0.97 & 0.35 & 0.69 & 0.68 \\
\hline Tangible & 47 & 6 & 176 & 31.68 & 29.26 & 3.39 & 0.35 & 14.07 & 0.68 \\
\hline \multirow[t]{2}{*}{ Total } & & & & 117.3 & 100.0 & & & & \\
\hline & 47 & 25 & 595 & 2 & 6 & 3.27 & 0.35 & 12.96 & 0.68 \\
\hline Total (average) & 47 & 13.15 & 29.50 & 22.83 & 3.73 & -0.64 & 0.35 & 0.45 & 0.68 \\
\hline Total Network & 47 & 11 & 220 & 49.21 & 37.22 & 2.60 & 0.35 & 9.20 & 0.68 \\
\hline
\end{tabular}




\section{Table 4.2}

Descriptive Statistics with Natural Supports

\begin{tabular}{|c|c|c|c|c|c|c|c|c|c|}
\hline \multirow[b]{2}{*}{ Measure } & \multirow[b]{2}{*}{$N$} & \multirow[b]{2}{*}{ Min } & \multirow[b]{2}{*}{ Max } & \multirow[b]{2}{*}{$M$} & \multirow[b]{2}{*}{$S D$} & \multicolumn{2}{|c|}{ Skewness } & \multicolumn{2}{|c|}{ Kurtosis } \\
\hline & & & & & & $\begin{array}{l}\text { Statisti } \\
\text { c }\end{array}$ & $\mathrm{SE}$ & Statistic & $\mathrm{SE}$ \\
\hline Emotional & 47 & 0 & 271 & 68.30 & 48.47 & 1.73 & 0.35 & 5.48 & 0.68 \\
\hline \multicolumn{10}{|l|}{ Emotional } \\
\hline (average) & 47 & 0 & 20 & 14.19 & 4.85 & -1.18 & 0.35 & 1.27 & 0.68 \\
\hline Tangible & 48 & 0 & 176 & 28.80 & 28.53 & 3.39 & 0.34 & 15.22 & 0.67 \\
\hline \multirow[t]{2}{*}{ Total } & & & & 104.1 & & & & & \\
\hline & 48 & 0 & 572 & 0 & 95.12 & 3.08 & 0.34 & 12.81 & 0.67 \\
\hline \multirow[t]{2}{*}{ Total (average) } & & & 29.5 & & & & & & \\
\hline & 48 & 0 & 0 & 19.81 & 6.81 & -1.11 & 0.34 & 1.22 & 0.67 \\
\hline
\end{tabular}


Table 4.3

Descriptive Statistics for Community Participation

\begin{tabular}{|c|c|c|c|c|c|c|c|c|c|}
\hline \multirow{2}{*}{ Measure } & \multirow{2}{*}{$N$} & \multirow{2}{*}{ Min } & \multirow{2}{*}{ Max } & \multirow[t]{2}{*}{$M$} & \multirow{2}{*}{$S D$} & \multicolumn{2}{|c|}{ Skewness } & \multicolumn{2}{|c|}{ Kurtosis } \\
\hline & & & & & & Statistic & SE & Statistic & SE \\
\hline Amount & 48 & 0 & 157 & 50.75 & 35.10 & 0.88 & 0.34 & 0.47 & 0.67 \\
\hline Sufficiency & 48 & 0.14 & 1.00 & 0.57 & 0.25 & -0.14 & 0.35 & -1.07 & 0.68 \\
\hline Breadth & 48 & 0 & 13 & 6.44 & 2.64 & 0.36 & 0.34 & 0.76 & 0.67 \\
\hline
\end{tabular}


Table 4.4

Correlation Matrix of Social Support and Community Participation Variables

\begin{tabular}{|c|c|c|c|c|c|c|}
\hline & $\begin{array}{c}\text { Emotional } \\
\text { (average) }\end{array}$ & Tangible & $\begin{array}{c}\text { Total } \\
\text { (average) }\end{array}$ & Amount & $\begin{array}{c}\text { Sufficienc } \\
\mathrm{y}\end{array}$ & Breadth \\
\hline $\begin{array}{l}\text { Emotional } \\
\text { (average) }\end{array}$ & -- & & & & & \\
\hline Tangible & -0.09 & -- & & & & \\
\hline $\begin{array}{l}\text { Total } \\
\text { (average) }\end{array}$ & $0.86 * *$ & 0.18 & -- & & & \\
\hline Amount & 0.32 & 0.11 & 0.06 & -- & & \\
\hline Sufficiency & -0.11 & 0.24 & 0.09 & $-0.37 *$ & -- & \\
\hline Breadth & 0.06 & 0.05 & 0.03 & $0.62 * *$ & 0.25 & -- \\
\hline
\end{tabular}

Note. Pearson correlations were utilized for all variables except for tangible support. Spearman correlations were used for tangible support.

$* * p<.01$, two-tailed. 
Table 4.5

Average Emotional Support by Source

\begin{tabular}{llll}
\hline Source & $M$ & $S D$ & $n$ \\
\hline Spouse or partner & 18.64 & 2.06 & 11 \\
Pets & 18.15 & 3.34 & 13 \\
Friends & 17.53 & 2.64 & 21 \\
Religious leaders & 17.50 & 3.54 & 2 \\
Healthcare providers & 17.17 & 2.57 & 9 \\
Counselor or therapist & 16.93 & 2.61 & 9 \\
Family or relatives & 16.58 & 3.14 & 38 \\
Work or school associates & 15.00 & 5.00 & 3 \\
Other & 14.75 & 6.13 & 4 \\
Neighbors & 14.30 & 4.03 & 11 \\
\hline
\end{tabular}


Table 4.6

Tangible Support by Source

\begin{tabular}{llll}
\hline Source & $M$ & $S D$ & $n$ \\
\hline Family or relatives & 12.00 & 9.90 & 92 \\
Friends & 7.23 & 14.07 & 52 \\
Neighbors & 4.56 & 10.92 & 33 \\
Spouse or partner & 2.02 & 3.83 & 11 \\
Pets & 1.85 & 4.28 & 17 \\
Healthcare providers & 1.02 & 2.65 & 11 \\
Counselor or therapist & 0.92 & 3.06 & 12 \\
Other & 0.67 & 2.60 & 6 \\
Work or school associates & 0.35 & 1.91 & 3 \\
Religious leaders & 0.29 & 1.47 & 2 \\
\hline
\end{tabular}




\section{Table 4.7}

Average Total Support by Source

\begin{tabular}{llll}
\hline Source & $M$ & $S D$ & $n$ \\
\hline Spouse or partner & 27.45 & 2.97 & 11 \\
Religious leader & 24.50 & 6.36 & 2 \\
Friends & 24.22 & 4.46 & 21 \\
Pets & 23.12 & 4.59 & 13 \\
Family or relatives & 23.04 & 3.91 & 38 \\
Healthcare providers & 21.78 & 4.99 & 9 \\
Neighbors & 21.35 & 5.65 & 12 \\
Other & 20.37 & 9.14 & 4 \\
Counselor or therapist & 20.11 & 3.98 & 9 \\
Work or school associates & 18.50 & 5.63 & 3 \\
\hline
\end{tabular}


Table 4.8

Correlation Matrix for Natural Supports

\begin{tabular}{|c|c|c|c|c|c|c|}
\hline & $\begin{array}{c}\text { Emotional } \\
\text { (average) }\end{array}$ & Tangible & $\begin{array}{c}\text { Total } \\
\text { (average) }\end{array}$ & Amount & $\begin{array}{c}\text { Sufficienc } \\
\mathrm{y}\end{array}$ & Breadth \\
\hline $\begin{array}{l}\text { Emotional } \\
\text { (average) }\end{array}$ & -- & & & & & \\
\hline Tangible & 0.29 & -- & & & & \\
\hline $\begin{array}{l}\text { Total } \\
\text { (average) }\end{array}$ & $0.97 * *$ & $0.40 * *$ & -- & & & \\
\hline Amount & 0.29 & 0.19 & $0.29 *$ & -- & & \\
\hline Sufficiency & -0.11 & 0.16 & -0.08 & $-0.37 *$ & -- & \\
\hline Breadth & 0.27 & 0.09 & 0.25 & $0.62 * *$ & -0.25 & -- \\
\hline
\end{tabular}

Note. Pearson correlations were utilized for all variable except for tangible support. Spearman correlations were used for tangible support.

$* * p<.01$, two-tailed.

$* p<.05$, two-tailed. 
Table 4.9

Participation Areas with Natural Supports

\begin{tabular}{llllll}
\hline Area & $N$ & Min & Max & $M$ & $S D$ \\
\hline Employment & 31 & 0.92 & 5 & 2.86 & 1.40 \\
Education & 30 & 0.33 & 5 & 3.10 & 1.41 \\
Relationships & 33 & 0.50 & 5 & 2.86 & 1.20 \\
Parenting & 16 & 0.75 & 5 & 3.15 & 1.29 \\
Leisure & 44 & 0.50 & 5 & 3.13 & 138 \\
\hline
\end{tabular}




\section{Figure 4.1}

Frequencies of sources of support reported by participants

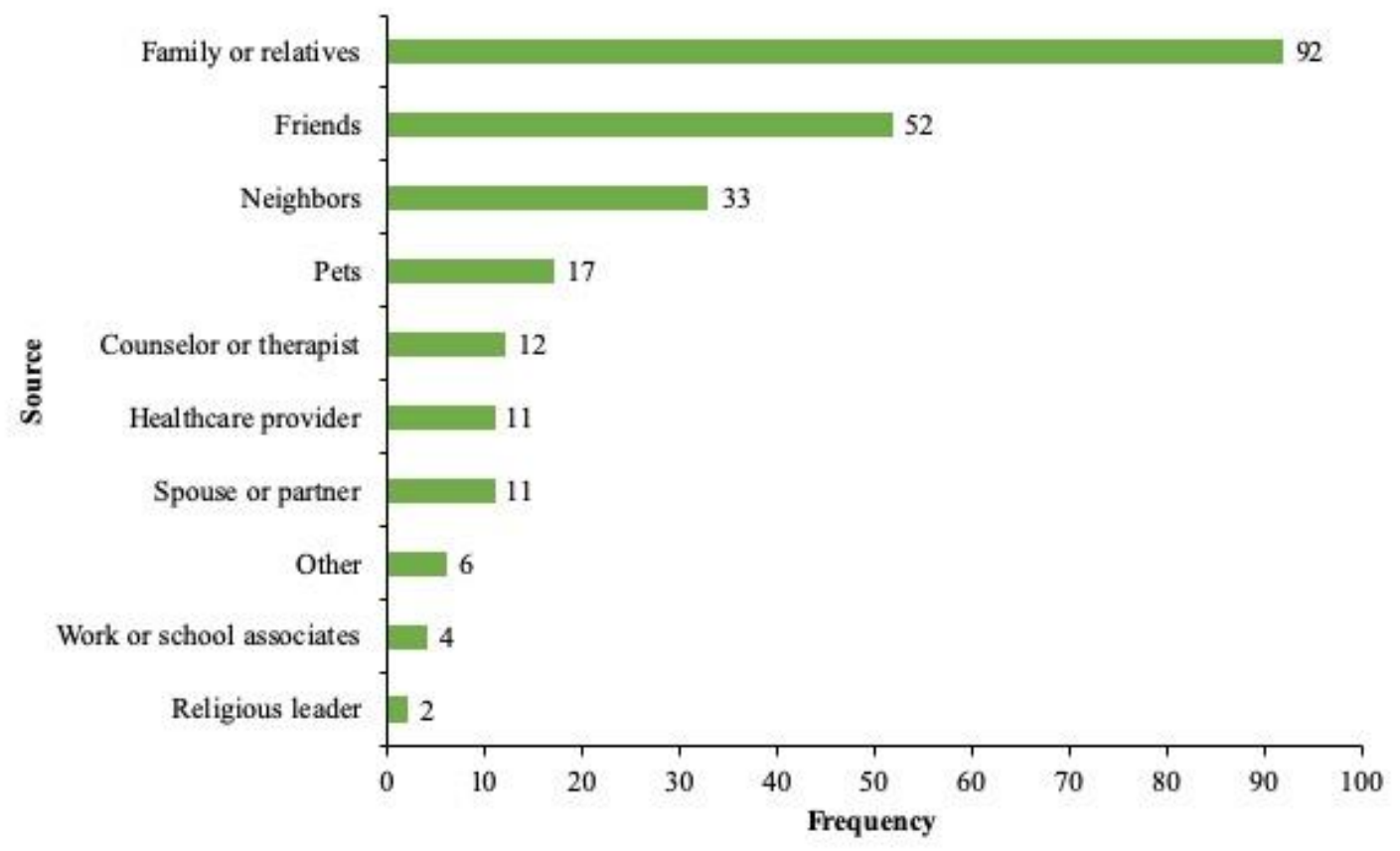

Note. Participants reported a total of 240 sources of support. 


\section{Figure 4.2}

Number of participants who reported at least one individual in a given support category

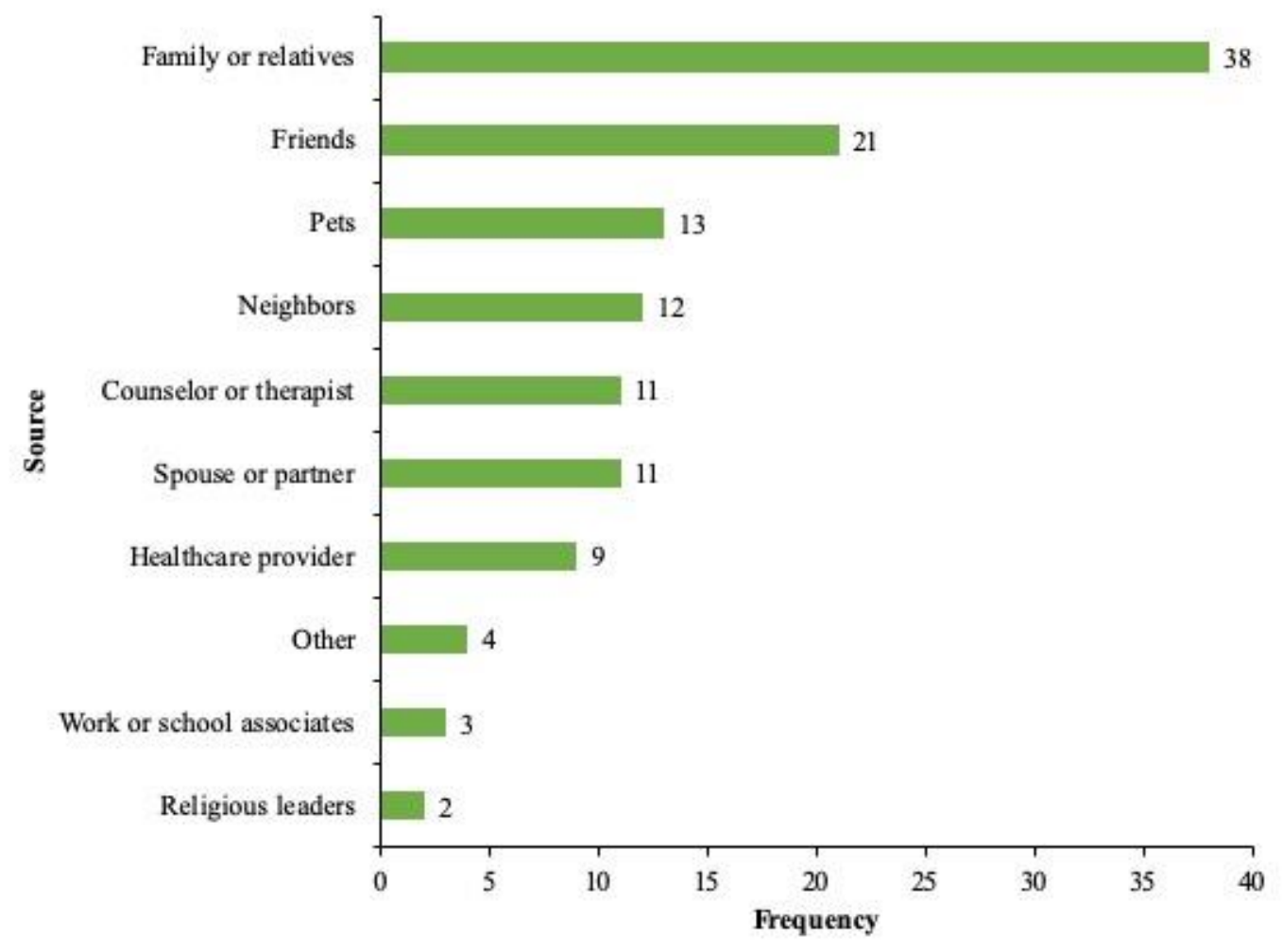

Note.

$N=48$. 


\section{References}

Abdallah, C., Cohen, C. I., Sanchez-Almira, M., Reyes, P., \& Ramirez, P. (2009).

Community integration and associated factors among older adults with schizophrenia. Psychiatric Services, 60(12), 16-64. Retrieved from https://ps.psychiatryonline.org/doi/pdf/10.1176/ps.2009.60.12.1642

Anthony, W. A., \& Blanch, A. (1987). Supported employment for persons who are psychiatrically disabled: An historical and conceptual perspective. Psychosocial Rehabilitation Journal, 11(2), 5-23. Retrieved from https://search-proquestcom.proxy.lib.pdx.edu/docview/1504152173/fulltextPDF/B9256567386A43DFPQ/1 ?accountid=13265

Anthony, W, Rogers, E., \& Farkas, M. (2003). Research on evidence-based practices: Future directions in an era of recovery. Community Mental Health Journal. Retrieved from http://link.springer.com/article/10.1023/A:1022601619482

Anthony, WA. (1993). Recovery from mental illness: The guiding vision of the mental health service system in the 1990s. Psychosocial Rehabilitation Journal, 16(4), 521538. Retrieved from http://psycnet.apa.org/journals/prj/16/4/11/

Anthony, WA. (2000). A recovery-oriented service system: Setting some system level standards. Psychiatric Rehabilitation Journal, 24(2), 159-168. Retrieved from http://psycnet.apa.org/journals/prj/24/2/159/

Aubry, T., \& Myner, J. (1996). Community integration and quality of life: A comparison of persons with psychiatric disabilities in housing programs and community residents who are neighbours. Canadian Journal of Community Mental Health, 
15(1), 5-20. https://doi.org/10.7870/cjcmh-1996-0001

Badger, T. A., McNiece, C., Bonham, E., Jacobson, J., \& Gelenberg, A. J. (2003). Health outcomes for people with serious mental illness: A case study. Perspectives in Psychiatric Care, 39(1), 23-32. https://doi.org/10.1111/j.1744-6163.2003.tb00670.x

Balcazar, F. E., Taylor, R. R., Keilhorner, G. W., Tamley, K., Benziger, T., Carlin, N., \& Johnson, S. (2004). Participatory action research: General principles and a study with a chronic health condition. In In L.A. Jason, C.B. Keys, Y.S. Suarez-Balcazar, R.R. Taylor, \& M.I. Davis (Eds). Participatory Community Research: Theories and Methods in Action. (pp. 17-35). Washington D.C.: American Psychological Association.

Banks, B., Charleston, T. G., \& Mank, D. (2001). Workplace supports, job performance, and intergration outcomes for people with psychiatric disabilities. Psychiatric Rehabilitation Journal, 24(4), 389-396. Retrieved from https://search-proquestcom.proxy.lib.pdx.edu/docview/1347253418/fulltextPDF/6D9724A99D184D76PQ/ 1 ? accountid $=13265$

Basset, T., Faulkner, A., Repper, J., \& Stamou, E. (2010). Lived Experience Leading The Way Peer Support in Mental Health. Nottingham.

Beal, G. (1999). The constitution of community: How individuals diagnosed with schizophrenia and their friends achieved community. Psychiatry, 62(2), 173-186. https://doi.org/10.1080/00332747.1999.11024863

Beal, G., Veldhorst, G., McGrath, J.-L., Guruge, S., Grewal, P., DiNunzio, R., \& Trimnell, J. (2005). Constituting community: Creating a place for oneself. 
Psychiatry, 68(3), 199-211. https://doi.org/10.1521/psyc.2005.68.3.199

Beels, C. C. (1981). Social support and schizophrenia. Schizophrenia Bulletin, 7(1), 5872. https://doi.org/10.1093/schbul/7.1.58

Berkman, L., Glass, T., Brissette, I., \& Seeman, T. (2000). From social integration to health: Durkheim in the new millennium. Social Science \& Medicine, 51(6), 843857. Retrieved from https://scholar.google.com/citations?view_op=view_citation\&continue=/scholar\%3 Fhl\%3Den\%26as_sdt\%3D0,38\%26authuser\%3D1\%26scilib\%3D1\&citilm=1\&citati on_for_view=Xac0OKUAAAAJ:hC7cP41nSMkC\&hl=en\&authuser=1\&oi=p

Blazer, D. G. (1982). Social support in an elderly community population. American Journal of Epidemiology, 115(5), 684-694. https://doi.org/10.1093/oxfordjournals.aje.a113351

Bond, G. R., Salyers, M. P., Rollins, A. L., Rapp, C. A., \& Zipple, A. M. (2004). How evidence-based practices contribute to community integration. Community Mental Health Journal, 40(6), 569-588. https://doi.org/10.1007/s10597-004-6130-8

Bradshaw, W., Armour, M. P., \& Roseborough, D. (2007). Finding a place in the world: The experience of recovery from severe mental illness. Qualitative Social Work, 6(1), 27-47. https://doi.org/10.1177/1473325007074164

Braun, V., \& Clarke, V. (2006). Using thematic analysis in psychology. Qualitative Research in Psychology, 3(2), 77-101. Retrieved from http://eprints.uwe.ac.uk/11735/2/thematic_analysis_revised_-_final.pdf Brusilovskiy, E., Townley, G., Snethen, G., \& Salzer, M. S. (2016). Social media use, 
community participation and psychological well-being among individuals with serious mental illnesses. Computers in Human Behavior, 65, 232-240. https://doi.org/10.1016/j.chb.2016.08.036

Burns-Lynch, W., Brusilovskiy, E., \& Salzer, M. S. (2016). An empirical study of the relationship between community participation, recovery, and quality of life of individuals with serious mental illnesses. Israel Journal of Psychiatry, 53(1), 46-55. Retrieved from https://cdn.doctorsonly.co.il/2016/08/09_Burns-Lynch_AnEmpirical-Study.pdf

Carling, P.J. (1995). Return to Community: Building Support Systems for People with Psychiatric Disabilities. Guilford Press.

Carling, Paul J. (1990). Major mental illness, housing, and supports: The promise of community integration. American Psychologist, 45(8), 969-975. https://doi.org/10.1037/0003-066X.45.8.969

Chavis, D. M., \& Wandersman, A. (1990). Sense of community in the urban environment: A catalyst for participation and community development. American Journal of Community Psychology, 18(1), 55-81. https://doi.org/10.1007/BF00922689

Chen, F.-P. (2010). Assisting adults with severe mental illness in transitioning from parental homes to independent living. Community Mental Health Journal, 46, 372380. https://doi.org/10.1007/s10597-009-9263-y

Cobb, S. (1976). Social support as a moderator of life stress. Psychosomatic Medicine, 38(5), 300-314. Retrieved from 
https://pdfs.semanticscholar.org/10ec/c3df00f4472cbdfc5509c77d43ecc85193da.pdf

Cohen, C. I., \& Sokolovsky, J. (1978). Schizophrenia and social networks: Ex-patients in the inner city. Schizophrenia Bulletin, 4(4), 546-560.

Cohen, S., \& Wills, T. A. (1985). Stress, social support, and the buffering hypothesis. Psychological Bulletin, 98(2), 310-357.

Cook, J. A., Lehman, A. F., Drake, R., McFarlane, W. R., Gold, P. B., Leff, H. S., ... Grey, D. D. (2005). Integration of psychiatric and vocational services: A multisite randomized, controlled trial of supported employment. American Journal of Psychiatry, 162(10), 1948-1956. https://doi.org/10.1176/appi.ajp.162.10.1948

Corin, E., \& Lauzon, G. (1992). Positive withdrawal and the quest for meaning: The reconstruction of experience among schizophrenics. Psychiatry, 55(3), 266-278. https://doi.org/10.1080/00332747.1992.11024600

Corrigan, P. W., \& Phelan, S. M. (2004). Social support and recovery in people with serious mental illnesses. Community Mental Health Journal, 40(6), 513-523. https://doi.org/10.1007/s10597-004-6125-5

Corrigan, P. W., \& Watson, Amy, C. (2002). Understanding the impact of stigma on people with mental illness. World Psychiatry. Retrieved from https://www.ncbi.nlm.nih.gov/pmc/articles/PMC1489832/pdf/wpa010016.pdf

Cummings, S. M., \& Kropf, N. P. (2009). Formal and informal support for older adults with severe mental illness. Aging \& Mental Health, 13(4), 619-627. https://doi.org/10.1080/13607860902774451

Cummins, R., \& Lau, A. (2003). Community integration or community exposure? A 
review and discussion in relation to people with an intellectual disability. Journal of Applied Research in .... Retrieved from

http://onlinelibrary.wiley.com/doi/10.1046/j.1468-3148.2003.00157.x/full

Davidson, L. (2005). More fundamentally human than otherwise. Psychiatry, 68(3), 243249. Retrieved from http://web.a.ebscohost.com.proxy.lib.pdx.edu/ehost/pdfviewer/pdfviewer?vid=1\&si d=7fbff5cb-6651-40cb-9347-1a279950de49\%40sessionmgr4010

Davidson, L., Bellamy, C., Guy, K., \& Miller, R. (2012). Peer support among persons with severe mental illnesses: A review of evidence and experience. World Psychiatry, 11(2), 123-128. https://doi.org/10.1016/j.wpsyc.2012.05.009

Davidson, L., Chinman, M., Kloos, B., Weingarten, R., Stayner, D., \& Tebes, J. K. (1999). Peer support among individuals with severe mental illness: A review of the evidence. Clinical Psychology: Science and Practice, 6(2), 165-187. Retrieved from https://s3.amazonaws.com/academia.edu.documents/44465989/Peer_Support_Amon g_Individuals_With_Seve20160406-203791e7a6po.pdf?AWSAccessKeyId=AKIAIWOWYYGZ2Y53UL3A\&Expires=152286 8305\&Signature=StSN5GLL8oFZUnq Y1pI\%2B VZzqNQg\%3D\&response-contentdisposition=inli

Davidson, L., Haglund, K. E., Stayner, D. A., Rakfeldt, J., Chinman, M. J., \& Kraemer Tebes, J. (2001). “It was just realizing...that life isn't one big horror”: A qualitative study of supported socialization. Psychiatric Rehabilitation Journal, 24(3), 275292. https://doi.org/10.1037/h0095084 
Davidson, L., \& McGlashan, T. H. (1997). The varied outcomes of schizophrenia. The Canadian Journal of Psychiatry, 42(1), 34-43. https://doi.org/10.1177/070674379704200105

Davidson, L., O’Connell, M., Tondora, J., Styron, T., \& Kangas, K. (2006). The top ten concerns about recovery encountered in mental health system transformation. Psychiatric Services, 57(5), 640-645. https://doi.org/10.1176/ps.2006.57.5.640

Davidson, L., Stayner, D. A., Nickou, C., Styron, T. H., Rowe, M., \& Chinman, M. L. (2001). "Simply to be let in": Inclusion as a basis for recovery. Psychiatric Rehabilitation Journal, 24(4), 375-388. Retrieved from https://search-proquestcom.proxy.lib.pdx.edu/docview/1347253334/fulltextPDF/7D1D6248E6BA4C57PQ/ 1 ?accountid=13265

Dewees, M., Pulice, R., \& McCormick, L. (1996). Community integration of former state hospital patients: Outcomes of a policy shift in Vermont. Psychiatric Services. Retrieved from http://psycnet.apa.org/psycinfo/1996-06687-006

Drake, R. E., McHugo, G. J., Bebout, R. R., Becker, D. R., Harris, M., Bond, G. R., \& Quimby, E. (1999). A randomized clinical trial of supported employment for innercity patients with severe mental disorders. Archives of General Psychiatry, 56(7), 627. https://doi.org/10.1001/archpsyc.56.7.627

Drake, R. E., McHugo, G. J., Becker, D. R., \& Clark, R. E. (1996). The New Hampshire study of supported employment for people with severe mental illness. Journal of Consulting and Clinical Psychology, 64(2), 391-399. Retrieved from https://search.proquest.com/docview/614315911/fulltextPDF/E30068843D5247E6P 
Q/1?accountid=13265

Farkas, M., Gagne, C., Anthony, W., \& Chamberlin, J. (2005). Implementing recovery oriented evidence based programs: Identifying the critical dimensions. Community Mental Health Journal, 41(2), 141-158. Retrieved from http://link.springer.com/article/10.1007/s10597-005-2649-6

Felton, B., \& Shinn, M. (1992). Social integration and social support: Moving "Social Support" beyond the individual level. Journal of Community Psychology, 20(2), 103-115. Retrieved from http://web.a.ebscohost.com.proxy.lib.pdx.edu/ehost/pdfviewer/pdfviewer?vid=1\&si d=3dd58681-b925-473c-b885-7853d92e1ee8\%40sessionmgr4010

Gold, P. B., Meisler, N., Santos, A. B., Carnemolla, M. A., Williams, O. H., \& Keleher, J. (2006). Randomized trial of supported employment integrated with assertive community treatment for rural adults with severe mental illness. Schizophrenia Bulletin, 32(2), 378-395. https://doi.org/10.1093/schbul/sbi056

Granerud, A., \& Severinsson, E. (2006). The struggle for social integration in the community - the experiences of people with mental health problems. Journal of Psychiatric and Mental Health Nursing, 13(3), 288-293. https://doi.org/10.1111/j.1365-2850.2006.00950.x

Greene, J. C., \& Caracelli, V. J. (1997). Defining and describing the paradigm issue in mixed-method evaluation. New Directions for Evaluation, 1997(74), 5-17. https://doi.org/10.1002/EV.1068

Greene, J. C., Caracelli, V. J., \& Graham, W. F. (1989). Toward a conceptual framework 
for mixed-method evaluation designs. Educational Evaluation and Policy Analysis Fall, 11(3), 255-274. Retrieved from https://journals.sagepub.com/doi/pdf/10.3102/01623737011003255?casa_token=g6 Q7jY9QNqAAAAAA:xGL3SSFuvWRGnE3zgkhd8EQZGKcH5gNqnnb3LHJY4Z_O3JfyULT57YmYaoIncpAnInATVhVNO2e

Hammer, M. (1981). Social supports, social networks, and schizophrenia. Schizophrenia Bulletin, 7(1), 45-57.

Harding, C. M., Zubin, J., \& Strauss, J. S. (1987). Chronicity in schizophrenia: Fact, partial fact, or artifact? Psychiatric Services, 38(5), 477-486. https://doi.org/10.1176/ps.38.5.477

Harding, C., \& Zahniser, J. (1994). Empirical correction of seven myths about schizophrenia with implications for treatment. Acta Psychiatrica Scandinavica, 90, 140-146. Retrieved from http://www.psychodyssey.net/wpcontent/uploads/2012/05/Empirical-correction.pdf

Hawkley, L. C., \& Cacioppo, J. T. (2010). Loneliness matters: A theoretical and empirical review of consequences and mechanisms. Annals of Behavioral Medicine : A Publication of the Society of Behavioral Medicine, 40(2), 218-227. https://doi.org/10.1007/s12160-010-9210-8

Headey, B. (2003). Pet ownership: Good for health? Medical Journal of Australia, 179(9), 460-461. Retrieved from www.mja.com.au

Heaney, Catherine, A., \& Israel, Barbara, A. (2008). Social networks and social support. In K. Glanz, B. K. Rimer, \& K. Viswanath (Eds.), Health behavior and health 
education: Theory, research, and practice (4th ed., pp. 189-210). San Francisco: Jossey-Bass. Retrieved from http://iums.ac.ir/files/hshesoh/files/beeduhe_0787996149(1).pdf\#page=227

Hendryx, M., Green, C. A., \& Perrin, N. A. (2009). Social support, activities, and recovery from serious mental illness: STARS study findings. The Journal of Behavioral Health Services \& Research, 36(3), 320-329. Retrieved from https://link.springer.com/content/pdf/10.1007\%2Fs11414-008-9151-1.pdf Hennings, B. A. (1999). Are consumers going to the dogs (and cats and birds)? New Directions for Mental Health Services, 1999(83), 45-49. https://doi.org/10.1002/yd.23319998307

Hesse-Biber, S., \& Leavy, P. (2010). The Practice of Qualitative Research. Sage. Retrieved from https://scholar.google.com/scholar?hl=en\&as_sdt=0\%2C38\&q=the+practice+of $+q u$ alitative+research+hesse+biber\&btnG=

Horwitz, A. V, Reinhard, S. C., \& Howell, S. (1996). Caregiving as reciprocal exchange in families with seriously mentally ill members. Journal of Health and Social Behavior, 37(37), 149-162. Retrieved from http://www.jstor.org/stable/2137270 House, J. S. (1981). Work stress and social support. Reading, Mass.: Addison-Wesley. Israel, B. A., Farquhar, S. A., Schulz, A. J., James, S. A., \& Parker, E. A. (2002). The relationship between social support, stress, and health among women on Detroit's east side. Health Education \& Behavior, 29(3), 342-360. https://doi.org/10.1177/109019810202900306 
Jones, D. R., Macias, C., Barreira, P. J., Fisher, W. H., Hargreaves, W. A., \& Harding, C. M. (2004). Prevalence, severity, and co-occurrence of chronic physical health problems of persons with serious mental illness. Psychiatric Services, 55(11), 12501257. Retrieved from http://ps.psychiatryonline.org/doi/abs/10.1176/appi.ps.55.11.1250

Kaplan, K., Salzer, M. S., \& Brusilovskiy, E. (2012). Community participation as a predictor of recovery-oriented outcomes among emerging and mature adults with mental illnesses. Psychiatric Rehabilitation Journal, 35(3), 219-229. https://doi.org/10.2975/35.3.2012.219.229

Kaplan, K., Salzer, M. S., Solomon, P., Brusilovskiy, E., \& Cousounis, P. (2011). Internet peer support for individuals with psychiatric disabilities: A randomized controlled trial. Social Science \& Medicine, 72(1), 54-62. https://doi.org/10.1016/J.SOCSCIMED.2010.09.037

Kawachi, I., \& Berkman, L. F. (2001). Social ties and mental health. Journal of Urban Health: Bulletin of the New York Academy of Medicine, 78(3). Retrieved from https://link.springer.com/content/pdf/10.1093/jurban/78.3.458.pdf

Kennedy, C. (1989). Community integration and well-being: Toward the goals of community care. Journal of Social Issues, 45(3), 65-77. https://doi.org/10.1111/j.1540-4560.1989.tb01555.x

Kline, R. B. (2015). The mediation myth. Basic and Applied Social Psychology, 37(4), 202-213. https://doi.org/10.1080/01973533.2015.1049349

Kloos, B, \& Townley, G. (2011). Investigating the relationship between neighborhood 
experiences and psychiatric distress for individuals with serious mental illness. Administration and Policy in Mental Health and Mental Health Services Research, 38(2), 105-116. Retrieved from http://link.springer.com/article/10.1007/s10488010-0307-y

Kloos, Bret, Zimmerman, S. O., Scrimenti, K., \& Crusto, C. (2002). Landlords as partners for promoting success in supported housing: "It takes more than a lease and a key." Psychiatric Rehabilitation Journal, 25(3), 235-244. Retrieved from https://search-proquestcom.proxy.lib.pdx.edu/docview/1347253476/fulltextPDF/C3191BE677FD44FEPQ/ 1 ?accountid $=13265$

Kostanjsek, N. (2011). Use of The International Classification of Functioning, Disability, and Health (ICF) as a conceptual framework and common language for disability statistics and health information systems. BMC Public Health, 11(4). https://doi.org/10.1186/1471-2458-11-S4-S3

Kraut, R., Kiesler, S., Boneva, B., Cummings, J., Helgeson, V., \& Crawford, A. (2002). Internet paradox revisited. Journal of Social Issues, 58(1), 49-74. https://doi.org/10.1111/1540-4560.00248

Kraut, R., Patterson, M., Lundmark, V., Kiesler, S., Mukophadhyay, T., \& Scherlis, W. (1998). Internet paradox: A social technology that reduces social involvement and psychological well-being? American Psychologist , 53(9). Retrieved from https://scholar.google.com/citations?user=HKGYvu4AAAAJ\&hl=en\&oi=sra\#d=gs_ md_cita- 
$\mathrm{d} \& \mathrm{u}=\% 2$ Fcitations\%3Fview_op\%3Dview_citation\%26hl\%3Den\%26user\%3DHKG Yvu4AAAAJ\%26citation_for_view\%3DHKGYvu4AAAAJ\%3Au5HHmVD_uO8C $\% 26$ tzom\%3D420

Kruzich, J. M. (1985). Community integration of the mentally iII in residential facilities. American Journal of Community Psychology, 13(5), 553-564. Retrieved from https://s3.amazonaws.com/academia.edu.documents/46229950/bf009232672016060 4-11909ii3rjn.pdf?AWSAccessKeyId=AKIAIWOWYYGZ2Y53UL3A\&Expires=15196981 04\&Signature=yW076Wtoz8UW\%2FfN7spiCyZHFDig\%3D\&response-contentdisposition=inline \%3B filename\%3DCommunity_in

Langford, C. P. H., Bowsher, J., Maloney, J. P., \& Lillis, P. P. (1997). Social support: A conceptual analysis. Journal of Advanced Nursing, 25(1), 95-100. https://doi.org/10.1046/j.1365-2648.1997.1997025095.x

Leavy, R. L. (1983). Social support and psychological disorder: A review. Journal of Community Psychology, 11(1), 3-21. https://doi.org/10.1002/15206629(198301)11:1<3::AID-JCOP2290110102>3.0.CO;2-E

Lester, H., \& Gask, L. (2006). Delivering medical care for patients with serious mental illness or promoting a collaborative model of recovery? British Journal of Psychiatry, 188(5), 401-402. Retrieved from http://www.improvingchroniccare. Machin, K., \& Repper, J. (2013). Recovery: a carer's perspective. Retrieved from http://citeseerx.ist.psu.edu/viewdoc/download?doi=10.1.1.688.2639\&rep=rep1\&typ $e=p d f$ 
Maton, K. I., Teti, D. M., Corns, K. M., Vieira-Baker, C. C., Seattle, J. R. L., Karen, W., ... Keating, D. P. (1996). Cultural specificity of support sources, correlates and contexts: Three studies of African-American and Caucasian youth. American Journal of Community Psychology, 24(4), 551-587. Retrieved from https://s3.amazonaws.com/academia.edu.documents/46431330/bf025067962016061 2-12045-

18yxc6f.pdf?AWSAccessKeyId=AKIAIWOWYYGZ2Y53UL3A\&Expires $=155772$ 2849\&Signature=fpj\%2FV\%2B6wFScZFKIRrXYUFWSv52I\%3D\&responsecontent-disposition=inline $\% 3 \mathrm{~B}$ filename\%3DCultural_

Mattsson, M., Topor, A., Cullberg, J., \& Forsell, Y. (2008). Association between financial strain, social network and five-year recovery from first episode psychosis. Social Psychiatry and Psychiatric Epidemiology, 43(12), 947-952. https://doi.org/10.1007/s00127-008-0392-3

McColl, M. A., Davies, D., Carlson, P., Johnston, J., \& Minnes, P. (2001). The community integration measure: Development and preliminary validation. Archives of Physical Medicine and Rehabilitation, 82(4), 429-434. https://doi.org/10.1053/apmr.2001.22195

Mccorkle, B. H., Dunn, E. C., Mui Wan, Y., \& Gagne, C. (2009). People with Serious Mental Illness Compeer Friends: a Qualitative Study of a Volunteer Friendship Programme for. International Journal of Social Psychiatry, 55(291), 291-305. https://doi.org/10.1177/0020764008097090

Mccorkle, B. H., Sally, A. E., Ae, R., Dunn, E. C., Lyass, A., Yu, A., \& Wan, M. (2008). 
Increasing social support for individuals with serious mental illness: Evaluating the compeer model of intentional friendship. Community Mental Health Journal, 44(5), 359. https://doi.org/10.1007/s10597-008-9137-8

McFarlane, W. R., Dushay, R. A., Deakins, S. M., Stastny, P., Lukens, E. P., Toran, J. W., \& Link, B. (2000). Employment outcomes in family-aided assertive community treatment. American Journal of Orthopsychiatry, 70(2), 203-214. Retrieved from https://search.proquest.com/docview/1038624044/fulltextPDF/A54A0F5C7E1742A EPQ/1?accountid=13265

McMillan, D., \& Chavis, D. (1986). Sense of community: A definition and theory. Journal of Community Psychology, 14(1), 6-23. Retrieved from http://mc7290.bgsu.wikispaces.net/file/view/McMillan_1986.pdf

Mechanic, D., \& Rochefort, D. A. (1990). Deinstitutionalization: An appraisal of reform. Annual Review of Sociology, 16, 301-328. Retrieved from https://about.jstor.org/terms

Morgan, D. L. (1998). Practical strategies for combining qualitative and quantitative methods: Applications for health research. Qualitative Health Research, 3, 362-376. Retrieved from https://journals-sagepubcom.proxy.lib.pdx.edu/doi/pdf/10.1177/104973239800800307

Naslund, J. A., Grande, S. W., Aschbrenner, K. A., \& Elwyn, G. (2014). Naturally occurring peer support through social media: The experiences of individuals with severe mental illness using YouTube. PLoS ONE, 9(10), 1-9. https://doi.org/10.1371/journal.pone.0110171 
Nations, U. (2006). United Nations convention on the rights of persons with disabilities. Retrieved from http://www.un.org/esa/socdev/enable/rights/convtexte.htm

Nelson, G, Lord, J., \& Ochocka, J. (2001). Empowerment and mental health in community: Narratives of psychiatric consumer/survivors. Journal of Community \& Applied Social Psychology. Retrieved from http://onlinelibrary.wiley.com/doi/10.1002/casp.619/full

Nelson, Geoffrey, Ochocka, J., Janzen, R., Trainor, J., Goering, P., \& Lomotey, J. (2007). A longitudinal study of mental health consumer/survivor initiatives: Part Voutcomes at 3-year follow-up. Journal of Community Psychology, 35(5), 655-665. https://doi.org/10.1002/jcop.20171

Norbeck, J. S., Lindsey, A. M., \& Carrieri, V. L. (1981). The development of an instrument to measure social support. Nursing Research, 30(5), 264-269. https://doi.org/10.1097/00006199-198109000-00003

Norbeck, J. S., Lindsey, A. M., \& Carrieri, V. L. (1983). Further development of the norbeck social support questionnaire. Nursing Research, 32(1), 4-9. https://doi.org/10.1097/00006199-198301000-00002

Organization, W. H. (2001). International classification of functioning, disability and health: ICF.

Orth-Gomér, K., \& Johnson, J. V. (1987). Social network interaction and mortality. Journal of Chronic Diseases, 40(10), 949-957. https://doi.org/10.1016/00219681(87)90145-7

Perkins, D. D., Florin, P., Rich, R. C., Wandersman, A., \& Chavis, D. M. (1990). 
Participation and the social and physical environment of residential blocks: Crime and community context. American Journal of Community Psychology, 18(1), 83115. https://doi.org/10.1007/BF00922690

Pinfold, V. (2000). "Building up safe havens all around the world”: Users' experiences of living in the community with mental health problems. Health \& Place, 6, 201-212. Retrieved from http://www.sciencedirect.com/science/article/pii/S135382920000023X

Prince, P. N., \& Gerber, G. J. (2005). Subjective well-being and community integration among clients of assertive community treatment. Quality of Life Research, 14(1), 161-169. https://doi.org/10.1007/s11136-004-2407-1

Reevy, G.M., \& Maslach, C. (2001). Use of social support: Gender and personality differences. Sex Roles, 44(7-8), 437-459,

Robson, D., \& Gray, R. (2007). Serious mental illness and physical health problems: A discussion paper. International Journal of Nursing Studies, 44(3), 457-466.

Retrieved from https://www.sciencedirect.com/science/article/pii/S0020748906002306

Royce-Davis, J. C. (2001). "It's the Day-to-Day Living That Matters": The meaning and process of community in the lives of a couple with significant psychiatric disabilities. American Journal of Community Psychology, 29(6), 807-832. Retrieved from https://link.springer.com/content/pdf/10.1023/A:1012957014209.pdf

Ryan, G. W., Health, R., \& Russell Bernard, H. (2003). Techniques to identify themes. Field Methods, 15(1), 85-109. https://doi.org/10.1177/1525822X02239569 
Salzer, M., \& Baron, R. (2016). Well Together - A blueprint for community inclusion: fundamental concepts, theoretical frameworks and evidence. Retrieved from http://www.tucollaborative.org/sdm_downloads/well-together/

Salzer, M. S., Brusilovskiy, E., Prvu-Bettger, J., \& Kottsieper, P. (2014). Measuring community participation of adults with psychiatric disabilities: Reliability of two modes of data collection. Rehabilitation Psychology, 59(2), 211.

Salzer, M. S., Kottsieper, P., \& Brusilovskiy, E. (2015). Intermethod reliability and factors affecting recall with the Temple University Community Participation measure. Journal of Mental Health, 24(4), 189-195. https://doi.org/10.3109/09638237.2015.1036976

Sarason, S.B. (1974). The Psychological Sense of Community: Prospects for a Community Psychology. San Francisco: Jossey-Bass.

Sarason, Seymour B. (1976). Community psychology, networks, and Mr. Everyman. American Psychologist, 31(5), 317-328. Retrieved from https://search-proquestcom.proxy.lib.pdx.edu/docview/614296588/fulltextPDF/568EC550B2564325PQ/1? accountid=13265

Sarason, I.G., Levine, H.M., Basham, R.B., \& Sarason, B. R. (1983). Assessing social support: The Social Support Questionnaire. Journal of Personality and Social Psychology, 44(1), 127-139.

Schwarzer, R. \& Leppin, A. (1989). Social support and health: A meta-analysis. Psychology and Health, 3(1), 1-15.

Seeman, T. (1996). Social ties and health: The benefits of social integration. Annals of 
Epidemiology, 6(5), 442-451. Retrieved from

https://scholar.google.com/citations?view_op=view_citation\&continue=/scholar\%3

Fh1\%3Den\%26as_sdt\%3D0,38\%26authuser\%3D1\%26scilib\%3D1\&citilm=1\&citati

on_for_view=Xac0OKUAAAAJ:qUcmZB5y_30C\&hl=en\&authuser=1\&oi=p

Segal, S. P., \& Aviram, U. (1978). The Mentally Ill in Community-Based Sheltered Care.

Segal, S. P., Silverman, C. J., \& Temkin, T. L. (2014). Self-help and community mental health agency outcomes: A recovery-focused randomized controlled trial.

Psychiatric Services, 61(9), 905-910. https://doi.org/10.1176/ps.2010.61.9.905

Shinn, M., Lehmann, S., \& Wong, N. W. (1984). Social interaction and social support.

Journal of Social Issues, 40(4), 55-76. https://doi.org/10.1111/j.1540-

4560.1984.tb01107.x

Shumaker, S. A., \& Brownell, A. (1984). Toward a Theory of Social Support: Closing Conceptual Gaps. Journal of Social Issues (Vol. 40). Retrieved from https://pdfs.semanticscholar.org/fc41/ef531e881f3ea80266ab0dc7b7c47e5861e7.pdf

Stanard, R. P. (1999). The effect of training in a strengths model of case management on client outcomes in a community mental health center. Community Mental Health Journal, 35(2), 169-179. Retrieved from https://link.springer.com/content/pdf/10.1023/A:1018724831815.pdf

Stroul, B. A. (1989). Community support systems for persons with long-term mental illness: A conceptual framework. Psychosocial Rehabilitation Journal, 12(3), 9-26. Retrieved from https://search.proquest.com/docview/1504156855/fulltextPDF/945EB09D367B452F 
$\mathrm{PQ} / 1$ ?accountid=13265

Talò, C., Mannarini, T., \& Rochira, A. (2014). Sense of community and community participation: A meta-analytic review. Social Indicators Research, 117(1), 1-28. https://doi.org/10.1007/s11205-013-0347-2

Tew, J., Ramon, S., Slade, M., Bird, V., Melton, J., \& Le Boutillier, C. (2012). Social factors and recovery from mental health difficulties: A review of the evidence. British Journal of Social Work, 42, 443-460. https://doi.org/10.1093/bjsw/bcr076 The President's New Freedom Commission on Mental Health: Achieving the Promise: Transforming Mental Health Care in America. (2003). Rockville, Maryland.

Toohey, A. M., Mccormack, G. R., Doyle-Baker, P. K., Adams, C. L., \& Rock, M. J. (2013). Dog-walking and sense of community in neighborhoods: Implications for promoting regular physical activity in adults 50 years and older. Health \& Place, 22, 75-81. https://doi.org/10.1016/j.healthplace.2013.03.007

Townley, G. (2015). "It Helps You Not Feel So Bad—Feel Like You Again”: The importance of community for individuals with psychiatric disabilities. Journal of Psychosocial Rehabilitation and Mental Health, 2(2), 113-124. Retrieved from http://link.springer.com/article/10.1007/s40737-015-0036-3

Townley, G, Kloos, B., \& Wright, P. (2009). Understanding the experience of place: Expanding methods to conceptualize and measure community integration of persons with serious mental illness. Health Place, 15(2), 520-531. Retrieved from http://www.sciencedirect.com/science/article/pii/S1353829208001020

Townley, G, Miller, H., \& Kloos, B. (2013). A little goes a long way: The impact of 
distal social support on community integration and recovery of individuals with psychiatric disabilities. American Journal of Community Psychology. Retrieved from http://onlinelibrary.wiley.com/doi/10.1007/s10464-013-9578-2/full

Townley, Greg, \& Kloos, B. (2009). Development of a measure of sense of community for individuals with serious mental illness residing in community settings. Journal of Community Psychology, 37(3), 362-380. https://doi.org/10.1002/jcop.20301

Townley, Greg, \& Kloos, B. (2011). Examining the psychological sense of community for individuals with serious mental illness residing in supported housing environments. Community Mental Health Journal, 47, 436-446. https://doi.org/10.1007/s10597-010-9338-9

Üstün, T. B., Chatterji, S., Bickenbach, J., Kostanjsek, N., \& Schneider, M. (2009). The International Classification of Functioning, Disability and Health: A new tool for understanding disability and health. Disability and Rehabilitation , 25(11-12), 565571. https://doi.org/10.1080/0963828031000137063

Walsh, J., \& Connelly, P. R. (1996). Supportive behaviors in natural support networks of people with serious mental illness. Health \& Social Work, 21(4), 296-303.

Retrieved from https://search.proquest.com/docview/1298063504?pqorigsite $=$ gscholar

Ware, N. C., Hopper, K., Tugenberg, T., Dickey, B., \& Fisher, D. (2007). Connectedness and citizenship: Redefining social integration. Psychiatric Services, 58(4), 469-474.

Whitley, R., \& Drake, R. (2010). Recovery: A dimensional approach. Psychiatric Services, 61(12), 1248-1250. Retrieved from 
http://ps.psychiatryonline.org/doi/abs/10.1176/ps.2010.61.12.1248

Wisdom, J. P., Saedi Auzeen, G., \& Green, C. A. (2009). Another breed of "Service" animals: STARS study findings about pet ownership and recovery From serious mental illness. American Journal of Orthopsychiatry, 79(3), 430-436. https://doi.org/10.1037/aM)16812

Wong, Yin-Ling I, \& Solomon, P. L. (2002). Community integration of persons with psychiatric disabilities in supportive independent housing: A conceptual model and methodological considerations. Mental Health Services Research, 4(1). Retrieved from http://repository.upenn.edu/spp_papers28.

Wong, Yin-Ling Irene, Stanton, M. C., \& Sands, R. G. (2014). Rethinking social inclusion: Experiences of persons in recovery from mental illness. American Journal of Orthopsychiatry, 84(6), 685-695. https://doi.org/10.1037/ort0000034

Woodward, A. T., Taylor, R. J., Bullard, K. M., Neighbors, H. W., Chatters, L. M., \& Jackson, James, S. (2008). Use of professional and informal support by African Americans and Caribbean Blacks with mental disorders. Psychiatric Services, 59(11), 1292-1298. Retrieved from https://ps.psychiatryonline.org/doi/pdf/10.1176/ps.2008.59.11.1292

Wright, E. R., Wright, D. E., Perry, B. L., \& Foote, C. E. (2007). Stigma and the sexual ssolation of people with serious mental illness. Social Problems, 54(1), 78-98. https://doi.org/10.1525/sp.2007.54.1.78

Yanos, P. T., Felton, B. J., Tsemberis, S., \& Frye, V. A. (2007). Exploring the role of housing type, neighborhood characteristics, and lifestyle factors in the community 
integration of formerly homeless persons diagnosed with mental illness. Journal of Mental Health, 16(6), 703-717. https://doi.org/10.1080/09638230701496378

Yanos, P. T., Rosenfield, S., \& Horwitz, A. V. (2001). Negative and supportive social interactions and quality of life among persons diagnosed with severe mental illness. Community Mental Health Journal, 37(5), 405-419. Retrieved from https://link.springer.com/content/pdf/10.1023/A:1017528029127.pdf

Yanos, P. T., Stefanic, A., \& Tsemberis, S. (2011). Psychological community integration among people with psychiatric disabilities and nondisabled community members. Journal of Community Psychology, 39(4), 390-401. https://doi.org/10.1002/jcop.20441

Zimolag, U., \& Krupa, T. (2009). Pet ownership as a meaningful community occupation for people with serious mental illness. American Journal of Occupational Therapy, 63(2), 126-137. https://doi.org/10.5014/ajot.63.2.126 


\section{Chapter 5: Discussion}

Research continues to demonstrate that individuals with serious mental illnesses lack opportunities for employment, have fewer meaningful personal relationships, struggle to obtain stable, decent housing, and experience stigma and discrimination from community members, despite efforts to improve these outcomes in mental health research and practice (Carling, 1995; Townley, Brown, \& Sylvestre, 2018; Ware et al., 2007). More than fifty years after the deinstitutionalization movement began, community mental health centers continue to struggle to provide adequate community-based services to individuals with serious mental illnesses, largely due to cutbacks in federal funding. Additionally, research suggests that models of care that are strengths-based and recoveryoriented have greater benefits than traditional, disease-oriented models of care (W Anthony, Rogers, \& Farkas, 2003; Lester \& Gask, 2006; Stroul, 1989; Üstün, Chatterji, Bickenbach, Kostanjsek, \& Schneider, 2009). Accordingly, the mental health field has shifted to promoting alternative ways to address mental health issues in the community, such as leveraging natural supports, training peers to provide services, and focusing on community inclusion and recovery (Carling, 1990; Davidson, Stayner, et al., 2001; Salzer \& Baron, 2016; Sarason, 1976).

Community inclusion is conceptualized as removing systematic barriers to promote equal opportunity for everyone to participate in the community (Davidson, 2005; Nelson, Lord, \& Ochocka, 2001; Salzer \& Baron, 2016). Although there is consensus in the mental health field that community inclusion and recovery are positive outcomes, research and interventions are still learning how to implement policies and practices that 
fully promote these goals (Davidson et al., 2006). Research suggests that a variety of individual and community level factors may influence community inclusion, particularly community participation, sense of community, and social support. First, community participation is defined as independent engagement in community-based contexts across any of the following social life domains: domestic life (e.g., cleaning, shopping), interpersonal life (e.g., formal relationships, intimate relationships, family relationships), major life activities (e.g., education and employment), and community, civic, and social life (e.g., politics, religion, culture; World Health Organization, 2001). Second, sense of community is defined as the feeling that one belongs to, and participates in, a larger collective of individuals (Sarason, 1974). Finally, social support has numerous definitions and subconstructs, including feeling loved or valued, providing advice, perceived social support, received support, or any exchange of resources aimed to benefit the receiver (Felton \& Shinn, 1992; Haber, Cohen, Lucas, \& Baltes, 2007; Shinn, Lehmann, \& Wong, 1984; Shumaker \& Brownell, 1984).

Community participation, social support, and sense of community are recognized as important constructs that are associated with community inclusion and recovery for individuals with serious mental illnesses (Davidson, Haglund, et al., 2001; Leavy, 1983; Townley, 2015). However, the connections between the three constructs had not been adequately explored in previous research. Therefore, the current dissertation examined the relationships between community participation, social support, and sense of community, as well as their influence on community inclusion, in order to provide recommendations for research, practice, and policy. 


\section{Summary of Dissertation Studies}

In previous chapters of this dissertation, I presented three manuscripts examining individual and community level supports that influence community inclusion and recovery for adults with serious mental illnesses. The first manuscript (Chapter 2; Terry et al., 2019) examined the association between community participation, sense of community, and mental health outcomes for adults with serious mental illnesses. Participants who reported higher levels of participation also reported higher levels of sense of community, lower levels of psychological distress, and higher levels of mental health functioning. Mediation analyses revealed that sense of community acted as a partial mediator between community participation, psychological distress, and mental health functioning. These findings indicate that while community participation is important, the feelings of belonging and acceptance from community members also significantly influence mental health for adults with serious mental illnesses. These results led to an increased interest in understanding the role of supportive relationships in facilitating community inclusion and recovery for adults with serious mental illnesses.

The second manuscript (Chapter 3; Terry \& Townley, 2019) was a literature review of social support and community inclusion for adults with serious mental illnesses. The review adopted a community psychology lens and operationalized social support as a resource that includes both individuals and organizations. Thirty-two articles were organized into three categories: defining community integration, supportive relationships, and mental health services. Key findings suggested that family, friends, and non-traditional supports (e.g., pets, neighbors, community members) influence 
community inclusion. However, there was a lack of research on the role of coworkers, significant others, and peers in supporting community inclusion. Additionally, most studies focused on a single type of support, rather than identifying and describing all of the supports available to adults with serious mental illnesses. Finally, while previous research demonstrated that natural supports (i.e., people who provide support in our daily lives, such as friends, family members, co-workers, and neighbors; Walsh \& Connelly, 1996) contribute to community inclusion, it was unclear how natural supports influence community participation more specifically.

Based on the findings from the first and second manuscripts, the third study aimed to identify and describe individuals who provide social support and examine the association between natural supports and community participation. Participants identified a variety of individuals as supports, including family members, spouses or partners, friends, neighbors, pets, counselors, health care providers, coworkers, and religious leaders. Family, friends, and neighbors were identified most often as supports. Quantitative data analysis revealed that spouses or partners, religious leaders, friends, pets, and family members provided the highest levels of social support. Additionally, social support provided by natural supports was positively related to community participation, such that higher levels of support were associated with a higher number of participation days in the past month. Qualitative analyses revealed six themes regarding the relationship between social support and community participation. Family and friends positively contributed to community participation by engaging in community activities (e.g., going to the park, going out to each) with participants. Alternatively, pets and 
neighbors did not appear to influence community participation, although pets were described as providing emotional support. Participants also discussed the role of mental health as a barrier to community participation and expressed desires to participate in activities with others more often.

\section{Contributions, Implications, and Future Directions}

The current dissertation drew upon data collected using multiple methods in diverse contexts across the United States. The first manuscript utilized quantitative data collected from a large sample of clients of communtiy mental health centers located throughout the United States. The second manuscript presented a detailed literature review of articles examining the link between social support and community inclusion in the United States and internationally. The third study collected data from residents in supportive housing sites in Portland, Oregon, which allowed for an in-depth examination of social support and community participation in a specific community. Both quanitative and qualitative data sources were analyzed in the third study, with qualitative data providing a more detailed and contextualized understanding of the relationship between social support and community participation. Collectively, the studies presented in this dissertation furthered our understanding of natural supports, community participation, as well as barriers to community particpation and community inclusion, which will be discussed in more detail below.

Natural supports. Consistent with the second manuscript, family members were frequently identified as supports in the third study (Beal et al., 2005; Bradshaw et al., 2007). Several participants discussed the important role famly members played in 
supporting their community participation compared to friends and community members. However, participants also reported that family provided lower levels of emotional support compared to other individuals (e.g., spouse or partners, pets). Mental health practitioners should work with family members to help them understand the significant role they can play in helping individuals with serious mental illlnesses achieve indepedence and community inclusion (Chen, 2010). Additionally, there is a lack of research regarding negative experiences social support, especially for individuals with serious mental illnesses. Findings from the second manuscript suggest that family members may act patronizingly and condescendingly toward individuals with serious mental illnesses (Davidson et al., 2001), or limit opportunities for them to become more independent (Bradshaw et al., 2007; Chen, 2010). Future research should examine whether family members provide negative support, and if so, how this affects community inclusion and participation.

Friends were also frequently identified as supports by participants in the third study. People with serious mental illnesses have more flexibility in choosing friends compared to family members. Additionally, friends may not feel the same level of responsibility or burden as family members; for example, friends may not feel responsible for providing money or housing to individuals with serious mental illnesses (Beal et al., 2005; Bradshaw, Armour, \& Roseborough, 2007; Chen, 2010; Davidson et al., 2001). Friends are also more abundantly available in the community and can play a more consistent and natural role compared to formal supports (Davidson et al., 2006). Further, the results from the second study suggest that there are more opportunities for 
friends to engage in reciprocal interactions and unconditional acceptance compared to family members, which is beneficial for community inclusion and recovery (Beal, 1999; Beal et al., 2005; Davidson, et al., 2001).

Results from the second manuscript suggest that neighbors and pets positively contribute to community inclusion (see also Townley \& Kloos, 2011; Zimolag \& Krupa, 2009). Participants reported that neighbors and pets provide emotional and tangible support in the third study. However, participants did not discuss neighbors and pets as supporting their community participation in the qualitative interviews. Nonetheless, the social support provided by neighbors and pets may positively influence individuals' comfort, happiness, and confidence in engaging in opportunities in the community. Future research should continue to explore the role of neighbors and pets in promoting community inclusion and community participation.

The second manuscript identified several gaps in the literature, including a lack of research on significant others. Although spouses or partners were not frequently identified in the third study, they provided higher levels of support compared to other sources (e.g., family or relatives). These results suggest that the quality of support from close relationships like significant others may be more important than sources of support that may involve a number of different people (e.g., neighbors, friends). Intimacy and romantic relationships should be a stronger focal point in mental health services, and future research should explore the role of significant others in promoting community participation. 
Community participation. Participants did not report engaging in a wide variety of activities in the third study. However, studies reviewed in the second manuscript suggests that casual, routine interactions with others that occur while engaging in the community may positively influence community inclusion (Beal et al., 2005; Townley, Miller, \& Kloos, 2013). As participants spend more time in the community, they will likely have more opportunities to develop friendships and relationships with community members. Additionally, results from the first manuscript suggest that the perception that one belongs to a community is positively associated with mental health outcomes. As such, mental health providers should encourage clients to participate in the community and develop goals for engaging independently in activities such as taking walks in the park, going to a museum, or getting coffee.

Barriers to community participation and community inclusion. Across the three studies, it is important to recognize that individuals with serious mental illnesses continue to report barriers to community participation and community inclusion, including poor physical and mental health, lower socioeconomic status, lack of employment opportunities, inadequate access to healthcare, transportation barriers, and mental health stigma (see also Bradshaw, Armour, \& Roseborough, 2007; Dewees, Pulice, \& McCormick, 1996). Most of these obstacles are difficult, if not impossible, for individuals to overcome on their own, and also challenging for service organizations to adequately address given resource constraints. Societal barriers, such as access to healthcare and socioeconomic factors, require significant changes to local and national policies. 
Nonetheless, a variety of interventions and efforts within service organizations and communities may reduce some of the barriers to inclusion that individuals with serious mental illness regularly face. For example, interventions that promote physical exercise (Richardson et al., 2005), improve access to transportation (Samuel, Lacey, Giertz, Hobden, \& LeRoy, 2013), and provide support from volunteers or pets (Mccorkle, Dunn, Mui Wan, \& Gagne, 2009; Toohey, Mccormack, Doyle-Baker, Adams, \& Rock, 2013; Wisdom et al., 2009) may be associated with increased community participation and community inclusion. Mental health organizations can work to locate supportive housing sites near public transportation and other resources for activity participation. The co-location of primary care and behavioral health services within the same site can also help to reduce barriers to service access. Finally, the general population would benefit from more education about mental health and increased opportunities for meaningful contact with people diagnosed with mental illnesses living in the community in order to reduce stigma and discrimination (Corrigan \& Watson, 2002).

Future considerations. The proposal for the third study initially included another research question that aimed to understand how characteristics of natural support relationships are related to community participation. The characteristics included frequency of contact, length of relationship, peer status, and method of interaction. Frequency of contact and length of relationship originated in the NSSQ (Norbeck, Lindsey, \& Carrieri, 1981), and the correlations between each characteristic and the community participation variables were not significant. 
Peer status and method of interaction were created and added to the survey. The response options for peer status included 'no' (scored as 0), 'yes' (scored as 1), and 'I don't know' (scored as 2). The response options for method of interaction included 'in person' (scored as 1), 'over the phone' (scored as 2), 'with social media' (scored as 3), and 'with letters' (scored as 4). Unfortunately, there were issues with calculating peer status and method of interaction for natural supports. In order to examine the influence, peer status and method of interaction have to be summed for all of the individuals that were identified as natural supports (up to 24 individuals), which does not result in interpretable findings for these variables. As such, peer status was calculated as the presence or absence of peers in the social network. Method of interaction was examined by whether the participant utilizes one or more than one of the methods. There were no significant correlations between frequency of peers, method of interaction, and the community participation variables.

Overall, this experience reiterated the importance of using established scales to conduct research. However, if I decide to supplement a survey with novel questions, I plan to pilot the questions more carefully and conduct preliminary analysis on these items. Additionally, the small sample was a limitation of the third study, particularly given the non-significant quantitative findings. The lack of significant findings between community participation and frequency of contact, length of length of relationship, peer status, and method of interaction do not suggest that these variables are not important, but rather that future studies should consider alternate approaches to measuring these variables, and also include more participants. I found it valuable to include both 
quantitative and qualitative data, but in the future, I would make changes to my plan, such as extending my timeline or enlisting research assistants. Otherwise, I might choose to focus on a solely quantitative, or solely qualitative research project.

\section{Conclusion}

The mental health field will likely always experience a supply and demand issue; mental health services continue to face substantial challenges, such as lack of funding, high client caseloads, and service provider burnout (Albee, 1959; Davidson et al., 2006). The three studies included in this dissertation contribute to the literature by identifying and describing a range of individuals (formal and natural) who provide support to adults with serious mental illnesses. Additionally, sense of community, social support, and community participation were examined as proxies of community inclusion. The third study took an important step in examining the association between natural supports and community participation. Overall, the present dissertation investigated and advocates for alternative ways that individuals, organizations, and communities can improve the lives of individuals with serious mental illnesses. Ultimately, although there will likely never be a sufficient number of professionals to meet the demand of all the people that require

mental health services (Albee, 1959), natural supports are abundant in the community and should be a focal point for research and intervention development. 


\section{References}

Abdallah, C., Cohen, C. I., Sanchez-Almira, M., Reyes, P., \& Ramirez, P. (2009).

Community integration and associated factors among older adults with schizophrenia. Psychiatric Services, 60(12), 16-64. Retrieved from https://ps.psychiatryonline.org/doi/pdf/10.1176/ps.2009.60.12.1642

Anthony, W. A., \& Blanch, A. (1987). Supported employment for persons who are psychiatrically disabled: An historical and conceptual perspective. Psychosocial Rehabilitation Journal, 11(2), 5-23. Retrieved from https://search-proquestcom.proxy.lib.pdx.edu/docview/1504152173/fulltextPDF/B9256567386A43DFPQ/1 ?accountid= 13265

Anthony, W, Rogers, E., \& Farkas, M. (2003). Research on evidence-based practices: Future directions in an era of recovery. Community Mental Health Journal. Retrieved from http://link.springer.com/article/10.1023/A:1022601619482

Anthony, WA. (1993). Recovery from mental illness: The guiding vision of the mental health service system in the 1990s. Psychosocial Rehabilitation Journal, 16(4), 521538. Retrieved from http://psycnet.apa.org/journals/prj/16/4/11/

Anthony, WA. (2000). A recovery-oriented service system: Setting some system level standards. Psychiatric Rehabilitation Journal, 24(2), 159-168. Retrieved from http://psycnet.apa.org/journals/prj/24/2/159/

Aubry, T., \& Myner, J. (1996). Community integration and quality of life: A comparison of persons with psychiatric disabilities in housing programs and community residents who are neighbours. Canadian Journal of Community Mental Health, 
15(1), 5-20. https://doi.org/10.7870/cjcmh-1996-0001

Badger, T. A., McNiece, C., Bonham, E., Jacobson, J., \& Gelenberg, A. J. (2003). Health outcomes for people with serious mental illness: A case study. Perspectives in Psychiatric Care, 39(1), 23-32. https://doi.org/10.1111/j.1744-6163.2003.tb00670.x

Balcazar, F. E., Taylor, R. R., Keilhorner, G. W., Tamley, K., Benziger, T., Carlin, N., \& Johnson, S. (2004). Participatory action research: General principles and a study with a chronic health condition. In In L.A. Jason, C.B. Keys, Y.S. Suarez-Balcazar, R.R. Taylor, \& M.I. Davis (Eds). Participatory Community Research: Theories and Methods in Action. (pp. 17-35). Washington D.C.: American Psychological Association.

Banks, B., Charleston, T. G., \& Mank, D. (2001). Workplace supports, job performance, and intergration outcomes for people with psychiatric disabilities. Psychiatric Rehabilitation Journal, 24(4), 389-396. Retrieved from https://search-proquestcom.proxy.lib.pdx.edu/docview/1347253418/fulltextPDF/6D9724A99D184D76PQ/ 1 ? accountid $=13265$

Basset, T., Faulkner, A., Repper, J., \& Stamou, E. (2010). Lived Experience Leading The Way Peer Support in Mental Health. Nottingham.

Beal, G. (1999). The constitution of community: How individuals diagnosed with schizophrenia and their friends achieved community. Psychiatry, 62(2), 173-186. https://doi.org/10.1080/00332747.1999.11024863

Beal, G., Veldhorst, G., McGrath, J.-L., Guruge, S., Grewal, P., DiNunzio, R., \& Trimnell, J. (2005). Constituting community: Creating a place for oneself. 
Psychiatry, 68(3), 199-211. https://doi.org/10.1521/psyc.2005.68.3.199

Beels, C. C. (1981). Social support and schizophrenia. Schizophrenia Bulletin, 7(1), 5872. https://doi.org/10.1093/schbul/7.1.58

Berkman, L., Glass, T., Brissette, I., \& Seeman, T. (2000). From social integration to health: Durkheim in the new millennium. Social Science \& Medicine, 51(6), 843857. Retrieved from https://scholar.google.com/citations?view_op=view_citation\&continue=/scholar\%3 Fhl\%3Den\%26as_sdt\%3D0,38\%26authuser\%3D1\%26scilib\%3D1\&citilm=1\&citati on_for_view=Xac0OKUAAAAJ:hC7cP41nSMkC\&hl=en\&authuser=1\&oi=p

Blazer, D. G. (1982). Social support in an elderly community population. American Journal of Epidemiology, 115(5), 684-694. https://doi.org/10.1093/oxfordjournals.aje.a113351

Bond, G. R., Salyers, M. P., Rollins, A. L., Rapp, C. A., \& Zipple, A. M. (2004). How evidence-based practices contribute to community integration. Community Mental Health Journal, 40(6), 569-588. https://doi.org/10.1007/s10597-004-6130-8

Bradshaw, W., Armour, M. P., \& Roseborough, D. (2007). Finding a place in the world: The experience of recovery from severe mental illness. Qualitative Social Work, 6(1), 27-47. https://doi.org/10.1177/1473325007074164

Braun, V., \& Clarke, V. (2006). Using thematic analysis in psychology. Qualitative Research in Psychology, 3(2), 77-101. Retrieved from http://eprints.uwe.ac.uk/11735/2/thematic_analysis_revised_-_final.pdf Brusilovskiy, E., Townley, G., Snethen, G., \& Salzer, M. S. (2016). Social media use, 
community participation and psychological well-being among individuals with serious mental illnesses. Computers in Human Behavior, 65, 232-240.

https://doi.org/10.1016/j.chb.2016.08.036

Burns-Lynch, W., Brusilovskiy, E., \& Salzer, M. S. (2016). An empirical study of the relationship between community participation, recovery, and quality of life of individuals with serious mental illnesses. Israel Journal of Psychiatry, 53(1), 46-55. Retrieved from https://cdn.doctorsonly.co.il/2016/08/09_Burns-Lynch_AnEmpirical-Study.pdf

Carling, P.J. (1995). Return to Community: Building Support Systems for People with Psychiatric Disabilities. Guilford Press.

Carling, Paul J. (1990). Major mental illness, housing, and supports: The promise of community integration. American Psychologist, 45(8), 969-975. https://doi.org/10.1037/0003-066X.45.8.969

Chavis, D. M., \& Wandersman, A. (1990). Sense of community in the urban environment: A catalyst for participation and community development. American Journal of Community Psychology, 18(1), 55-81. https://doi.org/10.1007/BF00922689

Chen, F.-P. (2010). Assisting adults with severe mental illness in transitioning from parental homes to independent living. Community Mental Health Journal, 46, 372380. https://doi.org/10.1007/s10597-009-9263-y

Cobb, S. (1976). Social support as a moderator of life stress. Psychosomatic Medicine, 38(5), 300-314. Retrieved from 
https://pdfs.semanticscholar.org/10ec/c3df00f4472cbdfc5509c77d43ecc85193da.pdf

Cohen, C. I., \& Sokolovsky, J. (1978). Schizophrenia and social networks: Ex-patients in the inner city. Schizophrenia Bulletin, 4(4), 546-560.

Cohen, S., \& Wills, T. A. (1985). Stress, social support, and the buffering hypothesis. Psychological Bulletin, 98(2), 310-357.

Cook, J. A., Lehman, A. F., Drake, R., McFarlane, W. R., Gold, P. B., Leff, H. S., ... Grey, D. D. (2005). Integration of psychiatric and vocational services: A multisite randomized, controlled trial of supported employment. American Journal of Psychiatry, 162(10), 1948-1956. https://doi.org/10.1176/appi.ajp.162.10.1948

Corin, E., \& Lauzon, G. (1992). Positive withdrawal and the quest for meaning: The reconstruction of experience among schizophrenics. Psychiatry, 55(3), 266-278. https://doi.org/10.1080/00332747.1992.11024600

Corrigan, P. W., \& Phelan, S. M. (2004). Social support and recovery in people with serious mental illnesses. Community Mental Health Journal, 40(6), 513-523. https://doi.org/10.1007/s10597-004-6125-5

Corrigan, P. W., \& Watson, Amy, C. (2002). Understanding the impact of stigma on people with mental illness. World Psychiatry. Retrieved from https://www.ncbi.nlm.nih.gov/pmc/articles/PMC1489832/pdf/wpa010016.pdf

Cummings, S. M., \& Kropf, N. P. (2009). Formal and informal support for older adults with severe mental illness. Aging \& Mental Health, 13(4), 619-627. https://doi.org/10.1080/13607860902774451

Cummins, R., \& Lau, A. (2003). Community integration or community exposure? A 
review and discussion in relation to people with an intellectual disability. Journal of Applied Research in .... Retrieved from

http://onlinelibrary.wiley.com/doi/10.1046/j.1468-3148.2003.00157.x/full

Davidson, L. (2005). More fundamentally human than otherwise. Psychiatry, 68(3), 243249. Retrieved from http://web.a.ebscohost.com.proxy.lib.pdx.edu/ehost/pdfviewer/pdfviewer?vid=1\&si d=7fbff5cb-6651-40cb-9347-1a279950de49\%40sessionmgr4010

Davidson, L., Bellamy, C., Guy, K., \& Miller, R. (2012). Peer support among persons with severe mental illnesses: A review of evidence and experience. World Psychiatry, 11(2), 123-128. https://doi.org/10.1016/j.wpsyc.2012.05.009

Davidson, L., Chinman, M., Kloos, B., Weingarten, R., Stayner, D., \& Tebes, J. K. (1999). Peer support among individuals with severe mental illness: A review of the evidence. Clinical Psychology: Science and Practice, 6(2), 165-187. Retrieved from https://s3.amazonaws.com/academia.edu.documents/44465989/Peer_Support_Amon g_Individuals_With_Seve20160406-203791e7a6po.pdf?AWSAccessKeyId=AKIAIWOWYYGZ2Y53UL3A\&Expires=152286 8305\&Signature=StSN5GLL8oFZUnq Y1pI\%2B VZzqNQg\%3D\&response-contentdisposition=inli

Davidson, L., Haglund, K. E., Stayner, D. A., Rakfeldt, J., Chinman, M. J., \& Kraemer Tebes, J. (2001). “It was just realizing...that life isn’t one big horror”: A qualitative study of supported socialization. Psychiatric Rehabilitation Journal, 24(3), 275292. https://doi.org/10.1037/h0095084 
Davidson, L., \& McGlashan, T. H. (1997). The varied outcomes of schizophrenia. The Canadian Journal of Psychiatry, 42(1), 34-43. https://doi.org/10.1177/070674379704200105

Davidson, L., O’Connell, M., Tondora, J., Styron, T., \& Kangas, K. (2006). The top ten concerns about recovery encountered in mental health system transformation. Psychiatric Services, 57(5), 640-645. https://doi.org/10.1176/ps.2006.57.5.640

Davidson, L., Stayner, D. A., Nickou, C., Styron, T. H., Rowe, M., \& Chinman, M. L. (2001). "Simply to be let in": Inclusion as a basis for recovery. Psychiatric Rehabilitation Journal, 24(4), 375-388. Retrieved from https://search-proquestcom.proxy.lib.pdx.edu/docview/1347253334/fulltextPDF/7D1D6248E6BA4C57PQ/ 1 ? accountid $=13265$

Dewees, M., Pulice, R., \& McCormick, L. (1996). Community integration of former state hospital patients: Outcomes of a policy shift in Vermont. Psychiatric Services. Retrieved from http://psycnet.apa.org/psycinfo/1996-06687-006

Drake, R. E., McHugo, G. J., Bebout, R. R., Becker, D. R., Harris, M., Bond, G. R., \& Quimby, E. (1999). A randomized clinical trial of supported employment for innercity patients with severe mental disorders. Archives of General Psychiatry, 56(7), 627. https://doi.org/10.1001/archpsyc.56.7.627

Drake, R. E., McHugo, G. J., Becker, D. R., \& Clark, R. E. (1996). The New Hampshire study of supported employment for people with severe mental illness. Journal of Consulting and Clinical Psychology, 64(2), 391-399. Retrieved from https://search.proquest.com/docview/614315911/fulltextPDF/E30068843D5247E6P 
Q/1?accountid=13265

Farkas, M., Gagne, C., Anthony, W., \& Chamberlin, J. (2005). Implementing recovery oriented evidence based programs: Identifying the critical dimensions. Community Mental Health Journal, 41(2), 141-158. Retrieved from http://link.springer.com/article/10.1007/s10597-005-2649-6

Felton, B., \& Shinn, M. (1992). Social integration and social support: Moving "Social Support" beyond the individual level. Journal of Community Psychology, 20(2), 103-115. Retrieved from http://web.a.ebscohost.com.proxy.lib.pdx.edu/ehost/pdfviewer/pdfviewer?vid=1\&si d=3dd58681-b925-473c-b885-7853d92e1ee8\%40sessionmgr4010

Gold, P. B., Meisler, N., Santos, A. B., Carnemolla, M. A., Williams, O. H., \& Keleher, J. (2006). Randomized trial of supported employment integrated with assertive community treatment for rural adults with severe mental illness. Schizophrenia Bulletin, 32(2), 378-395. https://doi.org/10.1093/schbul/sbi056

Granerud, A., \& Severinsson, E. (2006). The struggle for social integration in the community - the experiences of people with mental health problems. Journal of Psychiatric and Mental Health Nursing, 13(3), 288-293. https://doi.org/10.1111/j.1365-2850.2006.00950.x

Greene, J. C., \& Caracelli, V. J. (1997). Defining and describing the paradigm issue in mixed-method evaluation. New Directions for Evaluation, 1997(74), 5-17. https://doi.org/10.1002/EV.1068

Greene, J. C., Caracelli, V. J., \& Graham, W. F. (1989). Toward a conceptual framework 
for mixed-method evaluation designs. Educational Evaluation and Policy Analysis Fall, 11(3), 255-274. Retrieved from https://journals.sagepub.com/doi/pdf/10.3102/01623737011003255?casa_token=g6 Q7jY9QNqAAAAAA:xGL3SSFuvWRGnE3zgkhd8EQZGKcH5gNqnnb3LHJY4Z_O3JfyULT57YmYaoIncpAnInATVhVNO2e

Hammer, M. (1981). Social supports, social networks, and schizophrenia. Schizophrenia Bulletin, 7(1), 45-57.

Harding, C. M., Zubin, J., \& Strauss, J. S. (1987). Chronicity in schizophrenia: Fact, partial fact, or artifact? Psychiatric Services, 38(5), 477-486. https://doi.org/10.1176/ps.38.5.477

Harding, C., \& Zahniser, J. (1994). Empirical correction of seven myths about schizophrenia with implications for treatment. Acta Psychiatrica Scandinavica, 90, 140-146. Retrieved from http://www.psychodyssey.net/wpcontent/uploads/2012/05/Empirical-correction.pdf

Hawkley, L. C., \& Cacioppo, J. T. (2010). Loneliness matters: A theoretical and empirical review of consequences and mechanisms. Annals of Behavioral Medicine : A Publication of the Society of Behavioral Medicine, 40(2), 218-227. https://doi.org/10.1007/s12160-010-9210-8

Headey, B. (2003). Pet ownership: Good for health? Medical Journal of Australia, 179(9), 460-461. Retrieved from www.mja.com.au

Heaney, Catherine, A., \& Israel, Barbara, A. (2008). Social networks and social support. In K. Glanz, B. K. Rimer, \& K. Viswanath (Eds.), Health behavior and health 
education: Theory, research, and practice (4th ed., pp. 189-210). San Francisco: Jossey-Bass. Retrieved from http://iums.ac.ir/files/hshesoh/files/beeduhe_0787996149(1).pdf\#page=227

Hendryx, M., Green, C. A., \& Perrin, N. A. (2009). Social support, activities, and recovery from serious mental illness: STARS study findings. The Journal of Behavioral Health Services \& Research, 36(3), 320-329. Retrieved from https://link.springer.com/content/pdf/10.1007\%2Fs11414-008-9151-1.pdf Hennings, B. A. (1999). Are consumers going to the dogs (and cats and birds)? New Directions for Mental Health Services, 1999(83), 45-49. https://doi.org/10.1002/yd.23319998307

Hesse-Biber, S., \& Leavy, P. (2010). The Practice of Qualitative Research. Sage. Retrieved from https://scholar.google.com/scholar?hl=en\&as_sdt=0\%2C38\&q=the+practice+of $+q u$ alitative+research+hesse+biber\&btnG=

Horwitz, A. V, Reinhard, S. C., \& Howell, S. (1996). Caregiving as reciprocal exchange in families with seriously mentally ill members. Journal of Health and Social Behavior, 37(37), 149-162. Retrieved from http://www.jstor.org/stable/2137270 House, J. S. (1981). Work stress and social support. Reading, Mass.: Addison-Wesley. Israel, B. A., Farquhar, S. A., Schulz, A. J., James, S. A., \& Parker, E. A. (2002). The relationship between social support, stress, and health among women on Detroit's east side. Health Education \& Behavior, 29(3), 342-360. https://doi.org/10.1177/109019810202900306 
Jones, D. R., Macias, C., Barreira, P. J., Fisher, W. H., Hargreaves, W. A., \& Harding, C. M. (2004). Prevalence, severity, and co-occurrence of chronic physical health problems of persons with serious mental illness. Psychiatric Services, 55(11), 12501257. Retrieved from http://ps.psychiatryonline.org/doi/abs/10.1176/appi.ps.55.11.1250

Kaplan, K., Salzer, M. S., \& Brusilovskiy, E. (2012). Community participation as a predictor of recovery-oriented outcomes among emerging and mature adults with mental illnesses. Psychiatric Rehabilitation Journal, 35(3), 219-229. https://doi.org/10.2975/35.3.2012.219.229

Kaplan, K., Salzer, M. S., Solomon, P., Brusilovskiy, E., \& Cousounis, P. (2011). Internet peer support for individuals with psychiatric disabilities: A randomized controlled trial. Social Science \& Medicine, 72(1), 54-62. https://doi.org/10.1016/J.SOCSCIMED.2010.09.037

Kawachi, I., \& Berkman, L. F. (2001). Social ties and mental health. Journal of Urban Health: Bulletin of the New York Academy of Medicine, 78(3). Retrieved from https://link.springer.com/content/pdf/10.1093/jurban/78.3.458.pdf

Kennedy, C. (1989). Community integration and well-being: Toward the goals of community care. Journal of Social Issues, 45(3), 65-77. https://doi.org/10.1111/j.1540-4560.1989.tb01555.x

Kline, R. B. (2015). The mediation myth. Basic and Applied Social Psychology, 37(4), 202-213. https://doi.org/10.1080/01973533.2015.1049349

Kloos, B, \& Townley, G. (2011). Investigating the relationship between neighborhood 
experiences and psychiatric distress for individuals with serious mental illness.

Administration and Policy in Mental Health and Mental Health Services Research, 38(2), 105-116. Retrieved from http://link.springer.com/article/10.1007/s10488010-0307-y

Kloos, Bret, Zimmerman, S. O., Scrimenti, K., \& Crusto, C. (2002). Landlords as partners for promoting success in supported housing: "It takes more than a lease and a key." Psychiatric Rehabilitation Journal, 25(3), 235-244. Retrieved from https://search-proquestcom.proxy.lib.pdx.edu/docview/1347253476/fulltextPDF/C3191BE677FD44FEPQ/ 1 ?accountid $=13265$

Kostanjsek, N. (2011). Use of The International Classification of Functioning, Disability, and Health (ICF) as a conceptual framework and common language for disability statistics and health information systems. BMC Public Health, 11(4). https://doi.org/10.1186/1471-2458-11-S4-S3

Kraut, R., Kiesler, S., Boneva, B., Cummings, J., Helgeson, V., \& Crawford, A. (2002). Internet paradox revisited. Journal of Social Issues, 58(1), 49-74. https://doi.org/10.1111/1540-4560.00248

Kraut, R., Patterson, M., Lundmark, V., Kiesler, S., Mukophadhyay, T., \& Scherlis, W. (1998). Internet paradox: A social technology that reduces social involvement and psychological well-being? American Psychologist , 53(9). Retrieved from https://scholar.google.com/citations?user=HKGYvu4AAAAJ\&hl=en\&oi=sra\#d=gs_ md_cita- 
$\mathrm{d} \& \mathrm{u}=\% 2$ Fcitations\%3Fview_op\%3Dview_citation\%26hl\%3Den\%26user\%3DHKG Yvu4AAAAJ\%26citation_for_view\%3DHKGYvu4AAAAJ\%3Au5HHmVD_uO8C \%26tzom\%3D420

Kruzich, J. M. (1985). Community integration of the mentally iII in residential facilities. American Journal of Community Psychology, 13(5), 553-564. Retrieved from https://s3.amazonaws.com/academia.edu.documents/46229950/bf009232672016060 4-11909ii3rjn.pdf?AWSAccessKeyId=AKIAIWOWYYGZ2Y53UL3A\&Expires=15196981 04\&Signature=yW076Wtoz8UW\%2FfN7spiCyZHFDig\%3D\&response-contentdisposition=inline \%3B filename\%3DCommunity_in

Langford, C. P. H., Bowsher, J., Maloney, J. P., \& Lillis, P. P. (1997). Social support: A conceptual analysis. Journal of Advanced Nursing, 25(1), 95-100. https://doi.org/10.1046/j.1365-2648.1997.1997025095.x

Leavy, R. L. (1983). Social support and psychological disorder: A review. Journal of Community Psychology, 11(1), 3-21. https://doi.org/10.1002/15206629(198301)11:1<3::AID-JCOP2290110102>3.0.CO;2-E

Lester, H., \& Gask, L. (2006). Delivering medical care for patients with serious mental illness or promoting a collaborative model of recovery? British Journal of Psychiatry, 188(5), 401-402. Retrieved from http://www.improvingchroniccare. Machin, K., \& Repper, J. (2013). Recovery: a carer's perspective. Retrieved from http://citeseerx.ist.psu.edu/viewdoc/download?doi=10.1.1.688.2639\&rep=rep1\&typ e=pdf 
Maton, K. I., Teti, D. M., Corns, K. M., Vieira-Baker, C. C., Seattle, J. R. L., Karen, W., ... Keating, D. P. (1996). Cultural specificity of support sources, correlates and contexts: Three studies of African-American and Caucasian youth. American Journal of Community Psychology, 24(4), 551-587. Retrieved from https://s3.amazonaws.com/academia.edu.documents/46431330/bf025067962016061 2-12045-

18yxc6f.pdf?AWSAccessKeyId=AKIAIWOWYYGZ2Y53UL3A\&Expires $=155772$ 2849\&Signature $=\mathrm{fpj} \% 2 \mathrm{FV} \% 2 \mathrm{~B} 6 \mathrm{wFScZFKIRrXYUFWSv52I \% 3D \& response-}$ content-disposition=inline $\% 3 \mathrm{~B}$ filename\%3DCultural_

Mattsson, M., Topor, A., Cullberg, J., \& Forsell, Y. (2008). Association between financial strain, social network and five-year recovery from first episode psychosis. Social Psychiatry and Psychiatric Epidemiology, 43(12), 947-952. https://doi.org/10.1007/s00127-008-0392-3

McColl, M. A., Davies, D., Carlson, P., Johnston, J., \& Minnes, P. (2001). The community integration measure: Development and preliminary validation. Archives of Physical Medicine and Rehabilitation, 82(4), 429-434. https://doi.org/10.1053/apmr.2001.22195

Mccorkle, B. H., Dunn, E. C., Mui Wan, Y., \& Gagne, C. (2009). People with Serious Mental Illness Compeer Friends: a Qualitative Study of a Volunteer Friendship Programme for. International Journal of Social Psychiatry, 55(291), 291-305. https://doi.org/10.1177/0020764008097090

Mccorkle, B. H., Sally, A. E., Ae, R., Dunn, E. C., Lyass, A., Yu, A., \& Wan, M. (2008). 
Increasing social support for individuals with serious mental illness: Evaluating the compeer model of intentional friendship. Community Mental Health Journal, 44(5), 359. https://doi.org/10.1007/s10597-008-9137-8

McFarlane, W. R., Dushay, R. A., Deakins, S. M., Stastny, P., Lukens, E. P., Toran, J. W., \& Link, B. (2000). Employment outcomes in family-aided assertive community treatment. American Journal of Orthopsychiatry, 70(2), 203-214. Retrieved from https://search.proquest.com/docview/1038624044/fulltextPDF/A54A0F5C7E1742A $\mathrm{EPQ} / 1$ ?accountid=13265

McMillan, D., \& Chavis, D. (1986). Sense of community: A definition and theory. Journal of Community Psychology, 14(1), 6-23. Retrieved from http://mc7290.bgsu.wikispaces.net/file/view/McMillan_1986.pdf

Mechanic, D., \& Rochefort, D. A. (1990). Deinstitutionalization: An appraisal of reform. Annual Review of Sociology, 16, 301-328. Retrieved from https://about.jstor.org/terms

Morgan, D. L. (1998). Practical strategies for combining qualitative and quantitative methods: Applications for health research. Qualitative Health Research, 3, 362-376. Retrieved from https://journals-sagepubcom.proxy.lib.pdx.edu/doi/pdf/10.1177/104973239800800307

Naslund, J. A., Grande, S. W., Aschbrenner, K. A., \& Elwyn, G. (2014). Naturally occurring peer support through social media: The experiences of individuals with severe mental illness using YouTube. PLoS ONE, 9(10), 1-9. https://doi.org/10.1371/journal.pone.0110171 
Nations, U. (2006). United Nations convention on the rights of persons with disabilities. Retrieved from http://www.un.org/esa/socdev/enable/rights/convtexte.htm

Nelson, G, Lord, J., \& Ochocka, J. (2001). Empowerment and mental health in community: Narratives of psychiatric consumer/survivors. Journal of Community \& Applied Social Psychology. Retrieved from http://onlinelibrary.wiley.com/doi/10.1002/casp.619/full

Nelson, Geoffrey, Ochocka, J., Janzen, R., Trainor, J., Goering, P., \& Lomotey, J. (2007). A longitudinal study of mental health consumer/survivor initiatives: Part Voutcomes at 3-year follow-up. Journal of Community Psychology, 35(5), 655-665. https://doi.org/10.1002/jcop.20171

Norbeck, J. S., Lindsey, A. M., \& Carrieri, V. L. (1981). The development of an instrument to measure social support. Nursing Research, 30(5), 264-269. https://doi.org/10.1097/00006199-198109000-00003

Norbeck, J. S., Lindsey, A. M., \& Carrieri, V. L. (1983). Further development of the norbeck social support questionnaire. Nursing Research, 32(1), 4-9. https://doi.org/10.1097/00006199-198301000-00002

Organization, W. H. (2001). International classification of functioning, disability and health: ICF.

Orth-Gomér, K., \& Johnson, J. V. (1987). Social network interaction and mortality. Journal of Chronic Diseases, 40(10), 949-957. https://doi.org/10.1016/00219681(87)90145-7

Perkins, D. D., Florin, P., Rich, R. C., Wandersman, A., \& Chavis, D. M. (1990). 
Participation and the social and physical environment of residential blocks: Crime and community context. American Journal of Community Psychology, 18(1), 83115. https://doi.org/10.1007/BF00922690

Pinfold, V. (2000). "Building up safe havens all around the world": Users' experiences of living in the community with mental health problems. Health \& Place, 6, 201-212. Retrieved from http://www.sciencedirect.com/science/article/pii/S135382920000023X

Prince, P. N., \& Gerber, G. J. (2005). Subjective well-being and community integration among clients of assertive community treatment. Quality of Life Research, 14(1), 161-169. https://doi.org/10.1007/s11136-004-2407-1

Robson, D., \& Gray, R. (2007). Serious mental illness and physical health problems: A discussion paper. International Journal of Nursing Studies, 44(3), 457-466. Retrieved from https://www.sciencedirect.com/science/article/pii/S0020748906002306

Royce-Davis, J. C. (2001). "It's the Day-to-Day Living That Matters": The meaning and process of community in the lives of a couple with significant psychiatric disabilities. American Journal of Community Psychology, 29(6), 807-832. Retrieved from https://link.springer.com/content/pdf/10.1023/A:1012957014209.pdf

Ryan, G. W., Health, R., \& Russell Bernard, H. (2003). Techniques to identify themes. Field Methods, 15(1), 85-109. https://doi.org/10.1177/1525822X02239569

Salzer, M., \& Baron, R. (2016). Well Together - A blueprint for community inclusion: fundamental concepts, theoretical frameworks and evidence. Retrieved from 
http://www.tucollaborative.org/sdm_downloads/well-together/

Salzer, M. S., Brusilovskiy, E., Prvu-Bettger, J., \& Kottsieper, P. (2014). Measuring community participation of adults with psychiatric disabilities: Reliability of two modes of data collection. Rehabilitation Psychology, 59(2), 211.

Salzer, M. S., Kottsieper, P., \& Brusilovskiy, E. (2015). Intermethod reliability and factors affecting recall with the Temple University Community Participation measure. Journal of Mental Health, 24(4), 189-195.

https://doi.org/10.3109/09638237.2015.1036976

Sarason, S.B. (1974). The Psychological Sense of Community: Prospects for a Community Psychology. San Francisco: Jossey-Bass.

Sarason, Seymour B. (1976). Community psychology, networks, and Mr. Everyman. American Psychologist, 31(5), 317-328. Retrieved from https://search-proquestcom.proxy.lib.pdx.edu/docview/614296588/fulltextPDF/568EC550B2564325PQ/1? accountid=13265

Seeman, T. (1996). Social ties and health: The benefits of social integration. Annals of Epidemiology, 6(5), 442-451. Retrieved from https://scholar.google.com/citations?view_op=view_citation\&continue=/scholar\%3 Fhl\%3Den\%26as_sdt\%3D0,38\%26authuser\%3D1\%26scilib\%3D1\&citilm=1\&citati on_for_view=Xac0OKUAAAAJ:qUcmZB5y_30C\&hl=en\&authuser=1\&oi=p

Segal, S. P., \& Aviram, U. (1978). The Mentally Ill in Community-Based Sheltered Care.

Segal, S. P., Silverman, C. J., \& Temkin, T. L. (2014). Self-help and community mental health agency outcomes: A recovery-focused randomized controlled trial. 
Psychiatric Services, 61(9), 905-910. https://doi.org/10.1176/ps.2010.61.9.905

Shinn, M., Lehmann, S., \& Wong, N. W. (1984). Social interaction and social support. Journal of Social Issues, 40(4), 55-76. https://doi.org/10.1111/j.15404560.1984.tb01107.x

Shumaker, S. A., \& Brownell, A. (1984). Toward a Theory of Social Support: Closing Conceptual Gaps. Journal of Social Issues (Vol. 40). Retrieved from https://pdfs.semanticscholar.org/fc41/ef531e881f3ea80266ab0dc7b7c47e5861e7.pdf

Stanard, R. P. (1999). The effect of training in a strengths model of case management on client outcomes in a community mental health center. Community Mental Health Journal, 35(2), 169-179. Retrieved from https://link.springer.com/content/pdf/10.1023/A:1018724831815.pdf

Stroul, B. A. (1989). Community support systems for persons with long-term mental illness: A conceptual framework. Psychosocial Rehabilitation Journal, 12(3), 9-26. Retrieved from https://search.proquest.com/docview/1504156855/fulltextPDF/945EB09D367B452F $\mathrm{PQ} / 1$ ?accountid $=13265$

Talò, C., Mannarini, T., \& Rochira, A. (2014). Sense of community and community participation: A meta-analytic review. Social Indicators Research, 117(1), 1-28. https://doi.org/10.1007/s11205-013-0347-2

Tew, J., Ramon, S., Slade, M., Bird, V., Melton, J., \& Le Boutillier, C. (2012). Social factors and recovery from mental health difficulties: A review of the evidence. British Journal of Social Work, 42, 443-460. https://doi.org/10.1093/bjsw/bcr076 
The President's New Freedom Commission on Mental Health: Achieving the Promise:

Transforming Mental Health Care in America. (2003). Rockville, Maryland.

Toohey, A. M., Mccormack, G. R., Doyle-Baker, P. K., Adams, C. L., \& Rock, M. J. (2013). Dog-walking and sense of community in neighborhoods: Implications for promoting regular physical activity in adults 50 years and older. Health \& Place, 22, 75-81. https://doi.org/10.1016/j.healthplace.2013.03.007

Townley, G. (2015). “It Helps You Not Feel So Bad-Feel Like You Again”: The importance of community for individuals with psychiatric disabilities. Journal of Psychosocial Rehabilitation and Mental Health, 2(2), 113-124. Retrieved from http://link.springer.com/article/10.1007/s40737-015-0036-3

Townley, G, Kloos, B., \& Wright, P. (2009). Understanding the experience of place: Expanding methods to conceptualize and measure community integration of persons with serious mental illness. Health Place, 15(2), 520-531. Retrieved from http://www.sciencedirect.com/science/article/pii/S1353829208001020

Townley, G, Miller, H., \& Kloos, B. (2013). A little goes a long way: The impact of distal social support on community integration and recovery of individuals with psychiatric disabilities. American Journal of Community Psychology. Retrieved from http://onlinelibrary.wiley.com/doi/10.1007/s10464-013-9578-2/full

Townley, Greg, \& Kloos, B. (2009). Development of a measure of sense of community for individuals with serious mental illness residing in community settings. Journal of Community Psychology, 37(3), 362-380. https://doi.org/10.1002/jcop.20301

Townley, Greg, \& Kloos, B. (2011). Examining the psychological sense of community 
for individuals with serious mental illness residing in supported housing environments. Community Mental Health Journal, 47, 436-446. https://doi.org/10.1007/s10597-010-9338-9

Üstün, T. B., Chatterji, S., Bickenbach, J., Kostanjsek, N., \& Schneider, M. (2009). The International Classification of Functioning, Disability and Health: A new tool for understanding disability and health. Disability and Rehabilitation , 25(11-12), 565571. https://doi.org/10.1080/0963828031000137063

Walsh, J., \& Connelly, P. R. (1996). Supportive behaviors in natural support networks of people with serious mental illness. Health \& Social Work, 21(4), 296-303.

Retrieved from https://search.proquest.com/docview/1298063504?pqorigsite $=$ gscholar

Ware, N. C., Hopper, K., Tugenberg, T., Dickey, B., \& Fisher, D. (2007). Connectedness and citizenship: Redefining social integration. Psychiatric Services, 58(4), 469-474.

Whitley, R., \& Drake, R. (2010). Recovery: A dimensional approach. Psychiatric Services, 61(12), 1248-1250. Retrieved from http://ps.psychiatryonline.org/doi/abs/10.1176/ps.2010.61.12.1248

Wisdom, J. P., Saedi Auzeen, G., \& Green, C. A. (2009). Another breed of "Service" animals: STARS study findings about pet ownership and recovery From serious mental illness. American Journal of Orthopsychiatry, 79(3), 430-436. https://doi.org/10.1037/aM)16812

Wong, Yin-Ling I, \& Solomon, P. L. (2002). Community integration of persons with psychiatric disabilities in supportive independent housing: A conceptual model and 
methodological considerations. Mental Health Services Research, 4(1). Retrieved from http://repository.upenn.edu/spp_papers28.

Wong, Yin-Ling Irene, Stanton, M. C., \& Sands, R. G. (2014). Rethinking social inclusion: Experiences of persons in recovery from mental illness. American Journal of Orthopsychiatry, 84(6), 685-695. https://doi.org/10.1037/ort0000034

Woodward, A. T., Taylor, R. J., Bullard, K. M., Neighbors, H. W., Chatters, L. M., \& Jackson, James, S. (2008). Use of professional and informal support by African Americans and Caribbean Blacks with mental disorders. Psychiatric Services, 59(11), 1292-1298. Retrieved from https://ps.psychiatryonline.org/doi/pdf/10.1176/ps.2008.59.11.1292

Wright, E. R., Wright, D. E., Perry, B. L., \& Foote, C. E. (2007). Stigma and the sexual ssolation of people with serious mental illness. Social Problems, 54(1), 78-98. https://doi.org/10.1525/sp.2007.54.1.78

Yanos, P. T., Felton, B. J., Tsemberis, S., \& Frye, V. A. (2007). Exploring the role of housing type, neighborhood characteristics, and lifestyle factors in the community integration of formerly homeless persons diagnosed with mental illness. Journal of Mental Health, 16(6), 703-717. https://doi.org/10.1080/09638230701496378

Yanos, P. T., Rosenfield, S., \& Horwitz, A. V. (2001). Negative and supportive social interactions and quality of life among persons diagnosed with severe mental illness. Community Mental Health Journal, 37(5), 405-419. Retrieved from https://link.springer.com/content/pdf/10.1023/A:1017528029127.pdf

Yanos, P. T., Stefanic, A., \& Tsemberis, S. (2011). Psychological community integration 
among people with psychiatric disabilities and nondisabled community members.

Journal of Community Psychology, 39(4), 390-401.

https://doi.org/10.1002/jcop.20441

Zimolag, U., \& Krupa, T. (2009). Pet ownership as a meaningful community occupation for people with serious mental illness. American Journal of Occupational Therapy, 63(2), 126-137. https://doi.org/10.5014/ajot.63.2.126 


\section{Appendix A. Study 3 Measures}

\section{Social Support Questionnaire}

Please list each significant person in your life. Consider all the people who provide personal support for you or who are important to you. Use only first names or initials, and then indicate the relationships, as in the following example:

Example:

\section{First Name or Initials}

1. Mary $\mathrm{T}$

2. Bob

3. $\mathrm{M} \mathrm{T}$

4. Sam

5. Mrs. $\mathrm{R}$

\section{Relationship}

friend

brother

mother

friend

neighbor

Use the following list to help you think of people important to you, and list as many people as apply in your case.

- Spouse or partner

- Family members or relatives

- Friends

- Work or school associates

- Neighbors

- Health care providers

- Counselor or therapist

- Minister/priest/rabbi/other religious leader

- Pets

- Other

You do not have to use all 24 spaces. Use as many spaces as you have important persons in your life. For each person you listed, please answer the following questions by writing in the number that applies.

$$
\begin{aligned}
& 0=\text { not at all } \\
& 1=\text { a little } \\
& 2=\text { moderately } \\
& 3=\text { quite a bit } \\
& 4=\text { a great deal }
\end{aligned}
$$

Question 1: How much does this person make you feel liked or loved?

Question 2: How much does this person make you feel respected or admired? 
Question 3: How much can you confide in this person?

Question 4: How much does this person agree with or support your actions and thoughts?

Question 5: If you needed to borrow $\$ 10$, a ride to the doctor, or some other immediate help, how much could this person usually help?

Question 6: If you were confined to bed for several weeks, how could this person help you?

Question 7: To what extent does this person support you in employment (if important)?

Question 8: To what extent does this person support you in education (if important)?

Question 9: To what extent does this person support you in dating (if important)?

Question 10: To what extent does this person support you in parenting (if important and you have children)?

Question 11: To what extent does this person support you in leisure and recreation activities (if important)?

Question 12: How long have you known this person?

$$
\begin{aligned}
& 1=\text { less than six months } \\
& 2=6 \text { to } 12 \text { months } \\
& 3=1 \text { to } 2 \text { years } \\
& 4=2 \text { to } 5 \text { years } \\
& 5=\text { more than } 5 \text { years }
\end{aligned}
$$

Question 13: How frequently do you usually have contact with this person?

$$
\begin{aligned}
& 5=\text { daily } \\
& 4=\text { weekly } \\
& 3=\text { monthly } \\
& 2=\text { a few times a year } \\
& 1=\text { once a year or less }
\end{aligned}
$$

Question 14: How do you usually interact with this person?

$$
\begin{aligned}
& 1=\text { In person } \\
& 2=\text { Over the phone } \\
& 3=\text { With social media (e.g., email, Facebook, Twitter) }
\end{aligned}
$$




$$
4=\text { With letters }
$$

Question 15: Does this person identify themselves as a person diagnosed with a mental illness?

$$
\begin{aligned}
& 0=\text { No } \\
& 1=\text { Yes }
\end{aligned}
$$

Question 16: During the past year, have you lost any important relationships due to moving, a job change, divorce or separation, death, or some other reason?

$$
\begin{aligned}
& 0=\text { No } \\
& 1=\text { Yes }
\end{aligned}
$$

If yes:

16a. Please indicate the number of persons from each category who are no longer available to you.

\begin{tabular}{|l|l|}
\hline Spouse or partner & \\
\hline Family members or relatives & \\
\hline Friends & \\
\hline Work or school associates & \\
\hline Neighbors & \\
\hline Health care providers & \\
\hline Counselor or therapist & \\
\hline Minister/priest/rabbi/other religious leader & \\
\hline Pets & \\
\hline Other (specify) & \\
\hline
\end{tabular}

16b. Overall, how much of your support was provided by these people who are no longer available to you?

$$
\begin{aligned}
& 0=\text { none at all } \\
& 1=\text { a little } \\
& 2=\text { a moderate amount } \\
& 3=\text { quite a bit } \\
& 4=\text { a great deal }
\end{aligned}
$$




\section{$\underline{\text { Demographics }}$}

How do you identify your gender?

$$
\begin{aligned}
& 1=\text { Woman } \\
& 2=\text { Man } \\
& 3=\text { Prefer not to say } \\
& 4=\text { Prefer to self-describe }
\end{aligned}
$$

How old are you?

What race or ethnicity do you consider yourself to be? (check all that apply)

$$
\begin{aligned}
& 1=\text { White } \\
& 2=\text { Black } \\
& 3=\text { Latino or Hispanic } \\
& 4=\text { Native American } \\
& 5=\text { Asian } \\
& 6=\text { Native Hawaiian or Pacific Islander } \\
& 7=\text { Other (specify) }
\end{aligned}
$$

What is your primary mental health diagnosis?

$$
\begin{aligned}
& 1=\text { Major depression } \\
& 2=\text { Bipolar disorder/manic depression } \\
& 3=\text { Schizophrenia } \\
& 4=\text { Schizoaffective disorder } \\
& 5=\text { Anxiety disorder (Generalized, OCD, PTSD) } \\
& 6=\text { Other (specify) }
\end{aligned}
$$

What is your current marital status?

$$
\begin{aligned}
& 1=\text { Single or never married } \\
& 2=\text { In a relationship (not married) } \\
& 3=\text { Currently married } \\
& 4=\text { Separated } \\
& 5=\text { Divorced } \\
& 6=\text { Widowed }
\end{aligned}
$$

Do you have any biological children, meaning that they are not your step, adopted or foster children?

$$
\begin{aligned}
& 0=\text { No } \\
& 1=\text { Yes }
\end{aligned}
$$


Are any of your biological children currently under the age of $18 ?$

$$
\begin{aligned}
& 0=\text { No } \\
& 1=\text { Yes }
\end{aligned}
$$

What is your highest level of education?

$$
\begin{aligned}
& 1=\text { Less than } 9 \text { years of school } \\
& 2=9-12 \text { years of school (not graduated) } \\
& 3=\text { High school graduate or GED } \\
& 4=\text { Some college or vocational, trade, or business school } \\
& 5=\text { Associate or vocational graduate } \\
& 6=\text { College graduate (BS, BA, BSW etc.) } \\
& 7=\text { Some graduate school } ? \\
& 8=\text { Master's degree or equivalent } \\
& 9=\text { Doctoral degree or beyond }
\end{aligned}
$$

Have you ever been employed?

$$
\begin{aligned}
& 0=\text { No } \\
& 1=\text { Yes }
\end{aligned}
$$

Are you currently doing any work for pay?

$$
\begin{aligned}
& 0=\text { No } \\
& 1=\text { Yes }
\end{aligned}
$$

How many hours per week?

What is your current income? 


\section{Qualitative Interview}

1. Is social support important to you (why or why not)?

What does it feel like when you are receiving social support?

Can you tell me more about the relationships where you feel the most support?

Tell me about a time when [name] supports you?

2. Tell me more about some of the activities that you do on a regular basis.

Which of these activities do you prefer to do alone (refer back to TUCP items)?

Which of these activities do you prefer to do with others (refer back to TUCP item)?

Who do you do these activities with (e.g., family, friends, peers, etc.)?

3. How do the people you identified previously support you in participating in the activities that are important to you? (refer back to Social Support Questionnaire and probe for categories, e.g., family, friends, peers, etc.; and types, e.g., emotional, tangible, information support)

Which people do you feel the most support from in participating in activities and why?

How can the people you identified support you more in doing the activities that are important to you? (probe for emotional, tangible, informational support)

Anything else? 
Appendix B. Study 3 Recruitment Flyer and Consent Form

\section{Resident Experiences of Support and Community}

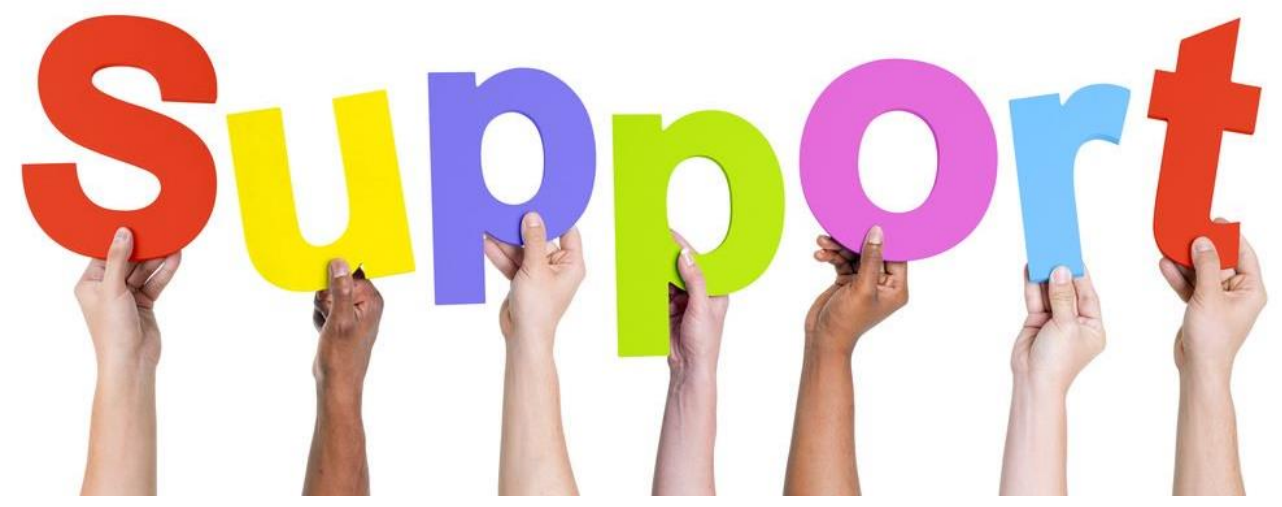

Hello! We are researchers at Portland State University. We want to learn about how friends, families, and other community members impact the community life of people who have experiences with mental health difficulties. You will be asked to complete a 30 minute to 1 -hour confidential research survey in the community room at your apartment complex.

You will receive up to $\$ 15$ cash for participating in this project.

Who can participate?

Heads of households who live in Cascadia Independent Housing and have a diagnosed mental illness are eligible. If you are interested in participating in the study, please contact me with information provided to the right.
Any questions?

Please call me, Rachel Terry, at 503-725-3900 or email me at rterry@pdx.edu to sign up for the study or to ask any questions you may have. Thank you for considering taking part in the project! 


\title{
CONSENT FOR PARTICIPATION IN RESEARCH PROJECT
}

\author{
Project Title: $\quad$ Resident Experiences on Support and Community \\ Researcher: $\quad$ Rachel Terry, Department of Psychology, Portland State \\ University
}

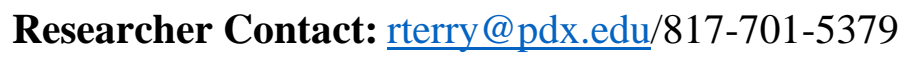

You are being asked to take part in a research study. The information below highlights the main information about this research for you to consider when making a decision whether or not to join in the study. Please carefully look over the information given to you on this form. Please ask questions about any of the information you do not understand before you decide to agree to take part.

\section{PURPOSE:}

In this research project, we want to learn about how social support and community experiences can affect daily life for people with a history of mental health difficulties. We have invited you to take part because you live in Cascadia's Independent Housing. In this research, we want to learn more about how people's relationships with others can affect their activities in the community. About 50 people will take part in this research. We will use what we learn from this research to improve housing and mental health services.

\section{PROCEDURE:}

We are interested in knowing more about how relationships with others make living in your community easier or more difficult for you. This might include things about your friends, families, neighbors, or community members that can affect your daily life.

If you decide to take part in the study, we will ask for your permission to do the following:

Research Survey. During the research survey, we will ask specific questions and record information about support you receive from friends, families, neighbors, and other people in your community. We will also ask about the activities and events that you may do in the community. With this research, we want to identify parts of housing, neighborhoods, community experiences, and services that can be made better to help people reach their goals for recovery from serious mental illness. Your answers will be recorded on an iPad or a paper-pencil survey.

Follow-up Questions. After the survey is done, you may be asked several follow-up questions about your relationships with others. We will ask how specific people in your life influence your participation in community activities. Your answers will be recorded on an audio device. NOTE: Not all participants will be asked to participate in this part of the study. 
The interviews will be conducted in the community room of your apartment complex. If you do not feel comfortable completing the interview in the community room, we will consider conducting the interview in a private office or your personal unit. We will tell you about any new information that may affect whether or not you want to continue in this research.

\section{DURATION:}

The research survey takes about 30 minutes and the follow-up questions (if you are selected) takes about 30 minutes.

\section{RISKS OR DISCOMFORTS:}

Although the interview is not meant to be upsetting in any way, people sometimes feel uneasy with questions about their neighborhood, relationships, or social activities. At any time, you can decide not to answer a particular question, take a break from the interview, or end the interview.

\section{BENEFITS:}

Information about what you find helpful for living in your community can be used to make services better for people with mental health difficulties in the future. We hope to learn about new ways to promote mental health and community supports and reduce stress.

\section{CONFIDENTIALITY:}

Your interviews and our study of your service use are completely confidential and private. They will not be shared with Cascadia staff. At all times, every effort will be made to guard your privacy. In the study records, only a code number will identify you and only the researchers can link your name with the number. No information from you will be shared without your permission.

There are two times when we cannot keep your answers private. First, if we have reason to believe you might hurt yourself, might hurt someone else, or might be hurt by others, we must report this to protect you and others. Second, agencies that oversee research can go through the PSU records to make sure that the research is being done right.

\section{COMPENSATION:}

You will be offered $\$ 10$ for doing the research survey and an additional $\$ 5$ if you are selected to complete the follow-up questions.

\section{CONTACT PERSON:}

The lead researcher will be happy to answer any questions or concerns that you may have about this study. You may contact Rachel Terry, M.S.. at 503-725-3900 or rterry@pdx.edu. 
You can also contact the Office of Research Integrity at Portland State University about your rights as a participant in this project. The Portland State University Institutional Review Board ("IRB") is overseeing this research. The IRB is a group of people who independently review research studies to ensure the rights and welfare of participants are protected. The Office of Research Integrity is the office at Portland State University that supports the IRB. If you have questions about your rights, or wish to speak with someone other than the research team, you may contact them at (503) 7255484 or hsrrc@pdx.edu.

\section{VOLUNTARY PARTICIPATION:}

Taking part in this study is totally up to you. Participation is voluntary and the only alternative is to not participate. You may stop or leave at any time and it will not be held against you. If you choose not to take part, it will not affect any service you receive from Cascadia. In the event that you want to stop taking part in this study, your information will be kept private or will be destroyed if you ask for it by writing a letter to us.

10. QUESTIONS: Before you sign the consent form on the following page, please ask any questions about any part of this study that is unclear to you. We can take as much time as you need. 


\title{
CONSENT FOR PARTIPATION IN A RESEARCH PROJECT
}

\author{
Title: Resident Experiences of Support and Community
}

Principal Investigator: Rachel Terry, M.S.

\begin{abstract}
AUTHORIZATION
I have read (or have had read to me) the contents of this form and have been encouraged to ask questions. I have received answers to my questions. I give consent to participate in this study. I understand that I do not have to participate in this study and can take away my consent at any time. I will receive a copy of this form for my records and future reference.

I understand that these data will be held confidentially by the researcher and used only for research purposes.
\end{abstract}

My signature below indicates my willingness to participate in this study.

Name of Adult Participant

Date

Signature of Adult Participant

Researcher Signature (to be completed at time of informed consent)

I have explained the research to the participant and answered all of his/her questions. I believe that he/she understands the information described in this consent form and freely consents to participate.

Name of Research Team Member

Signature of Research Team Member

Date 